\title{
The Politics of Getting the Joke: The Effects of Political Humor on Information Seeking Behavior
}

Bret Wilson

West Virginia University

Follow this and additional works at: https://researchrepository.wvu.edu/etd

\section{Recommended Citation}

Wilson, Bret, "The Politics of Getting the Joke: The Effects of Political Humor on Information Seeking Behavior" (2014). Graduate Theses, Dissertations, and Problem Reports. 269.

https://researchrepository.wvu.edu/etd/269

This Dissertation is protected by copyright and/or related rights. It has been brought to you by the The Research Repository @ WVU with permission from the rights-holder(s). You are free to use this Dissertation in any way that is permitted by the copyright and related rights legislation that applies to your use. For other uses you must obtain permission from the rights-holder(s) directly, unless additional rights are indicated by a Creative Commons license in the record and/ or on the work itself. This Dissertation has been accepted for inclusion in WVU Graduate Theses, Dissertations, and Problem Reports collection by an authorized administrator of The Research Repository @ WVU.

For more information, please contact researchrepository@mail.wvu.edu. 
The Politics of Getting the Joke:

The Effects of Political Humor on Information Seeking Behavior

\title{
Bret Wilson
}

Dissertation submitted to the Eberly College of Arts and Sciences

at West Virginia University

in partial fulfillment of the requirements

for the degree of

\author{
Doctor of Philosophy \\ in \\ Political Science
}

\author{
Robert D. Duval, Ph.D. Chair \\ Nicholas Bowman, Ph.D. \\ Erin C. Cassese, Ph. D. \\ John Kilwein, Ph. D. \\ Philip A. Michelbach, Ph. D. \\ Department of Political Science
}

\author{
Morgantown, West Virginia \\ 2014
}

Keywords: Political Media, Political Humor, Information Seeking, Political Interest, Experimental Research, Media Effects

Copyright 2014 Bret Wilson 


\author{
Abstract \\ The Politics of Getting the Joke: \\ The Effects of Political Humor on Information Seeking Behavior \\ Bret Wilson
}

Political humor plays a positive role in American democracy. It increases the political awareness and interest of the audience. There is a growing body of literature, both empirical and theoretical, that looks at role of political humor in American politics. In line with some of this literature, the present dissertation examines how The Colbert Report (in both video and single image meme formats) encourages the survey participants towards seeking more information about an important domestic issue: the fiscal cliff crisis.

Using two parallel experimental surveys, this dissertation empirically investigates the effect that political humor has on viewers. This dissertation tests whether or not participants that received the political humor frame are more likely to seek for more information on the topic. Secondly, this dissertation explores the possibility that political humor also inspires participants to spend more time on seeking out information. The investigation includes an experiment using videos as well as for an experiment involving single images memes. This dissertation builds upon existing studies on political humor effects in the field of political communication, and contributes to existing research on information seeking behavior in political psychology. 


\section{Acknowledgements}

This dissertation would not have been possible without all of the people that have helped me on the way.

I would like to thank all of the members of my dissertation committee. I want to thank my dissertation chair, Dr. Robert Duval. His help and guidance has been incalculable. He has been a great boss, advisor, and mentor. Dr. Nicholas Bowman was instrumental in helping me conceptualize how I need to present my thoughts. My experiments were aided by the professional contributions of Dr. Erin Cassese. Dr. Kilwein's professional support and logistical advise has been extremely helpful. His has had a great positive effect on me. I want to thank Dr. Philip Michelbach for making me a better academic, pushing me to be a better writer and thinker.

I also want to thank Dr. Jeff Worsham for his support throughout my graduate career. $\mathrm{He}$ introduced me to what it meant to be a graduate student, helped me through comprehensive exams, and helped me understand what kind of teacher I want to be when I grow up. I know that his support was behind me one hundred percent and that has meant more than I could tell him.

I want to thank the political science professors that have strengthened my resolve to stay in political science. Dr. Robert DiClerico and Dr. Jason Macdonald have been greatly influential in my choosing what kind of political scientist I want to be. They have shown me what it means to be dedicated to my craft and how I need to conduct myself as a professional.

I would like to acknowledge LeeAnn Greathouse, Ronny Thompson, and Donna MacIntire as all being instrumental in my graduate career. The three of you really make the department work. You three are great at your jobs and excellent human beings.

I would like to thank my mother for always being there for me. You helped me become the person I am today. I might be a little biased, but I think you did a pretty good job.

Last, but not least, I dedicate this dissertation to my wife, Holly, and to my daughter, Lillian. I have hit the lottery twice: first with an amazing wife, then with an amazing daughter. Thank you for holding me up when I needed it. Thank you for telling me to get up when I was down. Thank you for being so understanding. Thank you for your patience. Thank you for your support and positivity. Most importantly, thank you for being the most important people in my life. 


\section{Table of Contents}

ACKNOWLEDGEMENTS SACT

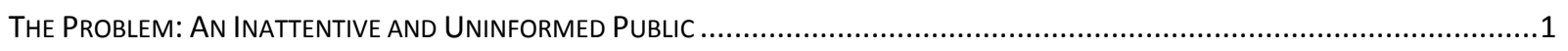

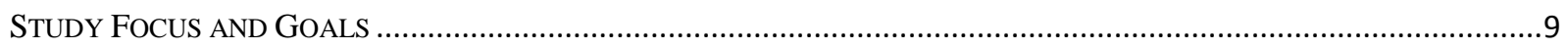

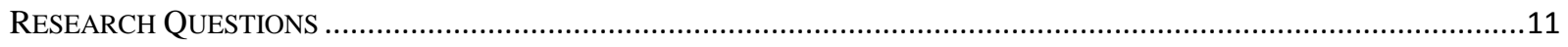

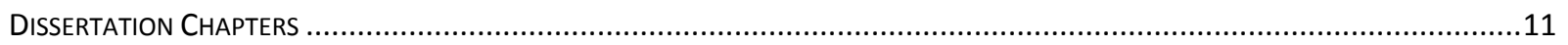

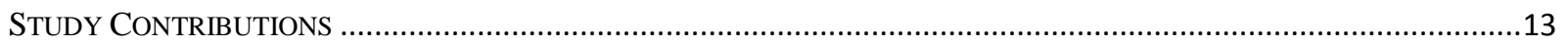

CHAPTER 2 LITERATURE REVIEW

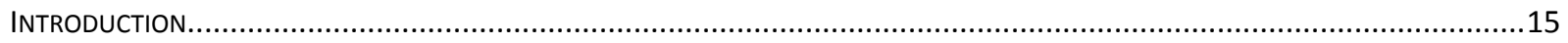

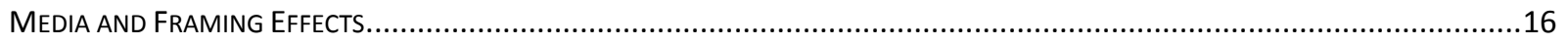

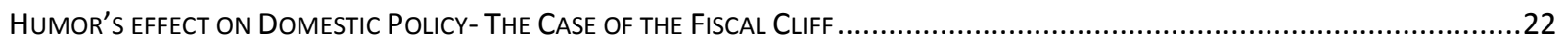

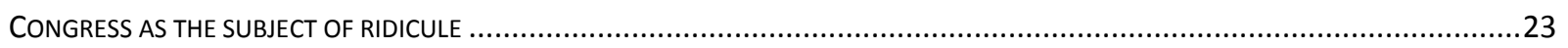

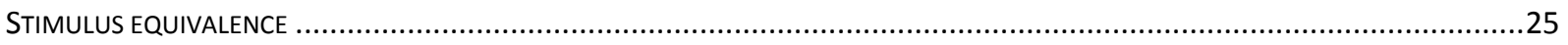

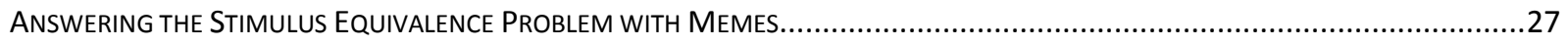

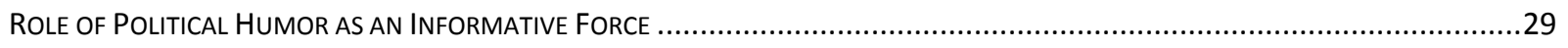

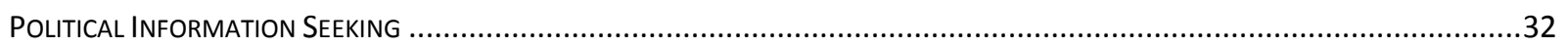

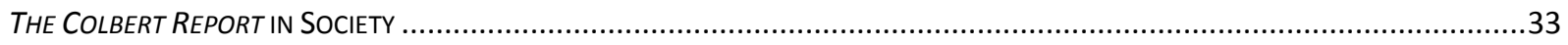

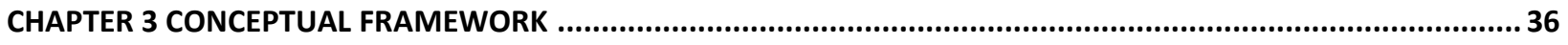

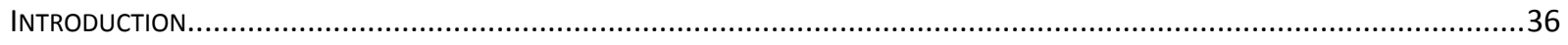

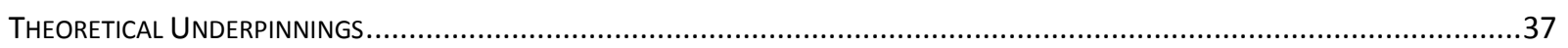

Conceptualizations of the Role of Political Humor and Political KNowledge .......................................................

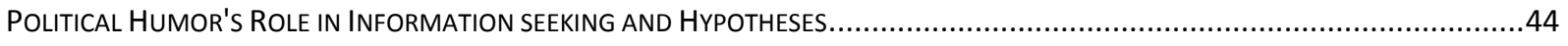

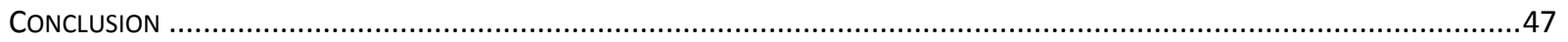

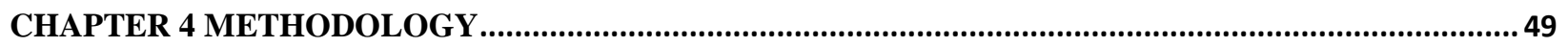

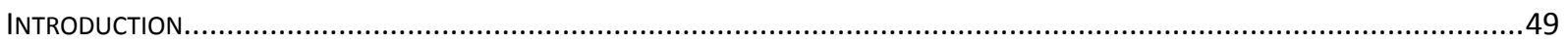

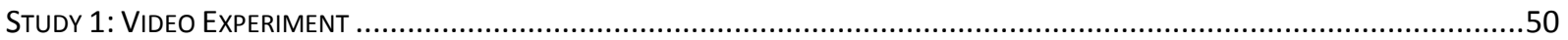

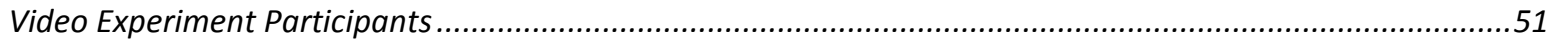




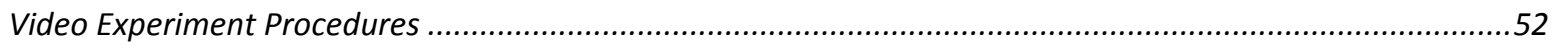

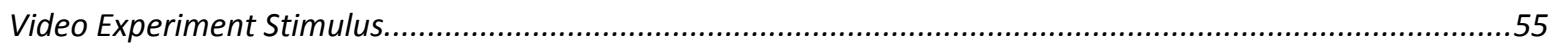

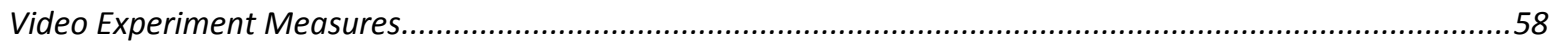

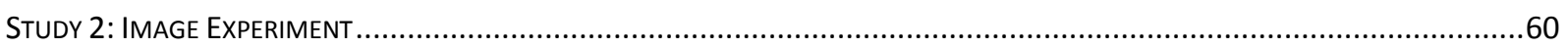

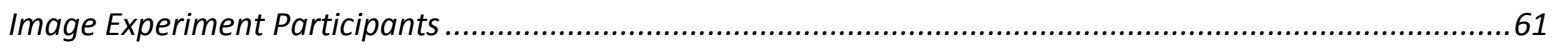

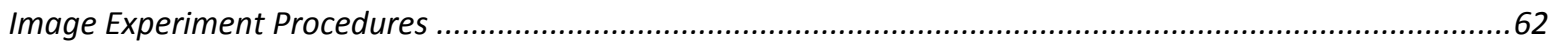

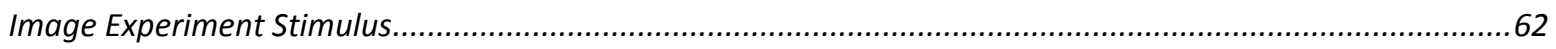

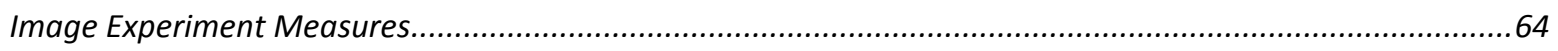

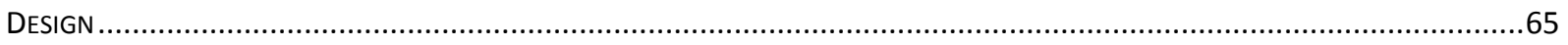

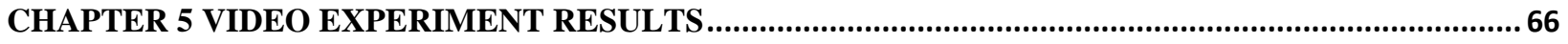

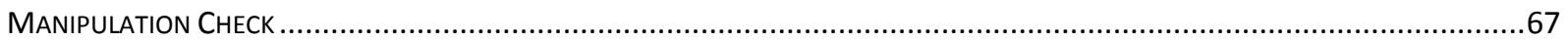

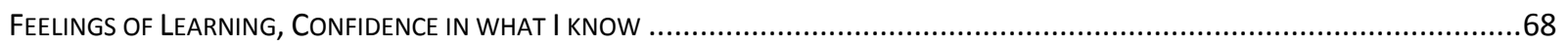

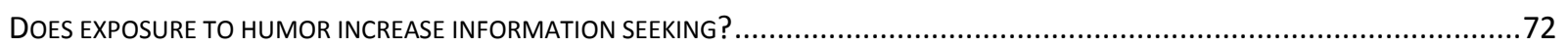

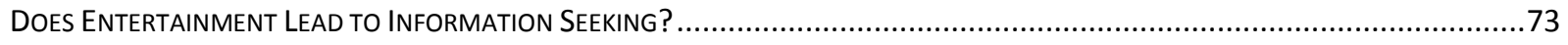

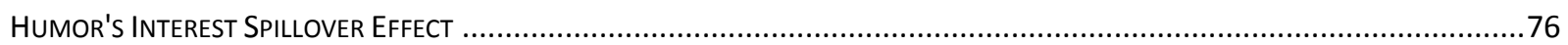

CHOOSING MORE INFORMATION: LOGISTIC REGRESSION ANALYSIS .........................................................................

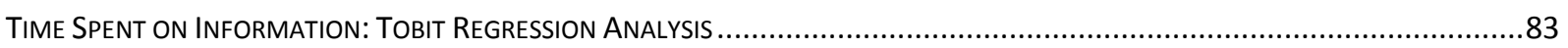

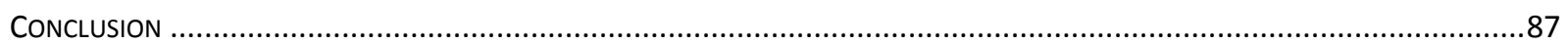

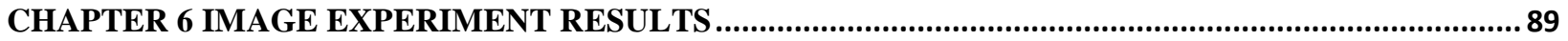

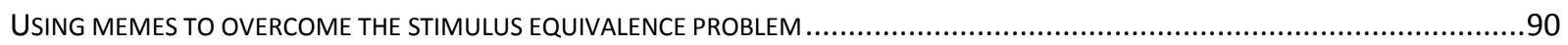

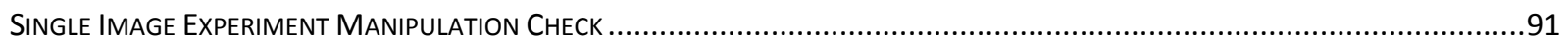

LEARNING AND KNOWING: DIFFERENCES BETWEEN EXPERIMENTAL CONDITION GROUPS ...................................................93

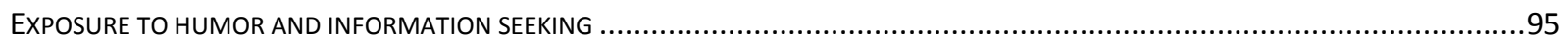

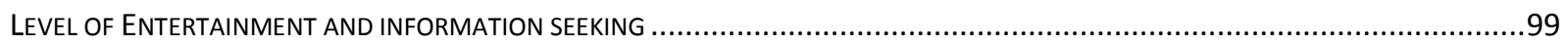

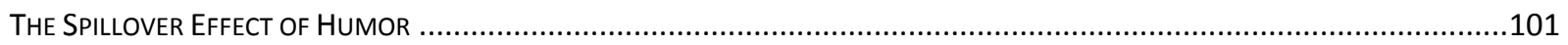

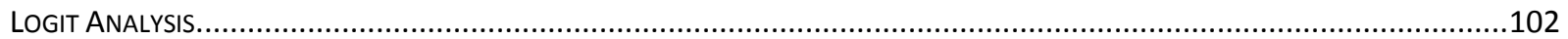

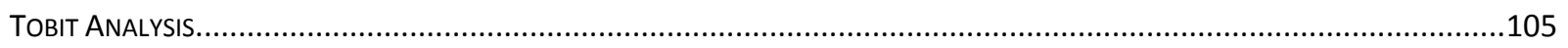

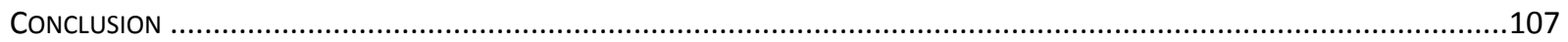

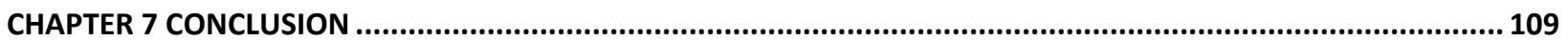

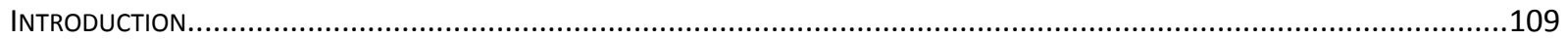

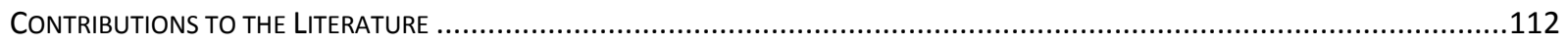

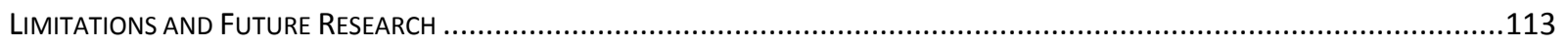

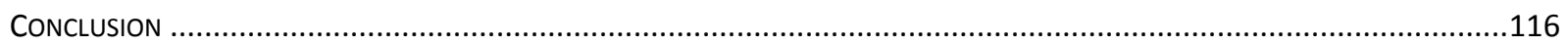

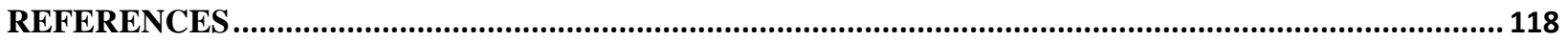

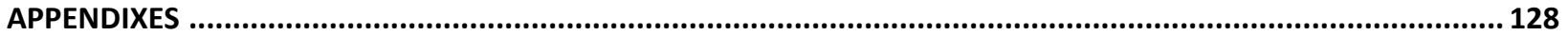




\section{LIST OF TABLES}

TABLE 1.1 Political InTEREST CORRELATED WITH NEWS CONSUMPTION .................................................................

TAble 1.2 FisCal Cliff KNOWledge: Few Aware that Military Would Be Cut Most ……............................5

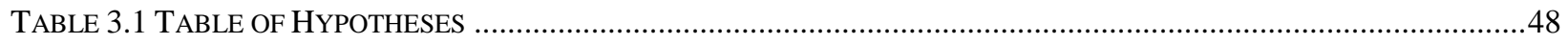

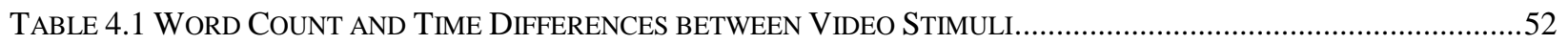

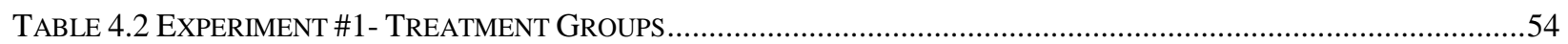

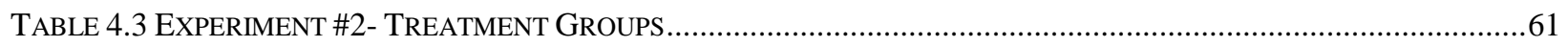

TABLE 5.1 ANALYSIS OF VARIANCE (ANOVA) - I THINK THAT I AM BETTER INFORMED ABOUT POLITICS AND

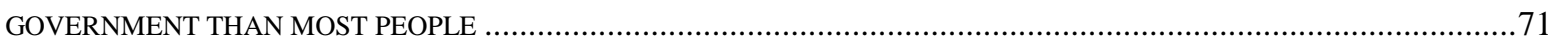

TABLE 5.2 ANALYSIS OF VARIANCE (ANOVA)- I AM VERY KNOWLEDGEABLE ABOUT THE "FISCAL CLIFF" AS AN

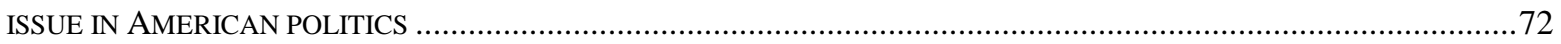

TABLE 5.3 AVERAGE TIME SPENT BROWSING RELATED STORY CONTENT BY VIDEO STIMULUS CONDITION ..................73

TABLE 5.4 ANALYSIS OF VARIANCE (ANOVA)- INTERESTED IN FOLLOWING MATTER OF POLITICS AND GOVERNMENT . .77

TABLE 5.5 LOGIT ANALYSIS OF POST VIDEO STIMULUS SEQUESTRATION INFORMATION SEEKING..............................81

TABLE 5.6 LOGIT ANALYSIS OF POST VIDEO STIMULUS FISCAL CLIFF INFORMATION SEEKING ...................................82

TABLE 5.7 LOGIT ANALYSIS OF POST VIDEO STIMULUS FISCAL CLIFF AND SEQUESTRATION INFORMATION SEEKING...83

TABLE 5.8 TOBIT ANALYSIS OF POST VIDEO STIMULUS FISCAL CLIFF INFORMATION SEEKING .....................................85

TABLE 5.9 TOBIT ANALYSIS OF POST VIDEO STIMULUS OF SEQUESTRATION INFORMATION SEEKING ............................86

TABLE 5.10 TOBIT ANALYSIS OF POST VIDEO STIMULUS OF FISCAL CLIFF AND SEQUESTRATION INFORMATION SEEKING

TABLE 6.1 ANALYSIS OF VARIANCE (ANOVA) - I THINK THAT I AM BETTER INFORMED ABOUT POLITICS AND

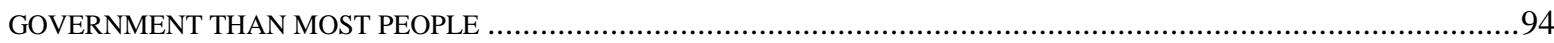

TABLE 6.2 ANALYSIS OF VARIANCE (ANOVA) - I AM VERY KNOWLEDGEABLE ABOUT THE "FISCAL CLIFF" AS AN

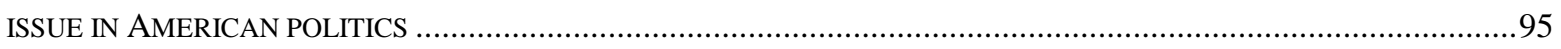

TABLE 6.3 AVERAGE TIME SPENT BROWSING RELATED STORY CONTENT BY VIDEO STIMULUS CONDITION .................96

TABLE 6.4 ANALYSIS OF VARIANCE (ANOVA) - SELECTION OF THE FISCAL CLIFF ARTICLE.....................................96

TABLE 6.5 ANALYSIS OF VARIANCE (ANOVA) - INTERESTED IN FOLlOWING MATTERS OF POLITICS AND

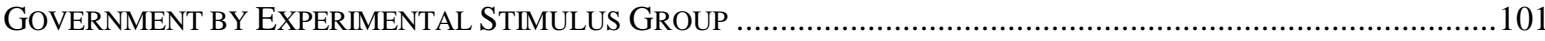

TABLE 6.6 LOGIT ANALYSIS OF POST IMAGE STIMULUS FISCAL CLIFF INFORMATION SEEKING ……..........................104

TABLE 6.7 TOBIT ANALYSIS OF POST IMAGE STIMULUS FISCAL CLIFF INFORMATION SEEKING ................................106 


\section{LIST OF FIGURES}

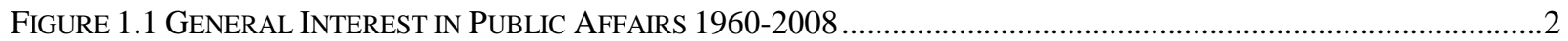

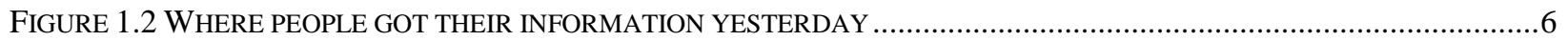

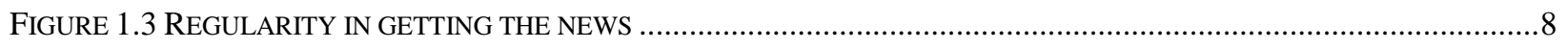

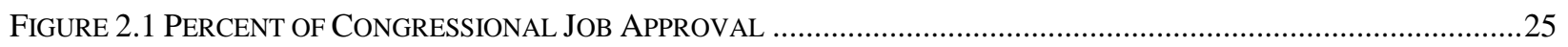

Figure 3.1 XeNOS AND BeCKeR'S (2009) MOdEl OF How Political HuMOR IMPACTS INFORMATION SEEKING......43

FigURE 3.2 THE LITERATURE'S MODEL OF INFORMATION SEEKING .................................................................

FigURE 3.3 How GETTING THE JoKE AFFECTS INFORMATION SEEKING ....................................................................45

FIGURE 4.1 HUMOROUS EXPERIMENTAL CONDITION IN CAPTIONED IMAGE EXPERIMENT ..........................................63

FIGURE 4.2 NEUTRAL EXPERIMENTAL CONDITION IN CAPTIONED IMAGE EXPERIMENT ................................................64

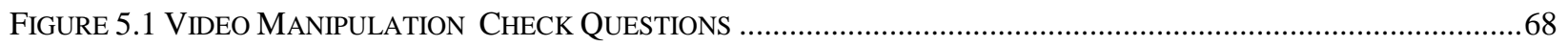

FIGURE 5.2 FEELING OF LEARNING BETWEEN THE TWO EXPERIMENTAL CONDITIONS ..............................................70

FIGURE 5.3 ENTERTAINMENT VALUE AND INFORMATION SEEKING OF EITHER ONE OF THE RELEVANT ARTICLES........74

FIGURE 5.4 ENTERTAINMENT ENJOYMENT AND AMOUNT OF TIME SPENT ON FISCAL CLIFF ARTICLE.............................75

FIGURE 5.5 ENTERTAINMENT ENJOYMENT AND AMOUNT OF TIME SPENT ON INFORMATION SEEKING ARTICLES...........76

FIGURE 5.6 INTERESTED IN FOLLOWING MATTERS OF POLITICS AND GOVERNMENT BY LEVEL OF ENTERTAINMENT .....77

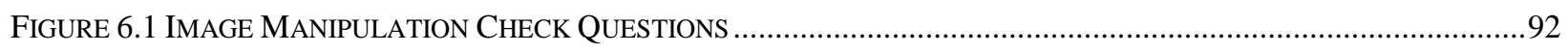

FIGURE 6.2 IMAGE POST STIMULUS PERCEIVED LEARNING ..............................................................................94

FIGURE 6.3 TIME SPENT ON FISCAL CLIFF ARTICLE BY EXPERIMENTAL CONDITION GROUP .....................................98

FIGURE 6.4 AVERAGE TIME SPENT ON INFORMATION SEEKING BY EXPERIMENTAL CONDITION GROUP.......................98

FIGURE 6.5 AVERAGE SELECTION OF FISCAL CLIFF ARTICLE BY ENJOYMENT OF IMAGE...........................................99

FIGURE 6.6 AVERAGE TIME SPENT ON FISCAL CLIFF ARTICLE BY HOW MUCH THEY ENJOYED IMAGE.........................100

FIGURE 6.7 INTERESTED IN FOLLOWING MATTERS OF POLITICS AND GOVERNMENT BY LEVEL OF ENTERTAINMENT ...102 


\section{List of Appendixes}

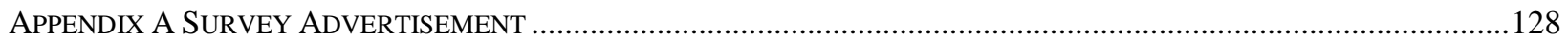

APPENDIX B FISCAL CLIFF NEWS FROM ABC, NEWSY, AND CNN ...............................................................130

APPENDiX C THE COLBERT REPORT: THE FISCAL CLIFF COMPROMISE- NOVEMBER $27^{\mathrm{TH}}, 2012$...... 


\section{Chapter 1 \\ Introduction \\ The Problem: An Inattentive and Uninformed Public}

We have an opportunity for everyone in the world to have access to all the world's information. This has never before been possible. Why is ubiquitous information so profound? It's a tremendous equalizer. Information is power.

Eric Schmidt, University of Pennsylvania

Commencement Address, 2009

Although democratic theory posits that an informed public is critical to a fully functioning democracy, the American public has been historically been seen as inattentive and ignorant of political affairs. The lack of knowledge about even domestic affairs is largely attributed to the complexity of politics and the lack of efficacy within the citizenry (Popkin and Dimock 1999). The American public's lack of political knowledge or, more precisely, their lack of desire to seek political information is problematic to the American democracy.

The American National Election studies data in Figure 1.1 shows, that Americans are, or have become, passively attentive to public affairs (2010). According to this research, only about $25 \%$ of people keep up with politics most of the time. There was a large decrease in participants that responded that they were interested in public affairs "most of the time" in the middle of the 1970s. These high interest respondents were largely replaced by respondents that answered that they were interested in politics "only every now and then." This is a sign that the American public is mostly inattentive and this inattentive public could be uninformed. This general decrease in interest in politics is likely to be problematic when we think about how being informed effects the quality and quantity of participation. 


\section{Figure 1.1 General Interest in Public Affairs 1960-2008}

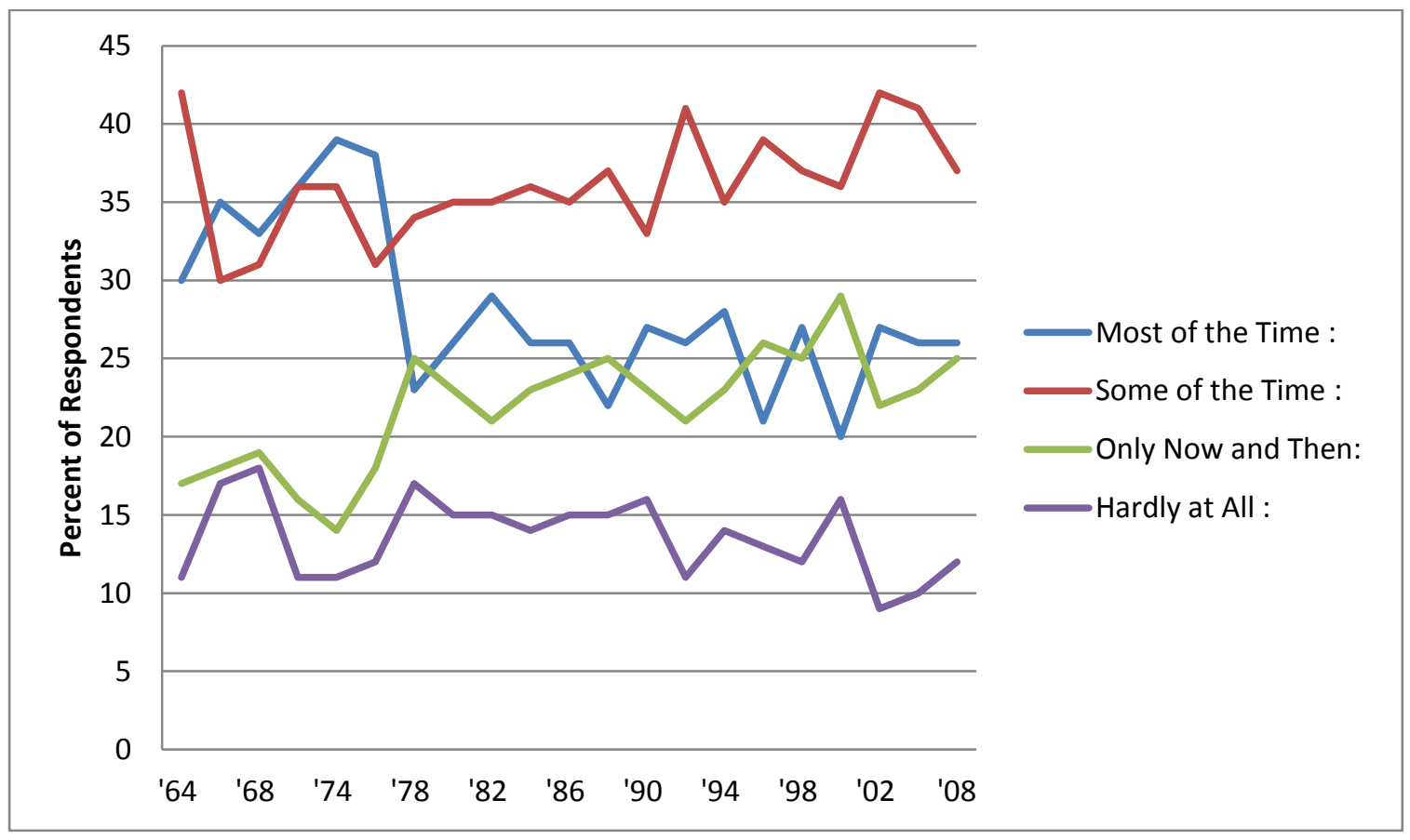

Source: The American National Election Studies Aug- 23-2010 1

The American political system allows for a wide variety of political participation, while leaving the decision to participate completely up to individual citizens. Citizens must stay informed so that they can correctly identify their interests and opportunities to participate in the political system (Delli Carpini and Keeter 1996, Verba and Nie 1987). This civic duty of staying informed about political events has been historically ignored by young Americans. Research done by the Pew Research Center (Purcell, Rainie, Mitchell, Rosenstiel, and Olmstead 2010)

1 Data was selected to start at 1964 because the wording of the question and potential responses changed. From 1964 onward, the wording of the question was the following: " people seem to follow (1964: think about) what's going on in government and public affairs most of the time, whether there's an election going on or not. Others aren't that interested. Would you say you follow what's going on in government and public affairs most of the time, some of the time, only now and then, or hardly at all?" This data was retrieved on the following website: http://www.electionstudies.org/nesguide/toptable/tab6d_5.htm 
demonstrates that young Americans are the least likely age group to follow the news all or most of the time.

\section{Table 1.1 Political Interest Correlated with News Consumption ${ }^{2}$}

\begin{tabular}{|l|l|l|l|}
\hline $\begin{array}{l}\text { News } \\
\text { Consumption }\end{array}$ & $\begin{array}{l}\text { High } \\
\text { Interest }\end{array}$ & $\begin{array}{l}\text { Moderate } \\
\text { Interest }\end{array}$ & $\begin{array}{l}\text { Low } \\
\text { Interest }\end{array}$ \\
\hline High & $84 \%$ & $37 \%$ & $15 \%$ \\
\hline Medium & $14 \%$ & $46 \%$ & $34 \%$ \\
\hline Low & $2 \%$ & $17 \%$ & $51 \%$ \\
\hline & $100 \%$ & $100 \%$ & $100 \%$ \\
\hline
\end{tabular}

Studies clearly suggest that people, and particularly young people, are not informed or interested in politics. This can put the quality of our democracy into question. Thomas Patterson (2000) notes, as seen in Table 1.1, that interest in politics heavily correlates with news consumption. Patterson goes further and says that interest in politics is the driving force to becoming an informed member of society. Patterson's argument is that the lack of quality televised news is causing the decline in interest and the subsequent decline of seeking information from televised news. This is problematic because without interest in politics, people generally do not seek information and, therefore, not become informed (Patterson 2000).

Having an uninformed public is problematic because "factual knowledge about politics is a critical component to citizenship" (Delli Carpini and Keeter 1996, pg 3). Without factual knowledge about governmental affairs citizens are unable to have fully developed positions on

\footnotetext{
2 From Patterson's 2000 Doing Well And Doing Good. Pg. 11. Patterson clearly shows the direct correlation between political interest and news consumption. While Patterson also argues that waning interest in politics is largely the fault of the media coverage (because of the lack of public policy content and focus on either soft news subjects or crime).
} 
issues because they may not even know what issues are currently relevant. Therefore, the act of seeking political information is essentially a political act itself because the information can open the door to other forms of political participation.

Ignorance in political affairs is normally attributed to a combination of lack of interest and a preoccupation with daily tasks (Popkin and Dimock 1999), but, in the day and age of the Internet and the fact that the current "fiscal cliff" issue affects every American, are those explanations valid? If accessibility to information is the problem, the Internet could be a great tool for gaining information. The problem is that the Internet, although it has great potential to give people access to information, is largely misused (Davis, Elin, Reeher 2002). The problem seems to be a lack of motivation and, more generally, a lack of political interest. The age-group that seems to have the largest deficit of political interest is between 18 and 25 years old. This group has historically been the least politically motivated, least interested, and least informed.

Increasingly, citizens are getting their information from the Internet. In the Pew Research Center's 2012 Media Consumption Survey (shown in Figure 1.2), they have recently started to chronicle the rise of Internet use in the public attaining political information. Pew's survey question asking people to answer "where they got their news from yesterday" showed that getting information from digital (internet) sources has been increasing. It seems like this trend is likely to continue and we, as researchers need to look at how this source for information is being used by citizens. 


\section{Table 1.2 Fiscal Cliff Knowledge: Few Aware} that Military Would Be Cut Most ${ }^{3}$

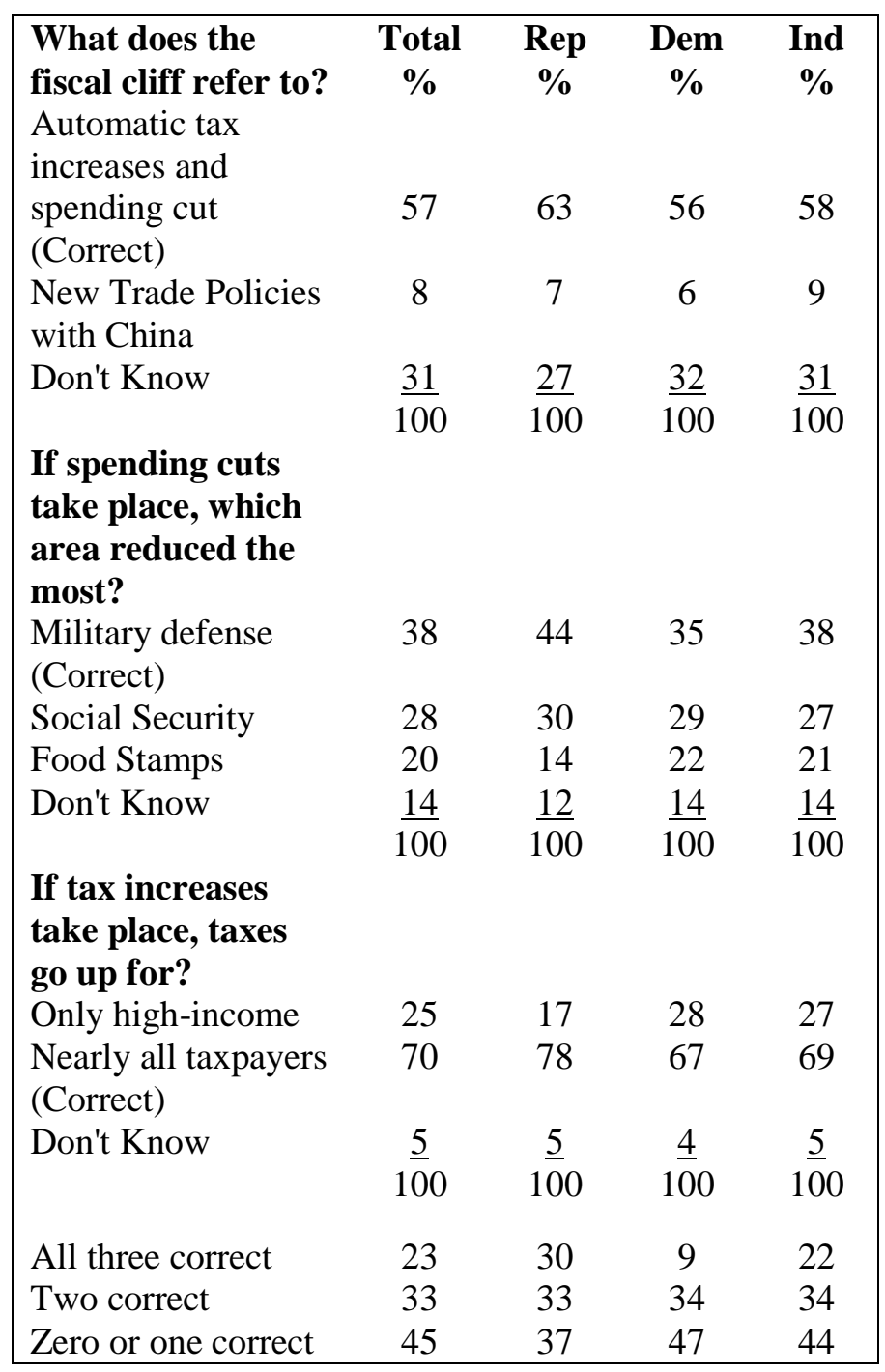

The Internet provides unlimited information that is easily accessible and readily available. In the golden age of Web 2.0, with so much information at one's fingertips, few barriers exist between the citizen and political information. The temporal cost of being exposed to political information is largely decreased by the Internet (e.g. Google and Wikipedia for two

\footnotetext{
${ }^{3}$ Pew Research Center December. 5-9, 2012, Q30-Q32. Figures may not add to $100 \%$ because of rounding.
} 
clear examples). The only likely significant barrier to keeping people from being fully informed citizens is the desire for information.

Figure 1.2

Where people got their information yesterday

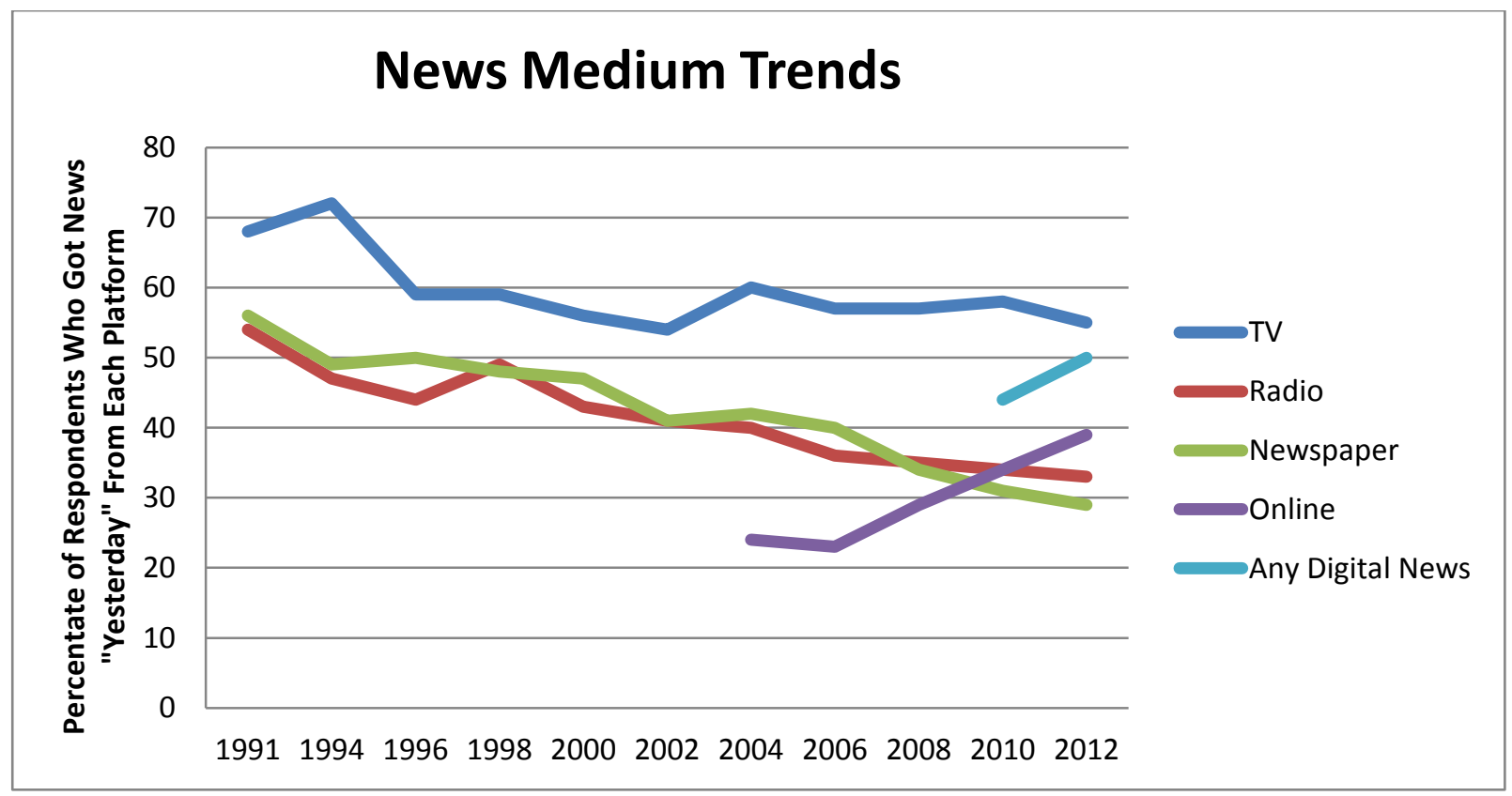

Source: PEW Research Center

2012 News Consumption Survey ${ }^{4}$

Although the American public has low levels of knowledge and political interest,

political humor could help spark some interest and incentivize uninformed citizens to seek

information. Seeking information is an important part of the learning process and actively

seeking out information and choosing to learn is an important step toward learning. The Internet

is crucial to this research because it makes the search for information, and the measuring of that

searching, easier.

\footnotetext{
${ }^{4}$ Data is from the following questions: Q9, Q11, Q13, Q17, Q20, Q21, Q 70, Q75, Q82, Q87. The data can be found at: http://www.people-press.org/2012/06/03/2012-media-consumption-survey/. Graph was found at http://www.people-press.org/2012/09/27/in-changing-news-landscape-even-television-is-vulnerable/
} 
Modern citizens are getting their political information from a wide range of news mediums. The Pew Research Center for People and the Press released a survey containing a widely reported fact that $21 \%$ of people ages 18 to 29 reported they regularly learned some news about political candidates or the 2004 presidential campaign from "comedy TV shows" and 13\% reported the same of "late-night TV shows" (Pew Research Center 2004). While the question of whether or not audiences actually learn from such shows is the subject of an important scholarly debate, direct learning from soft news is not the topic of this dissertation.

Not only are citizens getting their news from the Internet with more frequency, they are getting their news more sporadically than before. According to a Pew Research Center (2010) poll, people are checking on the news with less regularity than before. As shown in Figure 1.3, the percentage of news "grazers" increased by nine percentage points (from $48 \%$ to $57 \%$ ) between 2006 and 2010. This could mean that people might be more likely to not check the news regularly and only check the news when something has peeked their interest enough to investigate. 
Figure 1.3 Regularity in getting the news ${ }^{5}$

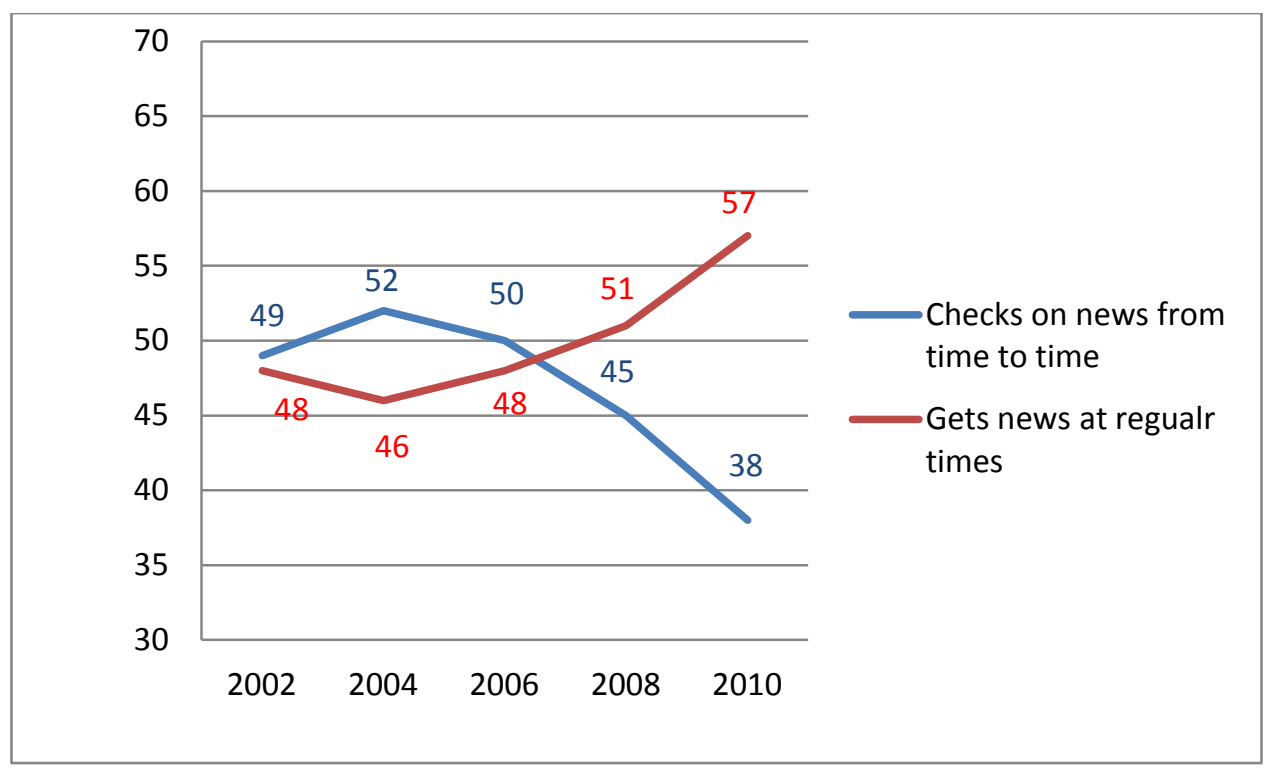

The question that this dissertation seeks to answer is whether or not political humor heightens audience members' attention to politics. Baum (2003) suggests that soft news, like political humor, can be a gateway to people becoming interested, involved, and knowledgeable to the world of politics. This dissertation argues (like Xenos and Becker 2009) that, although it may not be a great informative force, soft news has the power and ability to intensify information seeking behavior.

Although research done in political engagement focuses on activities like voting and actively participating in political campaigns as engagement (Verba, Schlozman, and Brady 1995), this dissertation focuses information seeking behavior because information seeking is the first step to thoughtful action. The civic volunteerism model shows us that political engagement can take both time and skills (Verba Schlozman, Brady 1995), it is assumed that most people

\footnotetext{
${ }^{5}$ Pew Research Center June 8-28, 2010. Q91.
} 
have enough skills to navigate the interenet and taking the time to focus on a political topic is the important factor in this dissertation.

\section{Study Focus and Goals}

This dissertation focuses on citizens seeking information about politics and how political humor can encourage that search. More specifically, this dissertation seeks to understand whether the perception of humor in a frame affects interest in the substantive topic of the frame. For the purpose of this analysis, two experimental survey designs were implemented. These experimental surveys test two different types of media, video and captioned single image, in an attempt to understand how much each affect information seeking.

The substantive political topic examined by this dissertation is the fiscal cliff. The fiscal cliff was a deadline created by Congress (December 31st, 2012 at midnight) that forced Congress to come to an agreement on the debt ceiling. If an agreement could not be met, two things would simultaneously happen: revenue would be increased with higher taxes and deep federal government spending cuts would take place. These cuts, called sequestration cuts, would be made in almost all areas of the federal budget. Some of the areas affected the most by the sequestration cuts are federal funding to states, defense spending, and federal infrastructure spending. This issue of the fiscal cliff, and the sequestration cuts that were to happen, were pushed back a few months thanks to the American Taxpayer Relief Act of 2012 (making the new deadline March 1st, 2013). A Congressional Connection Poll that measures how people felt about the fiscal cliff showed that the American public was generally ambivalent on the issue at the end of 2012 (Cooper 2012). Some people believe that cutting the spending would negatively impact the economy, others believe that it is a necessary cut, and some people just do not know 
how to feel about it. These issues of the fiscal cliff and sequestration are important to all citizens because it is a significant change to spending policy, but the public has seemed largely unaffected and disinterested in the topic.

Research done by Pew (2012) on the Fiscal Cliff, shown in Table 1.2, demonstrates that knowledge about the fiscal cliff was fairly low in December of 2012. There was some confusion on the part of the general public about the areas of the budget that were going to be affected most by the sequestration cuts. This is an indication that the public could, in general, learn more about the fiscal cliff and the impacts that come with sequestration.

Fundamentally, understanding what gets people interested in politics is an important issue for political science. Political issues tend to be too thorny and complex to be able to understand them in a timely manner, so political interest is frequently more salient than actual learning. While there is a general feeling of apathy about politics in America, some people do become interested. This research focuses on the potential for political humor to motivate people to be interested in politics especially with an eye to understanding what it is about political humor that makes it able to generate interest in politics. Although the American public is often times ignorant and dispassionate about political issues, political humor can positively activate citizens to seek for political information.

This study explores the effects of political events couched in humorous terms, focusing on the framing of Stephen Colbert, and analyzes its impact on viewers relative to neutral frames and a control group. In addition, this study examines two different types of media (video and single image memes) as different types of frames that could impact viewers. An experimental survey design was created and implemented for these studies. 


\section{Research Questions}

The general question that this dissertation attempts to answer is: does framing a public policy issue with humor affect a viewer's interest in politics? To answer that question this dissertation used an experimental survey design to gauge reactions from respondents. The survey instrument also measured the viewer's interest in the topic by their choice of whether or not to seek out more information on the topic.

Another secondary question that this dissertation seeks to answer is whether thinking political humor is funny, or "getting the joke," impacts the joke having an effect on bolstering political interest. This dissertation argues that discerning the humor in a political piece is essential to generating political interest because it is the fundamental driver of the emotional response. Having an emotional connection with a topic draws the viewer's attention toward that topic when given the choice to seek more information on the topic.

Other questions that this dissertation approaches are whether or not media richness, the quality of the media, affects the raising of political interest. Rich media theory suggests that rich media, like videos, tend to be an effective way of communicating complex issues (Daft and Lengel 1986). Is media richness directly or indirectly correlated with information seeking behavior?

\section{Dissertation Chapters}

The dissertation contains seven chapters, starting with this Introduction as Chapter 1, and a literature review in chapter 2 . The second chapter focuses its discussion on the burgeoning research in soft news and its focus on political humor. It explores research that looks at the 
importance of an informed public and how we understand the public's information seeking behavior. The literature review chapter sets up the discussion in the third chapter on the conceptual framework.

The third chapter on the conceptual framework uses the concepts of bounded rationality, cognitive dissonance, and media framing to create a theory of how political humor could lead to information seeking. This chapter examines how the research on political humor has conceptualized political humor's role in informing the citizenry. These conceptualizations are amalgamated in the chapter in order to understand the effect of political humor on its audience when it comes to information seeking.

The next chapter, Chapter 4, is a discussion of the methodology used to gather the data starting with the general procedure of the experimental survey. The second section of this chapter describes the experimental group conditions and basic layout of the video stimuli experiment and then goes into a full detail description. Then the chapter fully describes the single image for the image stimuli experiment. This chapter describes the use of both logit and Tobit analyses. Both of these analyses are important to examine because the dependent variable (information seeking) can be measured as both a dichotomously variable (whether or not someone looks for information) and a continuous variable (amount of time spent on information seeking). Similar logit analysis has been done when looking at information seeking (Xenos and Becker 2009), but Tobit analysis has not been utilized.

The findings from the video experiment are provided in the fifth chapter. First the chapter examines the descriptive statistics of the different experimental control groups. This includes the manipulation check questions to test some of the differences observed between the groups. 
Differences and similarities between the groups are noted in this chapter. Logit and Tobit analyses are presented as well.

The data and analysis from the single image experiment are provided in Chapter 6 .

Mirroring Chapter 5, Chapter 6 presents descriptive statistics in the beginning of the chapter with the similarities and differences shown. Manipulation check questions are analyzed in this section. Finally the more complex analyses (logit and Tobit) are presented.

Finally, Chapter 7 concludes the dissertation with a discussion of the implications of the findings for other research and what they mean for democracy. This chapter includes some discussion that compares the two experiments' findings and what they imply about political humor and the different media. Chapter 7 concludes with a discussion of the potential avenues for future research to more fully understand political humor and its effects on civic participation.

\section{Study Contributions}

This study explores the effects of political humor on the political behavior of information seeking. It does so by using an experimental design that is designed to look at how political humor affects people differently than the regular news and attempts to isolate the impact of humor as an important factor. Adding to the current literature on soft news effects, it is expected that this dissertation can contribute valuable insights in how to motivate people's interest in political issues and helping to create a more informed citizenry.

The main contribution to the field of political science, and (more specifically) political communications, is a greater understanding of how political humor can affect citizenry and political engagement. This dissertation claims that what causes viewers to be interested in a 
topic, yet unclear enough in the details or specifics of the issue, is seeing political humor and thinking it is funny. This builds onto research done in communication studies that suggests that soft news leaves an impression on how to feel about a topic without gaining much in the way of factual knowledge (Kim and Vishak 2008).

As a secondary, and methodological contribution to political communications, this dissertation developed a means of dealing with stimulus equivalence. Stimulus equivalence is a problem communication researchers have when they create or try to compare two different stimuli that only differ in the variable that they want to test and are similar in all other ways. Achieving stimulus equivalence is incredibly difficult, especially when researchers want to test video stimuli, but this dissertation used single image type memes to try to better approach the stimulus equivalence problem while still being culturally relevant and applicable.

I have now set up the problem of interest that, despite the plethora of information that is easily available on the Internet, Americans are generally uninformed in political affairs. It is thought that the origin of the lack of knowledge in the world of Web 2.0 is the lack of interest in politics. In this dissertation, I tested the potential that political humor could increase political interest and, therefore quite possibly, political knowledge. The next chapter contains a literature review of soft news, and political humor, research that suggests that entertainment shows that also contain political information could be good for American democracy. 


\section{Chapter 2 \\ Literature Review}

"Tell me and I forget, teach me and I may remember, involve me and I learn."

Benjamin Franklin

\section{Introduction}

As noted in the introduction, the problem this dissertation seeks to address is that people are generally uninformed about public affairs. This lack of knowledge originates from a lack of interest in those aspects of political behavior. And as noted in the first chapter, this problem is most pronounced among the youngest voting demographic, 18-25 year olds. This dissertation argues that political humor has the ability to raise political interest on topics for a short period of time. While this heightened interest might be of short duration, this dissertation argues that political humor still plays a positive role in American democratic life.

This study consists of analysis of two parallel experimental surveys that examine two parallel aspects of the effects of media on political information seeking. One is an experiment in which the effects of videos (one humorous clip from The Colbert Report and one a compilation of various news programs) is analyzed. The second experiment used captioned single image stimuli (one humorous and one neutral) to frame the same issue in an attempt to control for stimulus differences that inherently exists in the video experiment. This literature review chapter identifies previous research and studies on political humor and its various effects on the people that view it. 


\section{Media and Framing Effects}

There is a general consensus that the way that the media presents information affects how people perceive that information (Zaller 1992; Iyengar and Simon 2000; Nelson, Oxley, and Clawson 1997; Druckman 2004; Kellstedt 2000), but the way that media matters with regard to the public is a topic of debate. Media influence on mass public opinion has been often been characterized as having minimal effects, but some of the more recent studies suggest that the effects are significant enough to address (Cohen 1963; Iyengar, Peters, and Kinder 1982; Lippmann 1922). Lippmann (1922) suggests that the media allow people to gain knowledge and descriptions of events that they would otherwise have no connection. Experimental research was done to support Lippmann's claim and found that the media does influence viewers evaluations of political problems and presidential performance (Iyengar, Peters, and Kinder 1982).

People get information from mass communications and react in ways that are consistent with belief systems and emotional propensities. While mass communication effects are not overwhelming or totally controlling of the mass political beliefs (Druckman 2004) they are perhaps more than minimal. Instead of attitudes and positions being static and a priori, Zaller (1992) argues that people's opinions can be greatly influenced by their media experience. This dissertation argues that political humor, a specific genre of mass political communications, can frame a political issue or event with a humor, and potentially ideological, slant that affects the way the information is internalized by the audience ${ }^{6}$. Also, to add to Zaller's (1992) research, this dissertation argues that political apathy is not a static mode of being, and the way that a policy issue is framed can bring interest to an issue and make people more interested.

\footnotetext{
${ }^{6}$ How political humor affects the audience will be discussed in further detail in Chapter 3 .
} 
There are critics of the use of television, and video news in particular, in our democratic society (Postman 1984; Putnam 2000). Robert Putnam (2000) argues that gaining knowledge from television - and potentially the Internet - instead of engaging with others has decreased our perception of the importance of our social connections and the inherent democratic benefits of those connections. Others, like Neil Postman (1984), argue that television is an inferior way to gain information relating to politics. Postman argues that we cannot become informed from the videos from television because its purpose is to amuse, entertain, and distract viewers. This assertion made by Postman has some merit among certain types of media. According to a 2012 study conducted by Fairleigh Dickinson University Public Mind Poll, those who watch cable news outlets such as Fox News and MSNBC are less knowledgeable about political issues than citizens that report not following the news. The Public Mind Poll (2012) also suggests that people that pay attention to NPR tend to be more informed about international and domestic affairs than people that get their news from other sources. Finally, more in line with the argument made in this dissertation, this poll also finds that those who watch the Daily Show are more informed than those who watch $\mathrm{CNN}$ or that listen to talk radio.

There are scholarly proponents for video political entertainment. Jones (2010) argues that video political entertainment engages audiences in a way that audiences want to be engaged. "Entertaining politics," as Jones calls it, highlights the most interesting aspects of the political realm and makes it even more digestible and enjoyable for the audience. Political humor is a form of framing an issue and sometimes this could be seen as a negative frame (Moy, Xenos, and Hess 2006), but it could an avenue for making politics interesting to those who would normally think it was not (Baum 2003; Jones 2010). Political reporting and political punditry have 
become theater and less about actually informing the public (Fairleigh Dickinson University

Public Mind Poll 2012; Jones 2010; Patterson 2000), therefore political humor could be seen as a viable tool for political media.

Political humor is a fundamentally important aspect of the American political landscape. Political humor is, at its core, a form of political communication and political participation (Langeveld 1981). Early research done on humor effects, in marketing and psychology, suggest that humor has the ability to persuade viewers and change attitudes toward subjects (Berg \& Lippman,2001; Gruner, 1996; Lyttle, 2001; Schmidt, 1994; Scott, Klein, \& Bryant, 1990). It is a popular idea that political cartoons can be used to increase political literacy and a greater depth of political knowledge (Bedient and Moore 1985; Steinfirst 1995), and that humor can be used as a tool for persuasion (Bloom and Bloom 1979; Desousa and Medhurst 1982; Dudden 1985; Gruner 1992; Young 2004). Political humor is thus an important component of what the media can use to communicate to the public. The messages that political humor conveys to the public can range from the subversive to the informative.

Political humor is laden with politically relevant information. Brewer and Marquardt (2007) found that a majority of the stories on The Daily Show deal with a political topic or world affairs. One study (Fox, Koloen, and Sahin 2007) compared news coverage of the first presidential debate and the political conventions in 2004 on The Daily Show with Jon Stewart and network television nightly news. This study found that The Daily Show with Jon Stewart contained the same amount of substantive information as the broadcast network newscasts. Many other studies have shown that people, who are generally young and educated, learn from political humor (Baum 2002; Cao 2006; Pew 2008). Baum (2002) argues that political humor with high 
information content is a good thing because it makes it easier for people that would normally ignore politics to gain political information.

Recent studies have shown that late night political humor has had effects on different types of political attitudes (Baumgartner 2013; Baumgartner and Morris 2006; Baumgartner, Morris and Walth 2012; Moy, Xenos, and Hess 2006; Young 2004). Because soft news is seen as a tool to "break the attention barrier for issues of low salience" (Baum 2003; Neuman, Crigler and Just, 1992, p. 114), most studies that look at the effects of political humor on gaining attention to foreign affairs (Baumgartner and Morris 2008, Xenos and Becker 2009) or at its campaign effects (Baumgartner, Morris, and Walth 2012). The attention to foreign affairs in this research is well reasoned, but it is unnecessary. Political humor positively effects information seeking even on a domestically salient policy issue. This is partially because the public is largely uninformed and policy issues tend to be complex.

There is a debate over whether or not soft news, specifically political humor, is a positive agent in educating Americans. Baum (2002) argues that soft news (a larger category of which political humor could be seen as a subcategory), through the lowering of mental transaction costs, makes it easier for people with low motivation to gather political information to obtain it. People with low political interest are more likely to watch a political humor show for the entertainment value rather than actively seek out political information by reading a newspaper article. Because they are being exposed to political information in those shows, they learn something. According to Baum, this is positive because people with low interest are getting some information that they would otherwise not obtain. It is a positive "incidental by-product" effect of people looking for entertainment. 
This idea that soft news can inform is not universally accepted. Prior (2003) challenged Baum's idea that real learning takes place when people watch soft news. Prior argued that soft news is not as popular as hard news. Furthermore, and more importantly, Prior found that learning from soft news was not significant. Prior operationalization of learning was as long term factual retention (where knowledge is maintained for a long time and readily accessible). While Prior (2005) argues that as the public gravitates towards amusement it disconnects them from the political life. This dissertation argues that being amused by political entertainment can spark interest in the political world. Gaining interest in the political world could, in effect, be a gateway to becoming an informed political citizen.

Baum (2003) retorted that Prior misrepresented facts and made the test for soft news too hard. Furthermore, it is Baum's contention that Prior created a factual test that was too difficult for the viewers of soft news to pass. The size of soft news audiences, according to Baum, rivals that of hard news, so the exposure and cultural importance are similar. It is also Baum's contention that Prior's (2003) definition of learning, long term factual retention, is too narrow of a test for learning from soft news. Baum seems to concede that learning from soft news is marginal, but he argues that this marginal learning is a good thing because it is better than nothing at all.

There is research that looks at how viewing late night comedy shows correlates with other forms of political activity. A study from 2005 suggests that audiences, and candidates, focus their attention on soft news shows during political campaigns (Moy, Xenos, and Hess 2005). Through an analysis of the 2000 National Annenberg Election Survey, this research shows that consumption of late night comedy viewing has a positive relationship with the 
intention to vote and interpersonal political discussion. This finding was strongest with politically sophisticated people.

Kim and Vishak (2008) suggest that soft news (specifically the Daily Show with Jon Stewart) affects learning about politics in a different way than traditional news does. Using an experimental survey, this research found that when we watch traditional news the information is more likely to be compartmentalized and saved in our long-term memory than when we watch entertainment television. On the other hand, the information we learn through watching entertainment television is stored as an impression of the subject. This impression could leave information gaps and led to a person feeling a need for memory-based information to solidify their impression of the topic.

Jody Baumgartner and Jonathan Morris have researched the effects that political humor has on viewers. In one study (Baumgartner and Morris 2006), they found that The Daily Show negatively effects viewers' perceptions of candidates, the electoral system, and the news media. In this study, they also found that viewers of The Daily Show showed in an increased level of confidence in their ability to understand the complexities of the political world. In another study (Baumgartner and Morris 2008), they found that Stephen Colbert's attempts in poking fun of the right wing backfired and lead viewers to have more positive feelings towards President Bush and the Republican Party. These studies show how comedians affect their audience when they are making fun of others. In a recent study, Baumgartner (2013) found that watching negative political humor video clips negatively impacted the viewer's assessment of not only the targets of 
the clip they watched, but others as well ${ }^{7}$. This, as the author points out, is a "spillover effect" that political humor has. The negative views "spillover" onto other political figures. This effect helps to cause an audience that could be less likely to trust government and, potentially, participate in the political system. It seems that when political humorists act in a superior way they are not as effective in conveying their argument.

\section{Humor's effect on Domestic Policy- The Case of the Fiscal Cliff}

Most research that looks at the effects of political humor looks at its effects in either foreign policy (Baum 2003; Baumgartner and Morris 2008; Xenos and Becker 2009) or knowledge and opinions about political candidates (Baumgartner, Morris, and Walth 2011; Brewer and Cao 2006; Moy, Xenos, and Hess 2005; Young 2004, 2006; Young and Hoffman 2012). Researching the effects of political humor on knowledge and interest in foreign affairs makes sense because American's are notoriously ignorant and dispassionate about international politics. If political humor helps the uninformed and disinterested youth gain knowledge in a policy area, foreign policy is an area with great potential for growth because of American's notoriously low levels of knowledge about it. Looking at political humor's effects on knowledge and opinions about political candidates is important because it shows that political humor can influence young voters in either making a more informed choice or making the choice the comedian wants them to make. This research shows that political humor, in multiple forms, positively affects political interest even on salient domestic issues.

\footnotetext{
7 This work by Baumgartner is most likely inspired by his early work (Baumgartner and Morris 2006) where Baumgartner and Morris found that watching The Daily Show resulted in a negative reaction to candidates that are targets of jokes and, in addition, had more cynicism about the political process.
} 
A recent trend in American domestic politics has been the increased prevalence of fiscal debates that surround deadlines for some kind of compromise or agreement. The domestic issue of the fiscal cliff is multifaceted and complex. Understanding the fiscal cliff is important for many reasons. What the issue comes down to is that the fiscal cliff is a fight over all government spending: both gathering the revenues through taxation and policy expenditures. The debate is remains ongoing and the media is still using the "fiscal cliff" title as a short hand for the complicated issue that is the debate (Harrison 2013).

\section{Congress as the subject of ridicule}

In order to increase the likelihood that the audience thinks that the subject matter is funny, the target of the humor must be a group that is, almost, uniformly considered worthy of being the butt of the joke. Martineau (1972, pg. 1) purports that "Levine (1968) was correct to identify a lack of research and theory in humor despite its significance in human affair and its possible contribution to general behavioral theory." Martineau argues that one's relationship to humor depends on your being in the in-group or the out-group. Being in the in-group, being a part of the group that is making fun of some outside group, increases the likelihood of finding the material humorous. Out-group members, those who are either being made fun of, or are otherwise unfamiliar with the norms of the in-group, are less likely to find the humor to be funny.

An easy target for political humor has, historically, been Congress. In recent years, according to Gallup (2013), Congressional approval ratings have been waning (as shown in Figure 2.1). Congress is the perfect out-group to make fun of because there are only 535 of them and most of the people that are not Congressmen like to make fun of them. It is also important 
that Congress is a powerful institution and that makes many of the governmental decisions. That kind of power is ripe for subversive humor about how they are not doing a good job. Jokes about the ineptitude of Congress go far back into America culture. Consider Mark Twain's classic joke: "Reader, suppose you were an idiot. And suppose you were a member of Congress.... But then I repeat myself" (Paine 1912 pg 450). 
Figure 2.1

\section{Percent of Congressional Job Approval ${ }^{8}$}

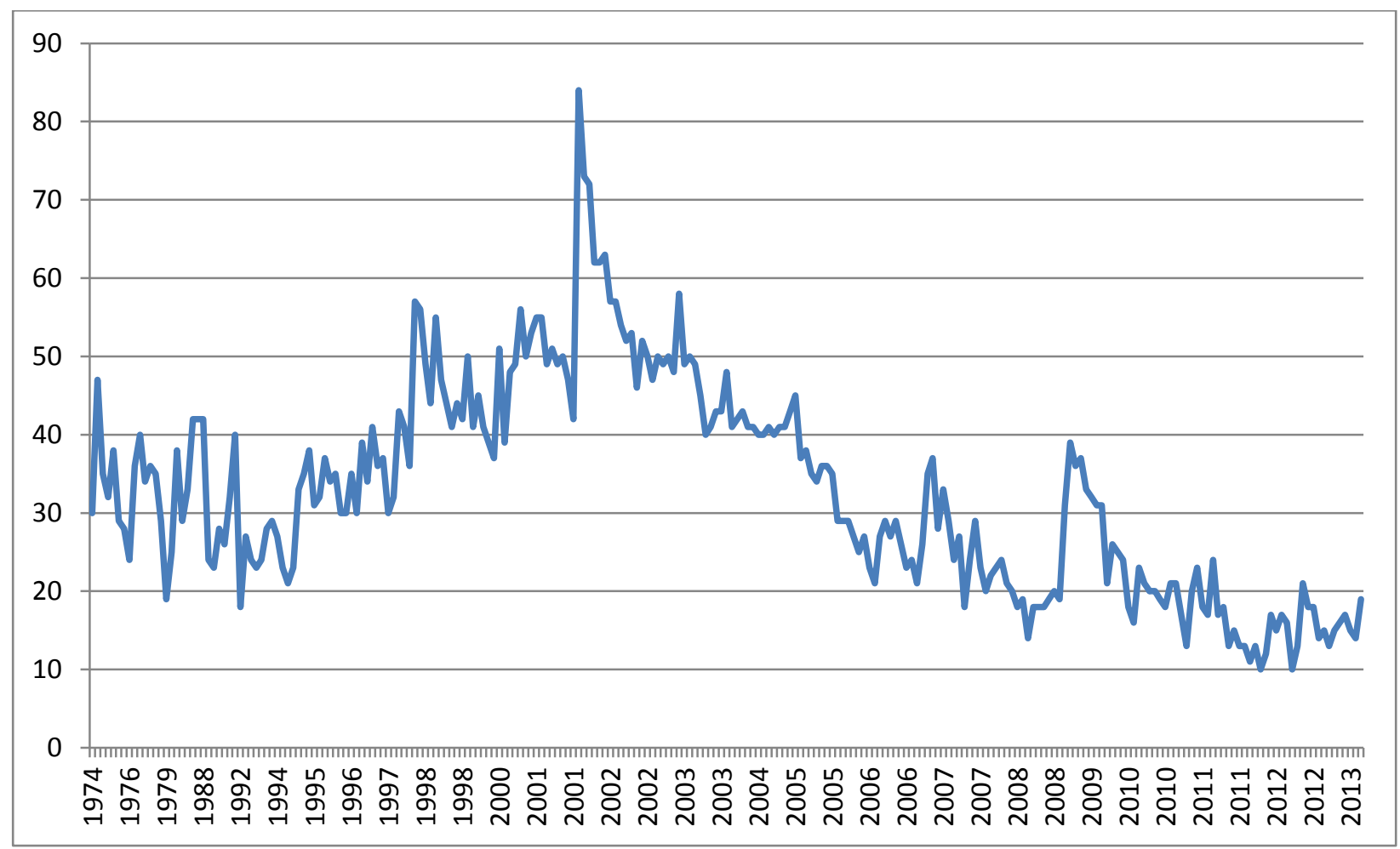

\section{Stimulus equivalence}

It is also important to note that there is a stimulus equivalence problem in researching differences between political humor and news effects. The stimulus equivalence problem is that there can be multiple differences between stimuli that confound studies that attempt to look for the effect of humor on political learning. These differences are numerous and include (but are not limited to) entertainment value, information that it contains, length (in time and words), visual stimuli (images, how the people in the video look, continuity of video), audience reaction/participation, quality of video and sound, and facial expressions and inflection. Much of

\footnotetext{
${ }^{8}$ Gallup asked the question "Do you approve or disapprove of the way that Congress is doing its job?" Data found on http://www.gallup.com/poll/1600/congress-public.aspx\#1. Accesses on October 17th, 2013
} 
the research in political humor has attempted to address the stimulus equivalence problem, but there is an absence of research that attacks the problem head on. Research on political humor tends to acknowledge that there is a significant difference in stimuli, but these researchers also intellectually shrug their shoulders and suggest that differences exist within the stimuli because there is a systemic difference between political humor and news media.

Some of the research done on soft news, and political humor, has not worried too much about controlling the stimuli to control for stimulus equivalence. In Baumgartner and Morris (2008), there are transcriptions of select portions of the stimuli that show very little equivalence. Young and Hoffman (2013) conducted a complicated longitudinal experimental study on the possible long-term effects of political humor. In the study, there were randomly assigned experimental conditions of videos that were 10 minutes long each week. The researchers acknowledge that their research was more focused on construct and ecological validity than the strictly controlled stimuli of other research.

One example of strictly controlled stimuli was research done by Xenos and Becker (2009). In their research they constructed stimuli of varying levels of humor. Along with the control group, Xenos and Becker (2009) included a humor clip, a news clip, and a hybrid clip. While the humor clip and the news clip were edited to create as much stimulus equivalence as they could, they also included the hybrid clip in order to see the effects of combining the stimuli.

Kim and Vishak's (2008) research is another example of controlling for stimulus equivalence. Video segments in this study, along with Xenos and Becker's (2009) study, were "about the same" in time and theme. Intercoder reliability was used to make sure that the videos used in the study were the same in theme and topic. While this research is dedicated to dealing 
with the stimulus equivalence problem, the level of equivalence that can be obtained in videos is limited.

These are good examples of nuanced approaches to the stimulus equivalence problem, but it is difficult to replicate this methodology because of the difficulty of obtaining the humor clips in an editable format. This type of research takes resources to record and edit televised shows. After shows are edited they can seem edited which threatens both construct and ecological validity.

The difficulty of achieving stimulus equivalence has lead to the need to seek out a way around the problem without threatening the construct and ecological validity of the stimuli. Framed single images is a good way to get around the problem without seeming too foreign or unique to the participants. These memes have become more prevalent in recent years and have saturated the Internet to the point of being mundane.

\section{Answering the Stimulus Equivalence Problem with Memes}

Dawkins (2006) argues that memes, or cultural transmissions, are like genetic transmissions and can give rise to a type of evolution. The evolution of language is an example that Dawkins makes. In The Meme Machine (1999), Susan Blackmore looks at how cultural information reproduces and evolves. For Dawkins (2006) and Blackmore (1999), the most important aspect of meme proliferation is replication. A great example of meme proliferation in the Web 2.0 age is the LOLCats phenomenon (Leigh 2009).

The LOLCats phenomenon, even if not experienced, is easily explained. You take a picture of cat, preferably making a funny expression, and you caption the picture with something funny. One of the most popular of these showed a cute kitty with big eyes and the caption "I 
can has cheezburger?" This concept of captioning a picture with something funny has, like many memes, replicated itself.

There have been many Internet memes that have made fun of countless people. For example, the day after Mitt Romney said that he was going to have to eliminate Big Bird and Sesame Street from the federal budget, there were all kinds of single image memes circulating on social networking sites, one of which showed a picture of Mitt Romney and was captioned "Soft on Wall Street. Hard on Sesame Street." Another example, are the memes that have come out about the lack of efficiency in the Affordable Care Act. One of the memes showed a bucket of money being poured into a toilet and the caption reads "Obamacare: because it's just money."

Like many things in America, this meme producing mechanism turned political quickly. These memes are prevalent. They are created by people of various political views. They are also created on the state level and local politics may get a few that are circulated within the community. These captioned images are now a part of the American political landscape and need to be studied to see if they have an effect on the audience. While it would be difficult to say that these captioned images would have much of any impact on the knowledge of the viewer, it could be a tool to pique someone's interest and get them thinking about a topic in a different way.

The proliferation of memes is important to this dissertation because many modern memes are humorous, and some of them are political. Quite a few memes are political humor memes. With all of these political humor memes being passed around, it begs the question of whether or not they influence political debate, political interests, or political opinions. This dissertation's single image experimental study is essentially the type of meme that gets created, shared, and 
reproduced. Although it is usually assumed that the media is primarily driven and controlled by elites (Zaller 1992), this dissertation looks at the potential effect of citizen created frames on the political interest levels of others. Before the discussion of whether or not political humor can increase political interest, it is important to look at political humor as being a way for the audience to become informed.

\section{Role of Political Humor as an Informative Force}

Everyone who has every taught an Introduction to American Government class has run across students that do not care to learn the material and they coast by, trying to do the least they can. Students are notorious for having a more restricted notion of relevance, and salience. Citizens generally act this way about information they do not find useful in their daily lives. Down's (1957) argues that citizens, as rational actors, do not have the incentive to gather information about politics just to be informed. So while disinterest in course materials may be disheartening to academics, the problem is simply indicative of rational decision-making in the face of minimal information about the importance of politics.

There have been other tests of Baum's hypotheses that have taken place in political science classrooms. If political humor can influence learning and interest, the college classroom is a great place to test that hypothesis. Studies have mixed results on the utility of political humor in the classroom.

Learning and interest effects were not found when researchers used Jon Stewart's America (The Book) as a supplemental textbook for an Introduction to American Government class (Baumgartner and Morris 2008). This research was looking for long term (four month) effects on people that were attempting to get a grade in a class. Furthermore, the test that 
Baumgartner and Morris (2008) put on Jon Stewart's fake textbook (to get college freshmen interested in American politics, and interested in citizenship test-like questions) was too long term of a test for the medium.

Although Baumgartner and Morris (2008) found that Jon Stewart's book was not useful in the classroom setting, Staci L. Beaver (2011) found that using video clips in an introductory U.S. politics course was useful in enhancing students' classroom participation, political participation, and critical-thinking skills. The different findings from these two studies highlight the importance of transaction costs when it comes to media effects (Baum 2003). The supplemental textbook was not effective because it is just another book for students to read (therefore they are more unlikely to read it) and watching videos in an introductory class, on the other hand, is generally popular with students and takes little to no energy. Therefore, low cost media (either a video or a framed single image meme) could have positive effects on the level of political interest of the viewing audience.

As mentioned in Chapter Two, soft news and political humor research focuses on young, usually college aged, people (Baumgartner and Morris 2008; Beaver 2011; Young and Hoffman 2013; Xenos and Becker 2009). There are two reasons for this focus. First of all, young people are historically not informed, not interested, and, therefore, not engaged. Secondly, young people are the ones that tend to watch political comedy shows. The Pew Research Center for People and the Press released a survey containing a widely reported fact that $21 \%$ of people ages 18 to 29 reported they regularly learned some news about political candidates or the 2004 presidential campaign from "comedy TV shows" and 13\% reported the same of "late-night TV shows" (Pew Research Center 2004). Self-reporting that they learn something from the 
entertainment shows is interesting, but it is important to analyze what they actually learn relative to what is learned from other sources.

Some studies suggest that comedy shows are very informative. In fact some research has shown that knowledge can be gained through comedy shows rather than traditional newscasts (McQuail 2005; Qin 2008). In a 2008 study, it was found that respondents that saw a Daily Show clip scored higher on knowledge questions than those who watched a similar $C N N$ clip.

Furthermore, those who were seeking entertainment were likely to score higher than those who were knowledge seekers (Qin 2008). Furthermore, political humor viewership has a positive relationship with knowledge about presidential candidates for younger, college-educated people (Cao 2006).

While there is research that looks at how political humor can help, directly or indirectly, to inform their viewers (Baum 2002; Qin 2008; Young and Hoffman 2013; Xenos and Becker 2009), the focus of this dissertation is the potential catalytic effect of political humor. Using political humor as a source for information may seem less than ideal to some (Prior 2002; Jon Jon Stewart C-Span Newhouse School Forum, 2004), but it seems reasonable to see it as a potential catalyst to information seeking. Although research shows that comedy shows are fairly informative (Cao 2006; Qin 2008), if political comedy also increases interest and information seeking then the effect could be more meaningful. The fundamental research question of this dissertation is that political humor increases interest in politics and that interest encourages the viewer to seek out more information. The next section focuses on research done on political information seeking. 


\section{Political Information Seeking}

Research on political information seeking is done in the spirit of democratic theory that suggests that an informed citizenry is important to a fully functioning democracy. Democratic theory posits that the ideal citizen in a democratic system would be active in the political sphere, and that the citizen's political activity would be grounded in political information (Chambers, 2003; Delli Carpini \& Keeter, 1996; Habermas, 1984). Overall levels of political knowledge in the United States are low (e.g., Kinder \& Sears, 1985; Neuman, 1986) and knowledge appears to be unequally distributed across the population (Converse, 2000). This is problematic because levels of political knowledge have been found to be consequential for participation, representation (e.g., McDevitt \& Chaffee, 2000; Zaller, 1992), and voter decision-making strategies (Lanoue, 1992).

Research has shown that exposure to political information is highly correlated with political knowledge (Chaffee and Frank 1996; Norris 2000; Wade and Schramm 1969). This research has also found that being educated is highly correlated with retention of information from video and print media (Wade and Schramm 1969). Watching television news has been shown to increase political knowledge and participation (Norris 2000). There is research demonstrating how traditional news media, television news and newspapers, help to close the gap of political information (Eveland, Hayes, Shah, and Kwak 2005, Eveland and Scheufele 2000), but this research does not look at what motivates people to seek out information in the first place.

Research that sought to understand whether or not political comedy could help increase interest in politics found that The Daily Show could increase political interest in foreign policy 
(Xenos and Becker 2009). This dissertation's goal is to see if another political comedy source, The Colbert Report, could increase interest in another policy area, domestic economic policy. Furthermore, it is the goal to test if a simple single framed image could affect political interest in a similar way. Finally, this dissertation seeks to understand if finding the content humorous positively correlates with higher interest and information seeking behavior.

Understanding the source of the humor is important. Political humor is a many varied and complex issue that is difficult to understand. Understanding the type of humor that the research used is important because different types of humor could affect the audience differently.

Negative, caustic political humor has been found to create negative opinions of candidates and politics in general (Baumgartner 2013), while more neutral, playful humor has been found to increase political interest and information seeking (Beaver 2008; Xenos and Becker 2009). In the next section, the source of the political humor, The Colbert Report, is discussed.

\section{The Colbert Report in Society}

There are various different types of humor (Young and Tisinger, 2006; Baumgartner and Morris, 2008). Stephen Colbert, the host of The Colbert Report and a somewhat unique media character, could have a somewhat unique effect (LaMarre, Landreville, Beam 2009; Baumgartner and Morris). According to Comedy Central's research (No Fact Zone 2010), The Colbert Report has been increasing viewership. The viewership of The Colbert Report is young (Pew Research Center 2010, 2012). According to the Pew Research Center, 74\% of regular viewers of The Colbert Report prefer their news delivered without a blatant bias (Pew Research Center 2011). 
Experimental research on The Colbert Report has shown complex and interesting findings (LaMarre, Landreville, Beam 2009). This research shows that, although all groups thought Colbert was funny, different groups thought his intention was different. Liberals thought he had a liberal message and used satire when he took (cartooned) conservative policy stances. Conservatives thought that Colbert is only pretending to be joking when he offers conservative policy positions. This is all additionally complicated when you think about the research that suggests that viewers of The Colbert Report were brought to agreement with President Bush, the Republican Congress, and Republican policies (Baumgartner and Morris 2008). For this dissertation it is important that research suggests that Colbert is universally funny (LaMarre, Landreville, and Beam 2009), because that means that Colbert is likely to spark interest in politics more than someone who is potentially more politically divisive.

The age group of The Colbert Report is important to think about because it is important for external validity that the age group of the show is close to the sample of the experiment. Although there were reports in 2009 (Berr 2009) that the average ages of The Daily Show and The Colbert Report viewership were "creeping up", in 2012 Pew Research Center for the People and the Press, The Colbert Report is dominated by young viewers. According to the Pew Research Center, $74 \%$ of regular viewers of The Colbert Report prefer their news delivered without a blatant bias (Pew Research Center 2011). The Daily Show and The Colbert Report are very popular with adults from the ages of 18-49 in the 11pm-midnight block (Bibel 2013).

In The Colbert Report, Stephen Colbert, while in character at least, thinks that he is an important player in the American political, and cultural, milieu. It is his assertion that politicians, celebrities, artists, and writers get a boost of popularity from coming onto his show. Colbert 
therefore takes some of the credit for good things that happen to people that come onto his show. He calls this the "Colbert bump:"

[t]he Colbert Bump is the curious phenomenon whereby anyone who appears on this program gets a huge boost in popularity ... Another lucky recipient of the Colbert Bump is former Arkansas Governor Mike Huckabee. Before he came on the Report, his presidential campaign was polling at $1 \%$. After his appearance, he soared to $3 \%$. That's a 300\% increase after a two-and-a-half-minute interview. If he keeps up that pace between now and the election, he'll be the first candidate ever to get elected with $88,128,000 \%$ of the vote.

Colbert Report June 21, 2007

A political scientist, James Fowler (2008), found that politicians did, in fact, benefit from going on The Colbert Report in the form of campaign contributions that are made shortly after going on the show. These effects might be a sign that The Colbert Report increases interest and political activity, but most likely, not as much as Stephen Colbert claims it does on the show. If, as Folwer (2008) and Colbert (2007) suggest, the "Colbert Bump" exists, then maybe the show can increase popularity of political issues in the same way that it increases popularity of political candidates or book sales.

This review of the literature is an important step towards talking about what this dissertation wishes to accomplish. While the research on soft news generally, and political humor specifically, has done a great job to starting the conversation, this dissertation wishes to fill a gap in the political literature in an attempt to gain further knowledge about political humor. In the next chapter, the conceptual framework is discussed. This conceptual framework is framed by the ways that previous research has looked at the effect of political humor, and then the contribution of this dissertation is expounded upon. 


\section{Chapter 3 \\ Conceptual Framework}

"Try not to have a good time...this is supposed to be educational."

- Charles M. Schulz

\section{Introduction}

In his work on political humor, Charles Schutz (1997) asserts that "humor is natural to politics" (pg 25) and political humor can play an important role in democratic life. Schulz argues that humor, particularly aggressive and invective humor, can be a peaceful way for citizens to air their grievances and release political tension. Schutz also goes on to argue that political humor could be a subversive learning tool. Humor has been seen by some as a useful tool in instruction for learning (Schutz 1977; Beavers 2011). This dissertation investigates the utility of political humor in a modern democratic society. The specific utilities that this dissertation investigates are political learning, interest, and efficacy.

This dissertation's conceptual framework logically follows and expands upon previous research. It is the central hypothesis of this dissertation that political humor encourages viewers to seek out relevant political information. To start this discussion, this dissertation focuses on how Baum's research on soft news $(2002,2003)$ changed the way researchers look at soft news in general, and political humor specifically ${ }^{9}$, because Baum thought that people could use soft news as a way to become informed about politics. The focus of this dissertation is on adding to

\footnotetext{
${ }^{9}$ While some political humor does belong in the categorization of soft news, it is acknowledged by some researchers that the humor aspect of political humor makes it distinctly different from other forms of soft news (Holbert 2005). Much of the work on soft news has focused on political humor instead of other forms of soft news.
} 
Baum's work by looking at political humor as a catalyst for information seeking behavior.

Baum's theory centered on the low transaction cost of soft news and how it could boost political interest and provide information to people that would otherwise not seek it out. This theory is not without its detractors, Prior (2003) argued against Baum's theory and found some evidence that soft news viewers are not really learning. If Baum is correct that political humor boosts political interest and Prior is correct in saying that people don't learn from political humor, then if political humor raises interest enough for people to seek out more information (from traditional news) and potentially learn something about the issue.

This chapter outlines and elaborates on this dissertation's conceptual framework. The beginning of this chapter discusses the theoretical underpinnings of the research which includes discussions of bounded rationality, issue framing, and political humor. Then this chapter demonstrates the previously discussed conceptions of how political humor affects it's audience. This demonstration shows a need for further understanding and explanation for the effects of political humor on its audience. Then this dissertation's conceptual framework, which is deeply rooted in the previously done research, is elucidated. Hypotheses are included with the conceptual framework and a table that summarizes the hypotheses can be found at the end of this chapter.

\section{Theoretical Underpinnings}

Scholarly work done on political framing and political humor, like this dissertation, has a base theory of bounded rationality (Simon 1957). Bounded rationality is the theory that people have limited information and cognitive limits. When people make decisions they can only act on the information that they have. Bounded rationality can be applied to information seeking 
behavior. Citizens are often bounded by their limited perception of topics. Citizens only seek out information if they think the information is pertinent. Political framing literature examines what changes citizens' perceptions of topics.

There are questions of whether or not the American public, by-and-large, are able to hold meaningful attitudes on topics. Some research suggests that public attitudes generally are not stable, informed, consistent, and connected to abstract principles and values (Converse 1964, Zaller 1992). The backbone of the framing literature is that public opinion is inconsistent and capricious. The framing literature looks at how frames, the way an idea or issue is presented, affect public opinion and behavior.

To understand the importance of the framing literature, we must understand what a frame is and what it does. Simply put, frames are the way we present an idea or an event. Political frames are normally put forward by politicians, the press, or interest groups. The way events are framed "organizes everyday reality" (Tuchman 1978, p. 193). Frames can give people an understanding of events. To make the frame make sense to a broad audience, or to make a sense of it themselves, those who frame could talk about a subject, event, or topic in a specific narrative (Gamson \& Modigliant 1987, Shah et al. 2002). Much of the framing literature talks about "framing effects" which are "different, but logically equivalent, words or phrases - such as 95\% employment or 5\% unemployment - cause individuals to alter their preferences" (Druckman 2003). This research looks at media effects and framing as a strategy to deliberately affect public opinion. 
Whether or not it is purposive, political humor frames political events and ideas. Recent research the ways in which political humor could affect its audience. One of the main theories of how political humor affects its audience comes from Matthew Baum. Matthew Baum's (2003) theory of how people who are not interested in political matters receive their information came from rational choice modeling and bounded rationality.

According to Baum (2003), political attentiveness is a matter of how we perceive the utility of the information. When people chose to be attentive to a political matter they calculate their perceived benefit of being attentive and they also take into account their perceived transaction costs. Baum's theory could be used to explain why American youth tend to be woefully ignorant and disinterested in political affairs. Many youth typically do not see what they can gain from political knowledge or action, but, as Baum points out, those same people may watch soft news programming for the entertainment. Baum's argument is that political humor, as a form of soft news, could be a conduit for information for people to become informed.

Finally Baum (2003) discusses the importance of water cooler events, events that are talked about in the workplace are normally popularized by soft news outlets. These water cooler events are important to many people because understanding them enough to talk about them is important for social interaction. Baum argues that some people get their understanding about major political events, water cooler events, by watching soft news programming. Part of the motivation to watch soft news shows is to have something interesting to discuss at the water cooler.

While Baum (2003) argues that soft news aides in giving political disinterested people an 
idea of what is happening politically, Prior (2003) argues that audiences do not really learn from soft news, but learning is more likely to happen from hard news. If both of these premises are true, political humor can only be useful if it gets people interested enough in a topic to investigate it further. Drawing from these theories, and the debate between Baum (2003) and Prior, this dissertation sees political humor as potentially having the ability to slightly inform, as argued by Baum (2003), but that if political humor had the ability to make people more interested in politics and investigate a topic, then it would be a much more important part of our democracy.

Now that the theoretical underpinnings rooted in rational choice and bounded rationality has been discussed, the next section of this chapter discusses how role of political humor in shaping political knowledge has been conceptualized in the past and how this dissertation conceptualizes this role.

\section{Conceptualizations of the Role of Political Humor and Political Knowledge}

The role of political humor in American politics has largely focused on how it affects the political knowledge of those who watch it (Baum 2002; Baum 2003; Baumgartner and Morris 2008; Prior 2003; Xenos and Becker 2009). Other studies have looked at how political humor affects attitudes towards politics (Baumgartner 2013; Baumgartner and Morris 2006; Baumgartner, Morris and Walth 2012; Moy, Xenos, and Hess 2006; Young 2004). Some of these studies have contradictory results. These contradictory results show a need for more research and thought on the topic. 
Baum's (2002) idea of how the audience gets information from soft news is that there is essentially information contained in the soft news itself. Political information is a part of what soft news does because the information provides a subtext for the joke or conversation. For Baum, the utility of soft news is not that it makes viewers more interested in politics, but that viewers learn from the content because they, being disinterested in the topic of public affairs, would not otherwise seek out political information. Consequently, people with low levels of interest, and therefore low levels of knowledge, gain from soft news because soft news is entertaining enough to attract them, but also has some news in it. This theory has been furthered by research, like that done by Pew (2010), that shows that eighteen to twenty-five year olds say that they get their information from political humor shows.

There have been many studies that have either attempted to support Baum's theory that people become informed or minimally get impressions about political actors and events directly from political humor. Brewer and Marquardt (2007) coded the content of The Daily Show with Jon Stewart for policy content and found that the show included a significant amount of policy information and policy frames. This research also suggests that young, educated people are the ones that are most likely to receive the benefit of being informed from political humor.

A study conducted by Pew Research Center's Project for Excellence in Journalism (2008) supports this conceptualization of the utility of political humor and American politics. This Pew study sought to compare The Daily Show with mainstream media in an attempt to test a number of journalistic comparisons. In this study, it was found that the news content on The Daily Show was very similar to that of cable news shows. It was also found that The Daily Show did miss some stories and spent much of the time critiquing cable news channel's coverage. 
The problem with Baum's theory that viewers of political humor become enlightened from watching soft news is that, although there are studies that say people get their news from shows like The Daily Show (Pew Research Center 2007) there are studies that suggest that real learning is not happening (Prior 2003). Furthermore, Jon Stewart himself argued that learning from his show is unlikely:

"My complaint about people saying that most kids get the news from you is not that I am worried that they are getting their news from me. The truth is that I know that they are not, because you can't because we don't do it. We just don't, there is not enough news to get. Its crumbs... if [kids] came to our show without knowledge, it wouldn't make any sense to them. It would be like Charlie Brown's teacher talking.” Jon Stewart C-Span Newhouse School Forum, 2004 Stewart and his staff ${ }^{10}$ have since backed off from statements that minimize the show's impact on viewers and society.

Xenos and Becker's (2009) found that an existing interest in politics is bolstered by the presence of the political humor frame. This model, depicted in Figure 3.2, theorizes that political humor can take existing political interest and augment it to increase the possibility that a person will search for the relevant political information. For Xenos and Becker (2009), people with lower interest levels are most influenced by watching political humor to boost their political interest. This dissertation builds on the Xenos and Becker model of information seeking to include how the viewer interprets the frame as a variable. How viewers interpret political humor, including if they find it humorous, could influence the impact of the humor on interest.

\footnotetext{
${ }^{10}$ Samantha Bee, a correspondent for The Daily Show with Jon Stewart, made a similar comment about the show being entertainment and not informative in an interview with Seamus O'Regan (Canada AM November 1st, 2004).
} 


\section{Figure 3.1 Xenos and Becker's (2009) Model of How Political Humor Impacts Information Seeking}

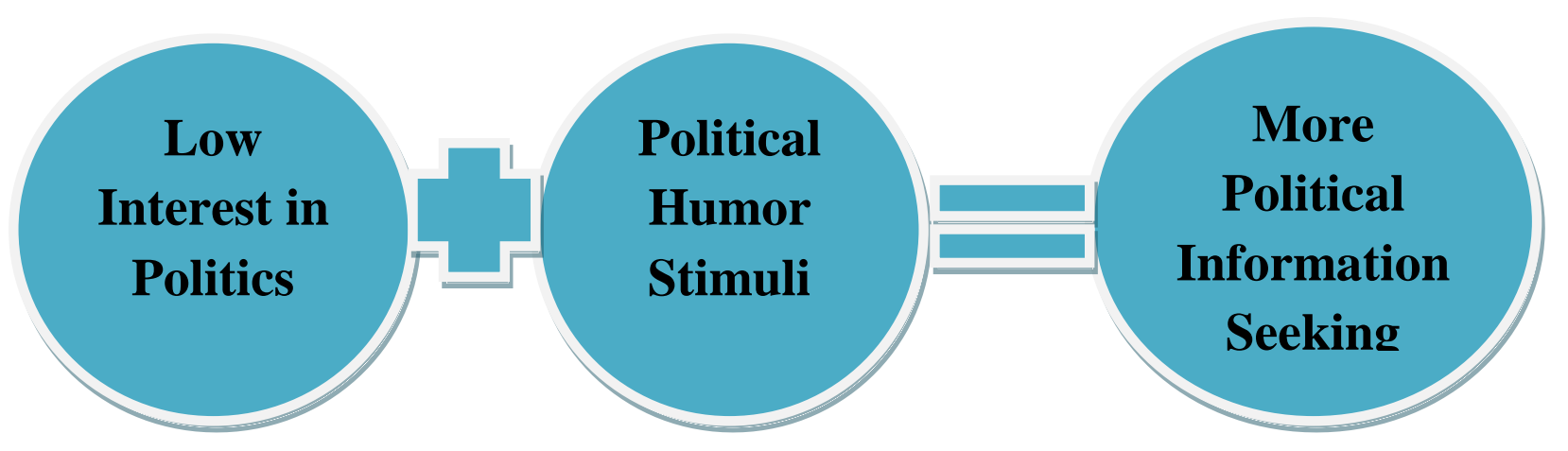

Drawing from Kim and Vishak (2008), the theory of this dissertation posits that there is an emotional reaction to the humor aspect of stimuli and, instead of creating a strong memory of the subject, a strong impression of how one should feel about the topic is formed. What this dissertation adds is that this impression, although it is rooted in some "facts," is not substantial enough keep cognitive dissonance away. The viewer then, more often than those who get standard news, needs to fill the logical leap that the impression gives them and feels compelled to look for more information. Thinking that the joke was funny increases this desire to look for more information because the humor creates a bond between the viewer and the position that they feel they should adopt.

Research suggests that political humor could result in lower political efficacy (Baumgartner 2013; Baumgartner and Morris 2006). This research suggests that because humor tends to make fun of someone or something, political humor creates a negative frame for politics. If political humor lowers political efficacy it would lower information seeking because lower political efficacy would mean that the political world would seem less accessible and the 
individual less likely to change it. When all of the political humor and political information seeking literature results come together, as shown in Figure 3.3, the results is case dependent (at best) and inconclusive (at worst). The reason for this is that the type of humor differs greatly in the political humor literature.

Figure 3.2 The Literature's Model of Information Seeking

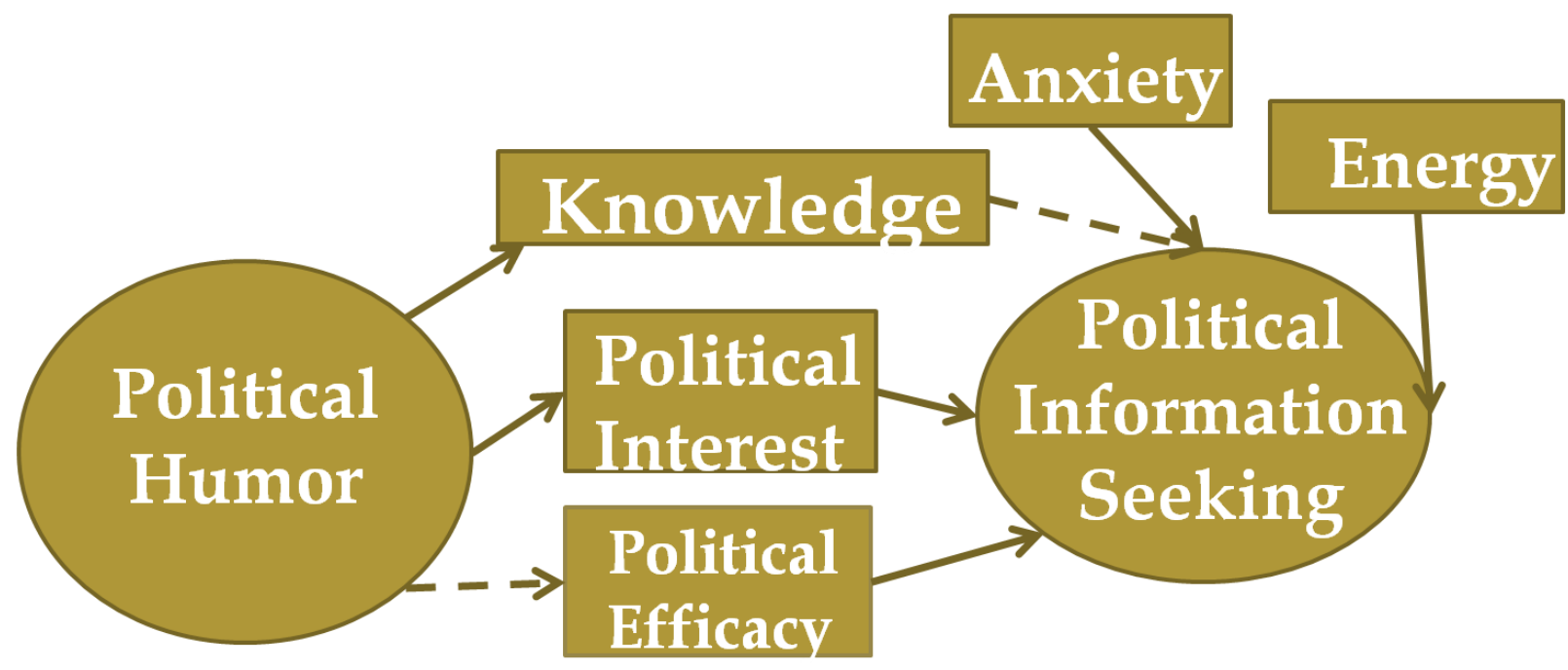

\section{Political Humor's Role in Information seeking and Hypotheses}

This dissertation seeks to discover the role that political humor plays in seeking out information about a topic. There are multiple factors that come into play when looking at political information seeking and isolating what it is about political humor that would lead to information seeking is an important move forward. The theory put forward suggests that political humor, because it entertains while providing a frame to a political subject, can spark interest in politics. The focus of this dissertation is whether or not one finds the political humor frame to be funny plays an important role in the effect that political humor makes vis-à-vis 
information seeking behavior. Getting the joke is what gives the joke impact and sparks the interest in the subject matter.

\section{Figure 3.3 How Getting the Joke Affects Information Seeking}

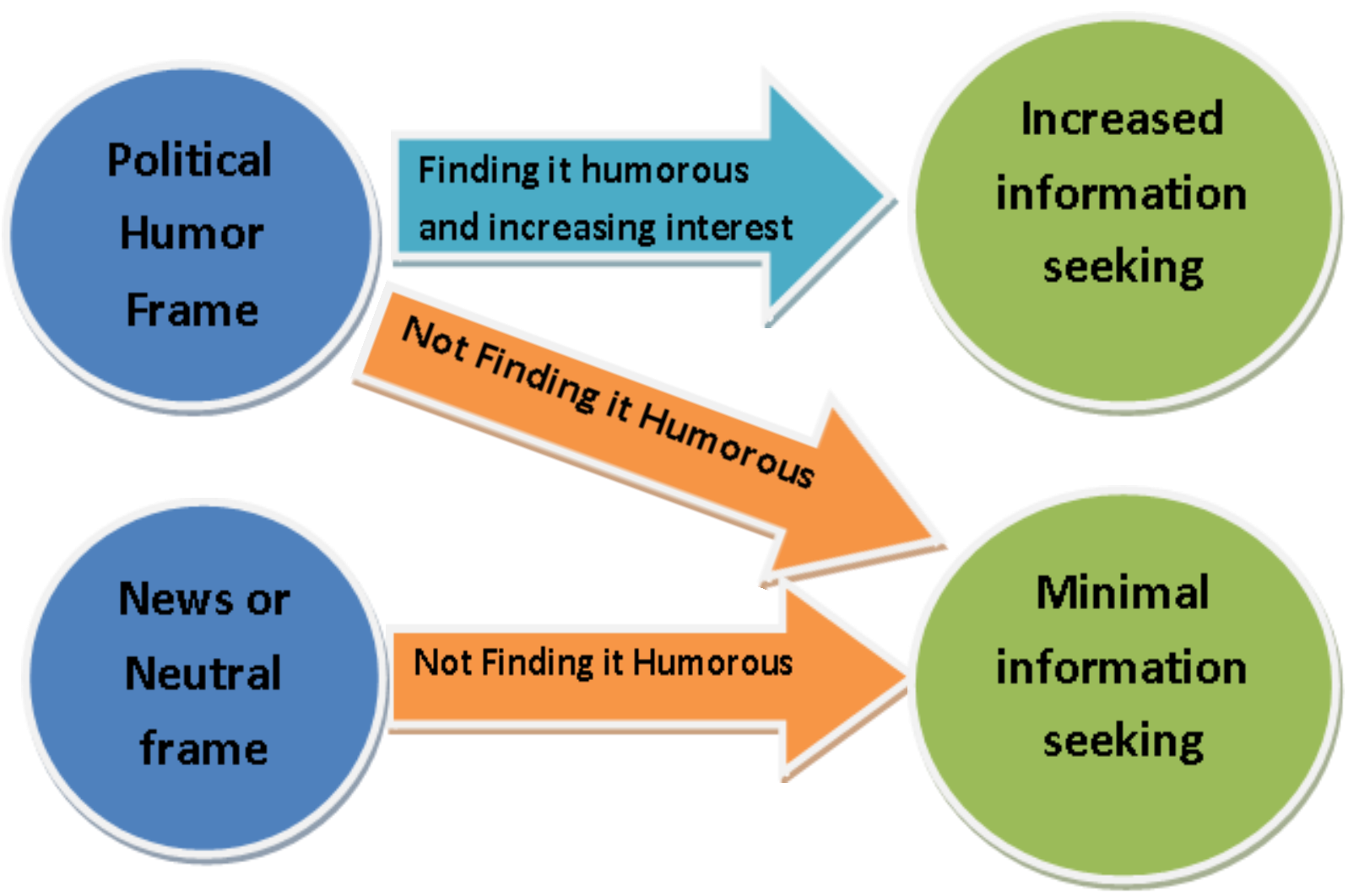

As mentioned in Chapter 1, research suggests that political interest is highly correlated with information seeking (Patterson 2000). This dissertation assumes that political interest is indeed the most important variables that lead to information seeking. The question that this dissertation seeks to answer is whether or not political humor can, even temporarily, raise interest in politics enough to encourage information seeking. This main hypothesis is shown in Figure 3.4. Exposure to the humorous frame is also be associated with more self-reported interest in politics. There is a positive association of how entertaining the person found the material and 
how attentive they are to the subject matter. These expectations are formalized in the first and second hypotheses:

\section{H1: Exposure to a policy issue through a humorous frame increases attentiveness to that} issue.

\section{H2: Enjoyment of the way that a policy issue is framed positively correlates with attentiveness to that issue.}

The third and fourth hypotheses use the concept of "spillover" from previous research (Baumgartner 2013) that found that negative political humor about one political target has a "spillover" effect into other aspects of the political world. Although this spillover may be easier with negative feelings, if humor increases interest in a political topic, that interest could spillover into politics in general. Therefore, this dissertation includes some spillover hypotheses. These hypotheses argue that getting the humor frame (H3), and enjoying that frame (H4), increase the likelihood that the respondent identifies as being interested in politics in general.

\section{H3: Exposure to a policy issue through a humorous frame is associated with increased self- reported interest in politics.}

\section{H4: Enjoyment of the way that a policy issue is framed positively correlates with self- reported interest in politics.}

One variable used is obtained by asking the respondents if they thought they learned from the experimental stimulus. This variable is important because it is a good manipulation check question. It is important, not only that both the news (or neutral) stimulus has as much of the same information as the humorous stimulus, but also it is important that both types of stimuli make the viewer feel like they learned at similar levels. Research has shown that learning from political humor is possible (Baum 2003). Baum (2002) suggests that learning happens in soft news as a result of a secondary mechanism to the entertainment aspect of soft news. This means 
that viewers of political humor might feel less informed by a show, than from traditional news, because the show is generally seen as an entertainment show and not an avenue of information.

It is not hypothesized that political party or ideology plays an important role in this research because if finding the content humorous is key to raising interest, and The Colbert Report is indeed found humorous by both sides of the political spectrum (LaMarre, Landreville, Beam 2009), then the effect should be universal. Although the conceptual framework suggests that there should not be an ideological effect, ideological were examined in this dissertation because there is research that suggests there are differences in media preferences. Pew (2010) research suggests that, for some topics, party affiliation can affect preferences of media coverage. Specifically, and most pertinent to this dissertation, independent voters are more likely to want more domestic policy coverage relative to Democrats and Republicans.

When viewers consume political humor content and then purposively seek out information, they are more likely to learn the information and take an interest in the topic in the future. User control with the ability to intently focus attention is the best way toward education. Being primed by political humor is a good way to get someone to seek information, but hyperlinks help expedite that process.

\section{Conclusion}

The conceptual framework for this dissertation has been discussed. The resulting hypotheses are listed in Table 3.1. This framework simply argues that if a policy is framed in a humorous way, attentiveness to that issue is increased. Furthermore, how enjoyable, or humorous, the consumer finds the policy frame positively impacts how interested that consumer reports being in that policy area. Finally, the spillover hypotheses (H3 and H4) argue that the 
positive effect of policy interest may be the primary effect, but this interest spills over into politics in general. Now that the conceptual framework has been discussed, the next chapter focuses on the methodology used by this dissertation.

\section{Table 3.1 Table of Hypotheses}

\begin{tabular}{|l|l|}
\hline H1 & Exposure to a policy issue through a humorous frame increases attentiveness to that issue. \\
\hline H2 & $\begin{array}{l}\text { Enjoyment of the way that a policy issue is framed positively correlates with attentiveness to that } \\
\text { issue. }\end{array}$ \\
\hline H3 & Exposure to a policy issue through a humorous frame increases self-reported interest in politics. \\
\hline H4 & $\begin{array}{l}\text { Enjoyment of the way that a policy issue is framed positively correlates with self-reported interest } \\
\text { in politics. }\end{array}$ \\
\hline
\end{tabular}




\section{Chapter 4 \\ Methodology}

\section{Introduction}

In this chapter I describe the methodology that was used to collect the data that is analyzed in Chapter 5 and Chapter 6 . This chapter begins by explaining the basic procedure of the survey. The utility of the static information board that was used is discussed. The different experimental conditions in the survey are also spelled out in this chapter. In describing the experimental conditions, the differences and similarities between the video stimuli in the single image experiment. Collection of the subjects of the survey, and some the characteristics of the participants are also detailed. The empirical analysis examines respondent's reactions to stimuli and their information seeking behavior after receiving their framing stimuli.

The conceptual framework described in the previous chapter provides the basis for this study. In the research process, the relationship between how viewers interpret a domestic policy frame and their ensuing search for information is explored using two online experiments with surveys used to collect information about the cases and their behavior. The two surveys use different stimulus media to cover the same issue: the fiscal cliff.

This is a design that requires two separate, but similar experimental designs. The designs are similar because they serve the purpose of testing "infotainment's" effect on information seeking behavior. The general designs of the two experiments are very similar because I wish to measure the same type of behavior. The differences in the experiments lay in the content of experimental treatments. The first experiment is a video survey that utilizes a video from The Colbert Report and a compilation news video that was created to make the information in the two videos as similar as possible. Acknowledging that those videos are not equivalent in 
stimulus, a second survey was created with a captioned single frame to control for stimulus equivalence.

\section{Study 1: Video Experiment}

The first experimental design is meant to test The Colbert Report's effect on information seeking behavior. Although researchers have attempted to look at how soft news affects information seeking (Xenos and Becker 2009), their research was limited and could be expanded upon. One limitation is that Xenos and Becker looked at one source of political humor (The Daily Show) and there is evidence that different types of political humor could have different effects (Baumgartner- online humor 2009, Baumgartner and Morris 2008). I want to look at The Colbert Report because there seem to be some interesting ideological interactions with Colbert's screen character (Baumgartner and Morris 2008; LaMarre, Landrevill, and Beam 2009).

Baumgartner and Morris (2008) found that Colbert's message persuades viewers in the same way that Bill O'Reilly does in that it increases support for Republicans and Republican policies. It also seems as though Colbert's brand of humor makes the political world seem more complicated to young adults (Baumgartner and Morris 2008), while it has been shown that The Daily Show makes the political world seem more accessible and clear (Baumgartner and Morris 2006). 


\section{Video Experiment Participants}

The video experiment had 172 participants responding, but 12 respondents were dropped from the analysis ${ }^{11}$ leaving 158 participants that were analyzed. There were 74 participants in the control group, 46 participants in the humorous (Colbert Report) video group, and 42 in the compilation news video group. The demographic composition of the participants is not that different from The Colbert Report audience composition. There were 112 females (70\%) and 48 males $(30 \%)^{12}$.

The average age was 22.33 which is about in the middle of the $18-25$ year old demographic that The Colbert Report tends to do well in. It is important to note that the people that took this survey (mostly between the ages 18-25) are of the Millennial generation. Millennials have been thought to be an important group of voters that are impacting the political landscape (Winograd and Hais 2008). With their focus and reliance on the Internet, social networking websites (life Facebook and Twitter), and texting, Millennials are changing the way that political information is being distributed by political actors and mass media. In fact, Millennials are the one age group that is least likely to get their political information from television, but will get that information from the internet instead (Winograd and Hais 2008). The fact that Millennials are the majority of the sample is not problematic because they are the group most likely to use the Internet to get their political information.

\footnotetext{
${ }^{11}$ Responses were omitted from analysis because they failed to finish the survey. One respondent was omitted from the survey because he attempted to take the survey more than once.

${ }^{12}$ There were no theoretical or observed differences in behavior between the genders.
} 


\section{Video Experiment Procedures}

This is an experimental design with a pretest, multiple experimental treatments (including a control), and a posttest. Subjects completed the survey online through the Qualtrics survey program. Pretest questions included questions on political interest, ideology, knowledge about the issue presented in the treatment, position on the issue, and general demographics. Information seeking behavior could be contingent on how ideology interacts with the perception of the humorous stimulus. There were questions about average hours per week spent doing the following: Internet use, news attention, political humor attention, and thinking/talking about politics.

\section{Table 4.1}

\section{Word Count and Time Differences between Video Stimuli}

\begin{tabular}{|l|l|l|}
\hline & Word Count & Time \\
\hline Colbert Report Video & 627 & $4: 23$ \\
\hline Connected News Clips & 731 & $3: 43$ \\
\hline Difference between & -104 & $0: 40$ \\
\hline
\end{tabular}

There are also unquantifiable differences between these stimuli. Due to the nature of the programming, the news clip video had more statistical and logistical details about the fiscal cliff. While the news video was nonstop in dispensing political information, The Colbert Report video contained pauses where the audience would laugh at jokes and Colbert took some time away from the issue to crack jokes about Canada, Mitt Romney, and the lack of minorities in 
Congress. Editing the details out of the news montage would have made it less melodious, possibly causing cognitive dissidence that would add another layer to the stimulus equivalence problem. The Colbert Report video also contained sarcasm and parody. Full transcripts of the two videos can be found in Appendix B and Appendix C.

Other differences are in the visuals. The Colbert Report has mostly Stephen Colbert sitting in front of the camera with some graphics over his shoulder. There are a few montage clips that he asks his studio assistant, "Jimmy," to play, but it is mostly just Stephen and the camera. This is contrasted with the news clips where there are a variety of anchors and reports that are sitting and standing. The fundamental differences between the goals of these types of programs are at the heart of these time and word count differences. The Colbert Report is focused on having a comedy show and the news is focused on dispensing information.

After the pretest questions, respondents were given one of three experimental treatments. One group was randomly selected to watch a Colbert Report clip. Another were randomly selected to receive a news program clip. The two clips were focused on the same topic and contained as much of the same information as possible. Manipulation check questions were asked to make sure that respondents receive the same message and information from the clips and the difference between the two is the humor aspect. The last group, the control group, did not receive a priming frame.

As part of the manipulation check, respondents were asked (if they were assigned to an experimental condition) if they enjoyed watching the clip and asked if they learned something from the clip. These are the same manipulation checks used in other research (Baumgartner and Morris, 2008, pg 629-630). The question about enjoyment is broken down into three elements of 
enjoyment: if the material was entertaining, if the material was interesting, and if the material was humorous. It is hypothesized that those that receive the humor experimental condition score higher on all of these questions.

The question on learning is important because it makes sure whether the respondents feel like they learned more from the humor or the news conditions. The alternate hypothesis to the main hypothesis of this dissertation (that humor increases interest, and information seeking, in political topics) is that news could saturate the viewer's brain with information and they fail to see the necessity for seeking out more information. This question makes sure that those who get the news condition are not feeling significantly more informed by the stimulus than those who get the humor stimulus.

\section{Table 4.2}

\section{Experiment \#1- Treatment Groups}

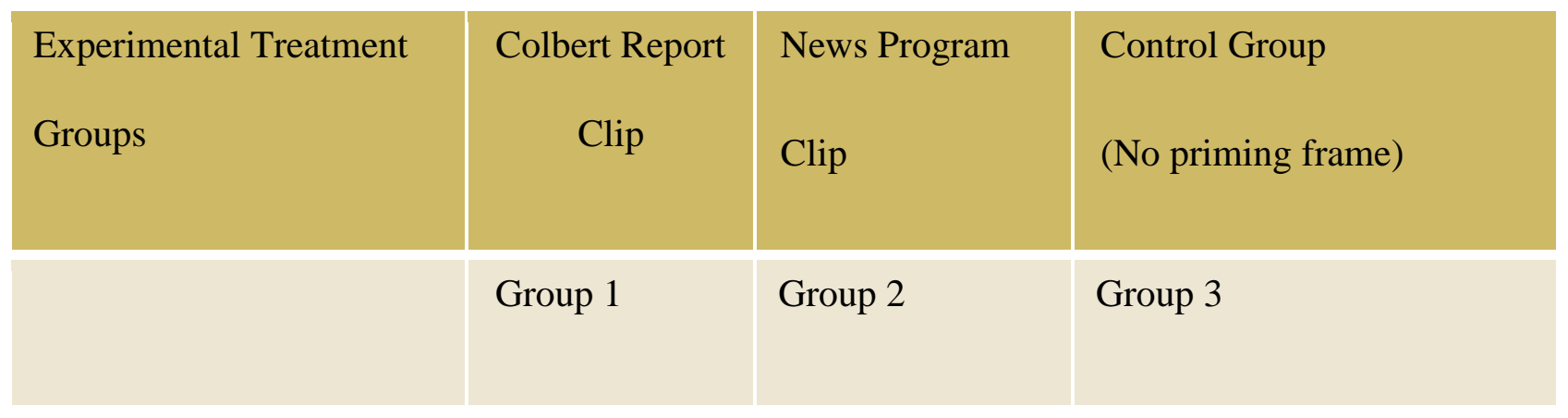

After the treatment, the respondents were asked questions about the information the clips provided them. There were also questions about the entertainment value of the clip and whether or not it was funny. These questions help serve as manipulation checks. I want to make sure that the treatment is similar in informational content and that the entertainment value/humorous content is the only difference. 
Then respondents were asked to pick stories out of a static information board.

Respondents could choose to look at information pertaining to the issue that was dealt with in the clip or they could look at completely different materials. Their choices, to get more information on the topic or not, and how long they spend on the information were recorded for analysis.

For each topic, in addition to being asked if they would like to investigate more information on the topic, the respondents were asked about their reactions to the material. Because it was an online study, respondents were asked if they were able to view the material (as to control for technical glitches). Subsequently, respondents that were not able to view all of the video, or see the single image, were dropped from the dataset.

Although it could be assumed that political humor is entertaining, funny and interesting, due to different tastes and humors, manipulation check questions were made to see if the humor videos were more entertaining, funny, and interesting than the news video. Respondents were asked if the material entertained them, if they thought it was funny, and if they understood the material. There was a question about how the material made them feel because studies have found that anxiety enhances one's propensity to seek information (Brader, 2005; Marcus and Mackuen 1993; Valentino, Hutchings, Banks, and Davis, 2008). Marcus and Mackuen (1993) also suggest that it is anxiety, rather than enthusiasm, that motivates people to learn political information (specifically about political candidates).

\section{Video Experiment Stimulus}

When the video stimuli were edited, they were done so with attempts to make them as equivalent as possible. Both videos were made to convey the same narrative that there was a looming fiscal cliff and that it is a scary, nuclear option that neither side purports to want. 
President Obama is reported in both videos to want to raise taxes on the wealthiest Americans as a means to pay for, or at least minimize, debt. It is clear in both videos that some Congressional Republicans were willing to go against the no tax pledge that they signed in order to avoid the very unpopular sequestration. Grover Norquist, advocate of a prominent anti-tax pledge, appears in both videos to tell those Republicans that the pledge that they signed was to be upheld for the entirety of their congressional careers. Both videos left the issue unresolved.

Another similarity of the two experimental conditions is that both include some of the same footage. Both videos include a montage of Congress members Lindsay Graham, Bob Corker, and Peter King saying that they were willing to overlook the pledge for the good of the country. Grover Norquist's response to these potential pledge breakers was also in both videos. Those were the similarities, but there were clear differences between the stimuli as well.

The differences are summarized in Table 4.1. After editing was done The Colbert Report video was four minutes and twenty three seconds and 627 words long, the compiled news video from Newsy, ABC News, and CNN clips was three minutes and forty three seconds and 731 words. A different of forty seconds one way and one hundred and four words the other way is a function of delivery styles of the different media. Political humor (like Stephen Colbert) leaves time for the audience to laugh making the video longer, but lacks in word count; while it is the job of news organizations (like Newsy, ABC News, and CNN) to provide content.

After the stimulus, or (in the case of the control group) without stimulus, respondents were asked to choose articles from a static information board. To capture information seeking, a static information board (Appendix F) from which respondents, after receiving the experimental treatment or condition, could choose articles to read. Respondents were able to chose between 
twenty four articles that were organized under four headings (US News, International News, Sports, Entertainment and Life). The intention was to create a static interface that resembled a news rich summary site like Google News. Many people use these types of websites to gather information and therefore a logical model to base the static information board. It was important to create an information board that was as close to natural looking and feeling as possible. The US News heading included a story about the fiscal cliff called "After "fiscal cliff" dive, more battles, new cliffs" and a story about sequestration called "Sequestration not favored method to cut budget deficit and how it might be a disservice to those who serve." Another story of interest was a story about how Stephen Colbert's sister was running for the House seat in South Carolina. The sports section included a story about soccer and how "2014 Brazil World Cup to offer seats for obese fans." Finally, the Entertainment and Life heading included important pop culture fare (“Justin Bieber Disses Lindsay Lohan”).

Respondents were told to choose as many stories to read about as they want and that the stories they choose were displayed when they proceeded to the next page. There is a general lack of knowledge of why people seek out information (Lau 1995). Researchers argue that the static information board, being a menu of information that would exist only in an "ideal world," does not accurately represent how information is available to voters during the electoral campaign and how people can get information when choosing political candidates (Lau 1995; Lau and Redlawsk 2001). This research addresses two of Lau's (1995) three categories of information searching variables: 1) content of search and 2) depth of $\operatorname{search}^{13}$. Although the work done by Lau and Redlawsk (2001) employed a dynamic processing tracing methodology

\footnotetext{
${ }^{13}$ Lau's (1995) third category, the sequence of search, was unavailable as a variable in the Qualtrics survey instrument.
} 
where subjects are asked to chose from a selected list of articles and is then presented with a new list of articles about different topics, a simple static information board was chosen for this study.

The static information board that was used in the experiments in this dissertation was modeled off of the technique used by Xenos and Becker (2009). The reason for the static information board as the means to test information seeking is that many studies suggest that people, after they have been activated to seek political information, seek out information in news sources rather than television or video sources (Caffee and Kanihan 1997). In their conclusion, Neuman, Crigler, and Just (1992, p.114) found that television is a tool that is good for bringing attention to issues with perceived low salience whereas "newspapers and magazines are better sources for new information when the audience is already motivated to pay attention."

\section{Video Experiment Measures}

Multiple measures were used as manipulation checks to make sure the stimuli had an effect. There were two dependent variables that measured information seeking. There was also a measure of interest in politics that was used for the spillover effect hypotheses.

\section{Enjoyment}

To serve as manipulation checks, respondents were asked to rate how much they enjoyed the stimulus. Level of enjoyment was measured in three dimensions: enjoyable, humorous, and interesting. All of these questions were measured with a 5-point Likert scale ${ }^{14}$. These are interrelated concepts that are highly correlated in the research, but it was important, as a

\footnotetext{
${ }^{14}$ Enjoyablity answers: $1=$ Not Enjoyable at all, 2= Somewhat Enjoyable, 3= Neutral, 4=Enjoyable, 5=Very Enjoyable, $6=$ Don't know. Humorous Answers: $1=$ Not Humorous at all, $2=$ Somewhat Humorous, $3=$ Neutral, 4=Humorous, 5=Very Humorous, 6=Don't know. Interesting Answers: 1= Not Interesting at all, 2= Somewhat Interesting, 3= Neutral, 4=Interesting, 5=Very Interesting, 6=Don't know.
} 
manipulation check, to test that all of these dimensions are different. The humorous dimension is the most important dimension for this research because of the focus on the effect of humor on information seeking, but the other dimensions are tested to make sure the experiment was not confounded by the different dimensions.

\section{Information Seeking}

This dissertation's first hypothesis is that exposure to a domestically relevant issue through a humorous medium is associated with increased attentiveness to that issue in another media. The dependent variable for this dissertation comes from two of the categories of variables suggested by Lau (1995): content of search, and depth of search ${ }^{15}$. The first dependent variable, content of search, which is used to operationalize attentiveness, is a dichotomous variable; whether or not respondents chose to read an article about the fiscal cliff. A logit model is used to analyze the impact of the humor frame on choosing the relevant articles. The second dependent variable, depth of search, is operationalized by the amount of time that respondents spent on those articles. Tobit analysis is done to test the impact of the humor frame on the duration of time spent on the article. Tobit analysis, which can be used to assess both whether an individual chooses to seek information, and then how long spend acquiring that information, has not been used to look at attentiveness to an issue before.

Tobit analysis is typically used when it is assumed that the values of the dependent variable clusters at a limiting value, usually zero (McDonald and Moffit 1980; Tobin 1958). This statistical tool has been used to look at the demand for consumer goods (Tobin 1958;

\footnotetext{
${ }^{15} \mathrm{Lau}$ (1995) suggests that there are three categories of variables to be considered when people are seeking information: 1) content of search, 2) depth of search, and 3) the sequence of search. While the content of what is chosen and the depth of the search could be measured, the Qualtrics survey system does not measure the order in which articles were chosen, therefore this measure was unavailable.
} 
Dagenais 1975, Cornik, Cox, and Gould 1993), tutoring expenditures (Tansei and Bircan 2006), numbers of hours worked per week (Rosen 1976) and year (Keeley et al. 1978), and number of moonlighting hours worked per week (Shishko-Rostker 1976) ${ }^{16}$. The Tobit model is used in this dissertation because in Tobit analysis all observations are used, both at the limit and above it, to estimate the line (McDonald and Moffit 1988).

\section{Political Interest}

Respondents were asked to rate how interested they are at following matters of politics and government (Most of the time, Some of the time, Occasionally, Never). This is an important variable because it is the dependent variable in testing the spillover hypotheses. If those who were in the humorous experimental group report being statistically more interested in following matters of politics and government than the control group and the news group, than that would be evidence that political humor effects political interest in general.

\section{Study 2: Image Experiment}

The second experiment focuses on how single framed image, ala the LOLCats "I Can Has Cheezburger" meme, could lead to information seeking behavior. These single image memes have become the new editorial cartoon. Editorial cartoons tend to be one-panel representations of something that happened in the news. Political cartoonist, Bill Mauldin, argued that it is the general goal of editorial cartoons to draw attention to a subject rather than to just be funny (Brinkman 1968). Brickman (1968) found that cartoons that were coupled with editorials resulted in greater opinion change than either one (editorial or editorial cartoon) alone.

\footnotetext{
${ }^{16}$ It is thought that the data in this dissertation will be closer in appearance to the moonlighting work down by Rishko-Rostker (1976) and the value of an auto purchase analysis done by Dagenais (1975) because both of those cases had fewer than twenty-five percent of the sample above the limit.
} 
Editorial cartoons on the Internet are less frequently coupled with editorials, so I wish to see if editorial cartoons draw attention to a subject (as Bill Mauldin suggests). If Mauldin was correct, then humorously captioned single images should have an effect in raising interest in a subject when compared to an image that does not share the editorial spirit.

The same basic design was followed from the first experiment, but the priming frame was in these single framed images instead of videos. There were three experimental treatment groups for the second design. Respondents were randomly selected to receive one of the experimental conditions.

\section{Table 4.3}

\section{Experiment \#2- Treatment Groups}

\begin{tabular}{|c|c|c|c|}
\hline $\begin{array}{l}\text { Experimental Treatment } \\
\text { Groups }\end{array}$ & $\begin{array}{c}\text { Humor Framed } \\
\text { Photo }\end{array}$ & $\begin{array}{l}\text { Neutral Framed } \\
\text { Photo }\end{array}$ & $\begin{array}{l}\text { Control Group (No } \\
\text { priming frame) }\end{array}$ \\
\hline & Group 4 & Group 5 & Group 3 \\
\hline
\end{tabular}

\section{Image Experiment Participants}

The image experiment had 234 participants respond, but 6 respondents were dropped from the analysis ${ }^{17}$ leaving 228 participants that were analyzed. There were 74 participants in the control group, 74 participants in the humorously framed (Colbert Report) image group, and 82 in the neutral group. There were 150 females (67\%) and 74 males (33\%). The average age was

\footnotetext{
${ }^{17}$ Responses were omitted from analysis because they failed to finish the survey.
} 
22.66 which is about in the middle of the 18-25 year old demographic that The Colbert Report tends to do well in.

\section{Image Experiment Procedures}

The procedures for the single image experiment were exactly the same as the video experiment because the experiments were conducted as if they were the same experiment. The stimulus equivalence problem makes it so they could not be analyzed together, but running them as the same experiment streamlined the collection process. The only difference between the experiments was the stimuli.

\section{Image Experiment Stimulus}

The single image study used one image for the two conditions. The image contained a picture of the congressional houses on the left side, a picture of the White House on the right, and the words "The Fiscal Cliff" in between the two images. The humorous experimental condition (seen in Figure 4.1) included the following quote from Stephen Colbert that was a part of his November $27^{\text {th }}, 2012$ episode (the same episode that was featured in the video experiment). 


\section{Figure 4.1 Humorous Experimental Condition in Captioned Image Experiment}

"It all started back in 2011 during the showdown over raising our debt ceiling...

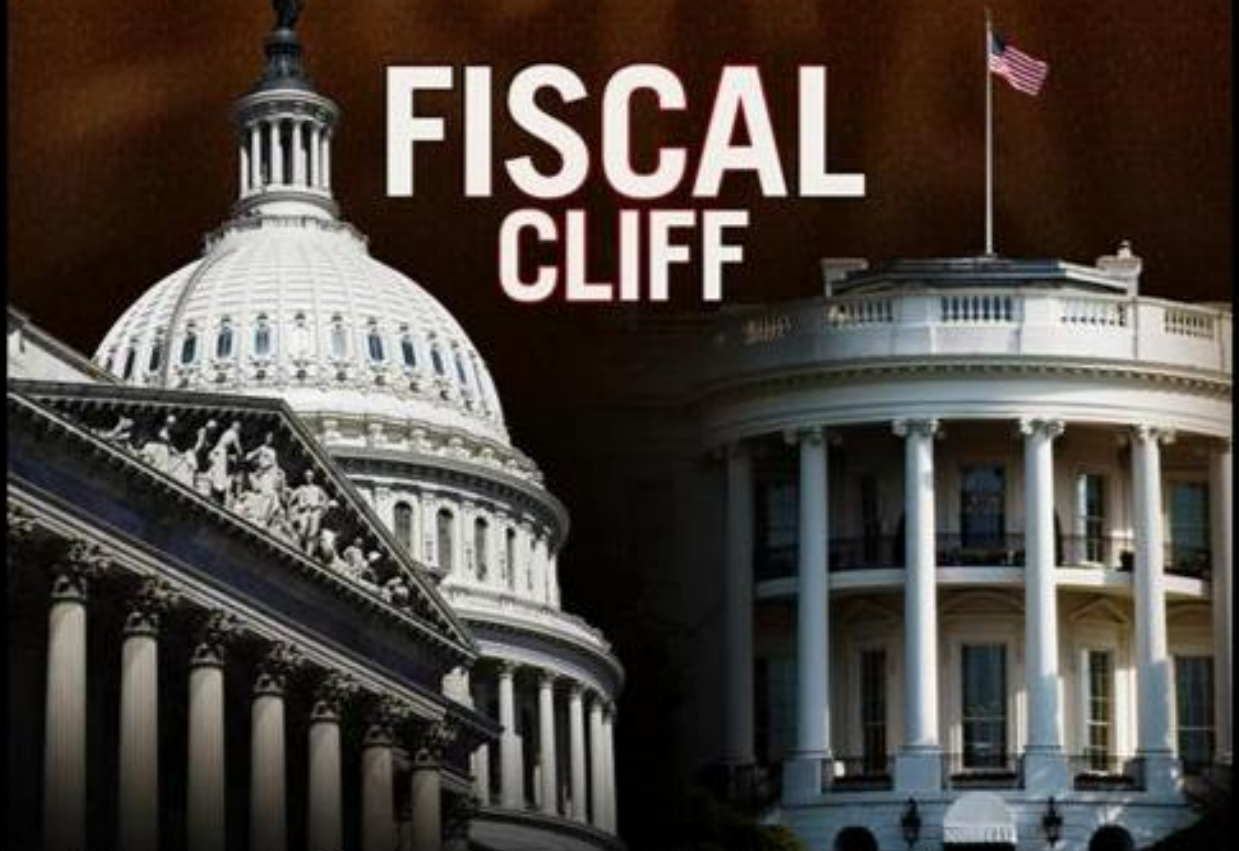

Republicans wanted spending cuts... Obama wanted to raise taxes.

Which led to a budget crisis that Congress solved by not solving it. Instead, they handed it over to something called the 'super congress,' which couldn't fail because it was super. Unfortunately, it was also Congress... so it failed." Stephen Colbert

The non-humorous condition (seen in Figure 4.2) received an augmented version of the Colbert quote. This version of the quote took the humor out of the quote, but left the overall message and amount of information. I choose this medium in an attempt to maximize stimulus equivalence and to show that these types of memes, as long as they include humor, can also be effective catalysts to information seeking behavior. 


\section{Figure 4.2 Neutral Experimental Condition in Captioned Image Experiment}

\section{It all started back in 2011 during the showdown over raising our debt ceiling...}

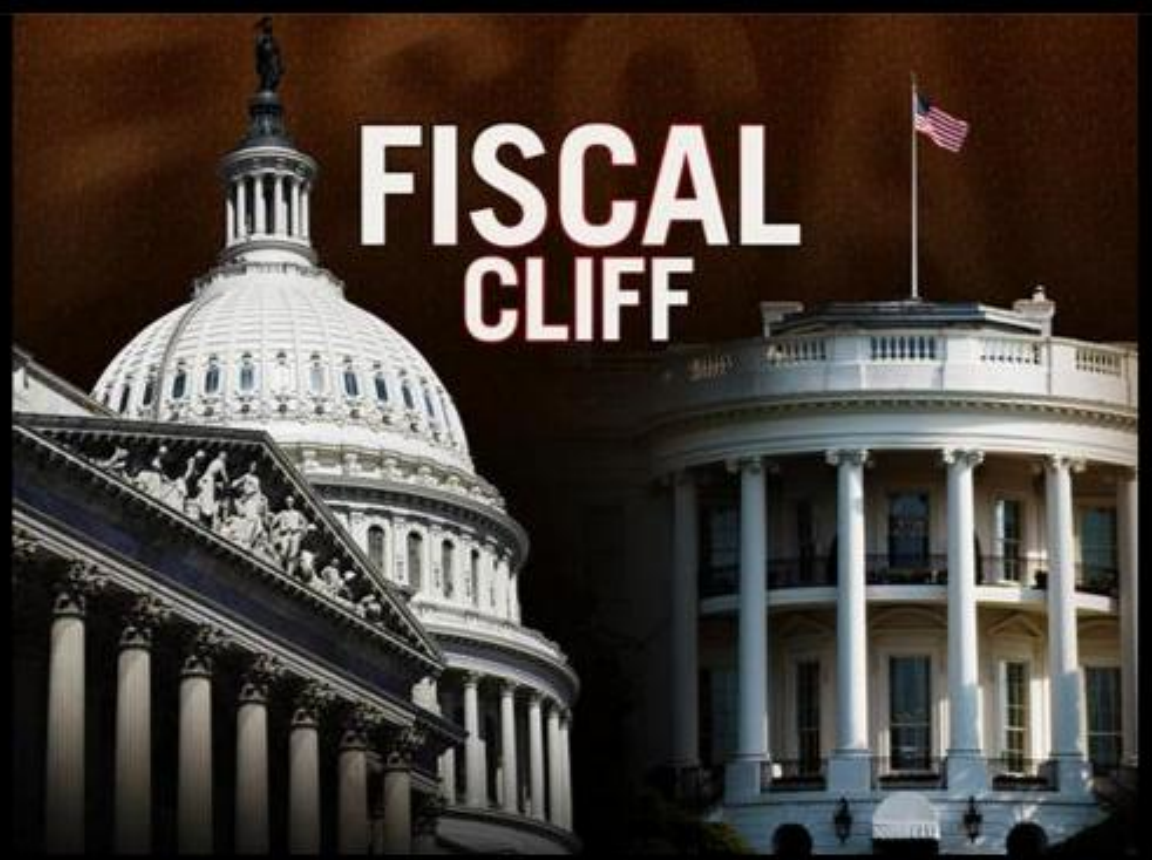

Republicans wanted spending cuts... Obama wanted to raise taxes.

Which led to a budget crisis that congress has yet to solve.

\section{Image Experiment Measures}

The measures for the image experiment were the same as the video experiment. The only difference between the experiments in measures was that the question about sequestration was not analyzed for the single image experiment. The question was still asked, but not theoretically important. 


\section{Design}

There was an advertisement for this survey (Appendix A). Focus of the advertisement for the survey was done at a Midwestern university, but the advertisement was proliferated beyond the University. Advertisements were done on the University wide advertisement board that is seen when students and faculty check their email. The advertisement was also emailed through department chairs. The advertisement even went out through the WVU Political Science and Communication departments' Facebook pages. While the nature of the advertisement was geared toward undergraduate participation, there were participants that did not fit into this demographic (including a couple of professors). The average age of the participants was just under 22 years old. Most of the people that participated were from West Virginia University. This is good because it is the average age group that watches shows like The Colbert Report. There is about an equal amount of Republicans and Democrats. 


\section{Chapter 5}

\section{Video Experiment Results}

In this chapter, the study's empirical data from the video experiment is analyzed to see whether or not the humor video in the experiment resulted in more interest and, subsequently, more information seeking from respondents. The structure of this chapter begins with a discussion of some descriptive statistics and move towards statistical models of the effects of political humor. This chapter includes sections that describe the respondents, political information seeking behaviors, late night comedy viewership, manipulation check questions, descriptive comparisons of the different experimental groups, and model analyses of the impact of humor on attention to relevant information.

This chapter displays a straightforward analysis. First, the manipulation check questions are analyzed to make sure that the stimuli produced the desired response. After it is verified that the video stimuli were significantly different in entertainment, humor, and enjoyability, the analysis focuses the dependent variable of information seeking. There is also analysis performed to test the spillover effect that humor has when it comes to interest in politics.

This dissertation's dependent variable, information seeking behavior, is, by survey design, measured in multiple ways. The first way this dissertation measures information seeking behavior is whether or not respondents sought out information. This is a dichotomous variable that is analyzed with two-group mean comparison tests and logistic regression. This dichotomous way of measuring information seeking is enriched by the two stories that they could have chosen that would have counted as information seeking. Respondents could choose from one story about the fiscal cliff and one story about sequestration. Both are major components to 
the video stimuli.

The second way information seeking was measured was the amount of time spent on the article. The variances are too high to do a t test on this data, but Tobit analysis is done on this dependent variable. There are three model groups for the Tobit analysis as well. The first group is on the time spent on the fiscal cliff article. The second group is on the sequestration article. And the third analysis combines the time spent on both of those articles.

\section{Manipulation Check}

To serve as manipulation checks, respondents were asked to rate how enjoyable, humorous, and interesting they thought the content was. After the assigned stimulus video, respondents were asked how enjoyable, humorous, and interesting they found the video. All of these questions were measured with a 5-point Likert scale ${ }^{18}$. This measure was created to establish that The Colbert Report video had more entertainment value than the news video because it is entertainment, a factor that could make the audience more interested and more likely to seek out more information about the topic.

Illustrated in Figure 5.1, the variable of concern for this dissertation, the humor effect, had the biggest difference in average value between the two groups. It is also interesting to note that the perception of the video being interesting is significant with those who got The Colbert Report video thinking it was more interesting than those who got the news video. Now that it is clear that The Colbert Report video was more enjoyable, humorous, and interesting than the

\footnotetext{
${ }^{18}$ Enjoyablity answers: $1=$ Not Enjoyable at all, 2= Somewhat Enjoyable, $3=$ Neutral, 4=Enjoyable, 5=Very Enjoyable, $6=$ Don't know. Humorous Answers: $1=$ Not Humorous at all, $2=$ Somewhat Humorous, $3=$ Neutral, 4=Humorous, 5=Very Humorous, $6=$ Don't know. Interesting Answers: $1=$ Not Interesting at all, $2=$ Somewhat Interesting, 3= Neutral, 4=Interesting, 5=Very Interesting, 6=Don't know.
} 
news video, the focus must now turn to any other effects that exist that could change the interpretation of the data.

Figure 5.1 Video Manipulation Check Questions

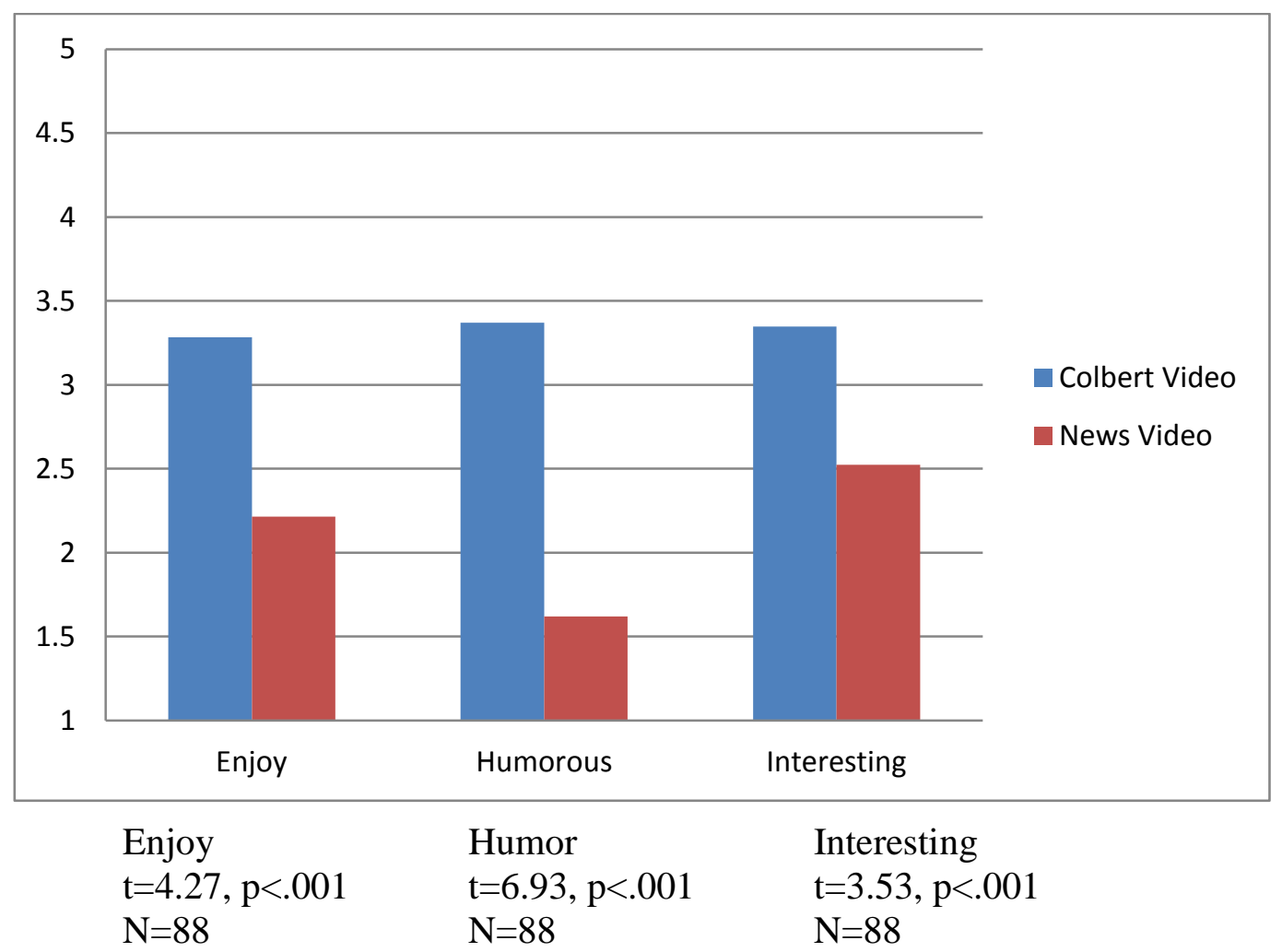

\section{Feelings of Learning, Confidence in what I know}

Scholars, for good reason, are not trustful of self-reported learning (Chaffee and Kanihan 1997). This measure is not meant to measure learning, as such, but to measure whether or not the participant felt like they learned. Specifically, it is testing the feeling of being informed from the stimuli. If the participants felt like they learned more from one condition or another, that feeling of being informed could impact their information seeking behavior. This is a useful question because it tests the assumption of stimulus equivalence. 
Previous research (Baumgartner and Morris 2006) suggests that regular viewership of political humor increases confidence in comprehending political materials. It could be hypothesized that a feeling of learning taking place while watching political humor could aid in this correlation between watching political humor and confidence in understanding the political world. If this were the case, it would confound the analysis of this dissertation and contradict the idea that political humor increases information seeking.

One of first questions that respondents were asked when the video stimulus was over was "Did you learn something from the material?"Their answer was a either Yes (which equals zero) or No (which equals one). When comparing the feeling of learning between the humor condition and the news condition, as seen in Figure 5.2, there was not a significant difference. This helps to address the assumption that political humor does not cause cognitive dissonance by introducing a sense that learning has taken place. 
Figure 5.2 Feeling of learning between

the two experimental conditions

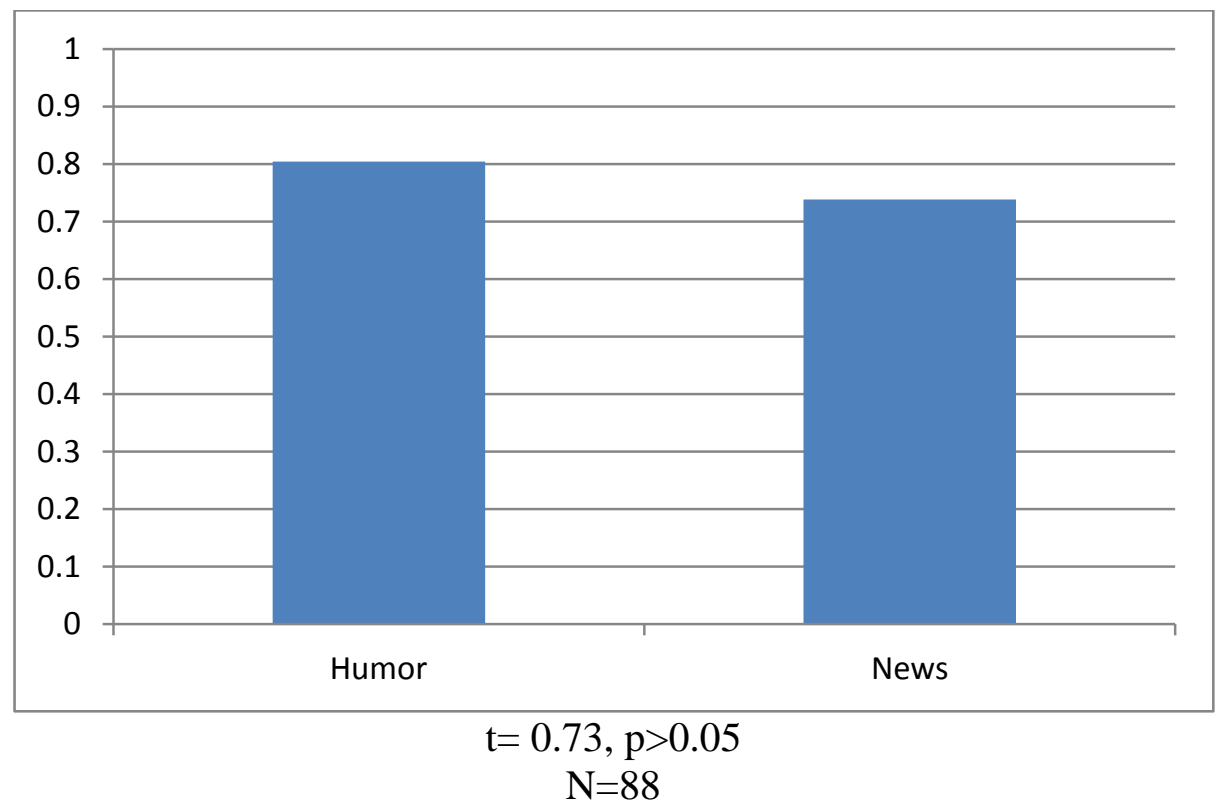

Although the respondents might not have purported to have learned more from the video, there needs to be a check on their overall confidence of understanding the political world because of findings in previous research (Baumgartner and Morris 2006). If there are differences in knowing or understanding the political world or political issues, this could help theorize possible causal mechanisms for the models at the end of the chapter.

Table 5.1 and Table 5.2 provide additional factors that could measure the respondent's confidence in their capability to understand the political realm. Table 5.1shows the average answer to the statement "I think that I am better informed about politics and government than most people" by experimental condition group. Respondents were given the following choices: 1=Strongly Disagree, 2=Disagree, $3=$ Neither Agree nor disagree, 4= agree,5=Strongly Agree . The two-group difference of means t-tests with equal variance showed that there was no statistical difference between any combinations of the groups. 


\section{Table 5.1 Analysis of Variance (ANOVA) - I think that I am better informed about politics and government than most people}

\begin{tabular}{|l|l|l|l|l|l|}
\hline $\begin{array}{l}\text { DV- I think that I better information } \\
\text { (Three Experimental Groups) }\end{array}$ & $\mathrm{N}$ & Mean & SD & F & Prob > F \\
\hline Colbert Video & 46 & 3.109 & 1.215 & 0.62 & 0.5411 \\
\hline Control & 74 & 3.145 & 1.208 & & \\
\hline News Video & 42 & 2.881 & 1.435 & & \\
\hline
\end{tabular}

Being knowledgeable about the fiscal cliff is the topic of Table 5.2. Respondents were asked their level of agreement for the following statement: "I am very knowledgeable about the "fiscal cliff" as an issue in American politics (1=strongly disagree to 5=strongly agree). The "fiscal cliff" was the main topic of both experimental video conditions and it is expected to have the largest effect on the respondents. There is statistical significance when comparing the average response of knowledge about the "fiscal cliff" between the control group and those who watched the Colbert Report clip. This is evidence that supports Baumgartner and Morris's (2006) research that found that political humor can increase confidence in knowledge about politics, but a lack of statistically significant difference between the two experimental condition groups is noteworthy because that confidence in knowing the "fiscal cliff" partially came from just watching a video on the topic. 
Table 5.2 Analysis of Variance (ANOVA)- I am very knowledgeable about the "fiscal cliff" as an issue in American politics

\begin{tabular}{|l|l|l|l|l|l|}
\hline $\begin{array}{l}\text { DV- I am very knowledgeable about fiscal cliff } \\
\text { (Three Experimental Groups) }\end{array}$ & N & Mean & SD & F & Prob > F \\
\hline Colbert Video & 46 & 3.065 & 1.29 & 3.36 & 0.04 \\
\hline Control & 74 & 2.49 & 1.26 & & \\
\hline News Video & 42 & 2.90 & 1.23 & & \\
\hline
\end{tabular}

\section{Does exposure to humor increase information seeking?}

The first hypothesis of this dissertation is that exposure to the first display of the difference between the experimental condition groups is shown in Table 5.3. This table shows that the humorous frame seemed to have a direct correlation to information seeking when it came to searching for the information pertaining to the fiscal cliff.

Time spent on the article could very well be more of a function of desire for more information because of ignorance and not a function of increased interest. If this is the case, the differences in time spent on the fiscal cliff article and the sequestration article could be a function of the way the stimuli focused on the fiscal cliff, but only marginally mentioned sequestration. In thinking about time spent on the news article, it would make sense that an increased feeling of knowledge of the fiscal cliff would produce less attention to that article relative to the issue of sequestration. 


\section{Table 5.3 Average time spent browsing related story content by video stimulus condition}

\begin{tabular}{lll}
\hline Condition & Fiscal Cliff Content & Sequestration Content \\
\hline Control & $70.07(103.44)$ & $149.56(134.44)$ \\
News Clip & $5.75(1.23)$ & $140.59(148.92)$ \\
Colbert Clip & $127.60(185.29)$ & $118.26(85.79)$ \\
\hline
\end{tabular}

Note $\mathrm{N}=163$. Cell entries are average number of seconds spent accessing related news content. Standard deviations appear in parentheses.

\section{Does Entertainment Lead to Information Seeking?}

This section is focused at analyzing the data pertaining to this dissertation's second hypothesis. Namely, that enjoyment of the way that a policy issue is framed positively correlates with attentiveness to that issue. Another main hypothesis of this dissertation is that finding a policy frame to be humorous results in the viewer becoming more interested in that policy. Figure 5.3 shows that, generally, there is a positive correlation between how entertaining the video is, and how likely they were to seek information, with being perceived as more entertaining being associated with seeking more information.

The reason that there is a drop in the information seeking at the third option interval is because of the wording on the five point scale. The third option on the Likert scale, being "neutral", might have been confusing or problematic for respondents. For example the enjoyable question gave the following answer choices: 1) Not Enjoyable at all 2) Somewhat Enjoyable 3) Neutral 4)Enjoyable 5)Very Enjoyable 6)Don't know. 
Figure 5.3 Entertainment Value and Information Seeking of either one of the relevant articles

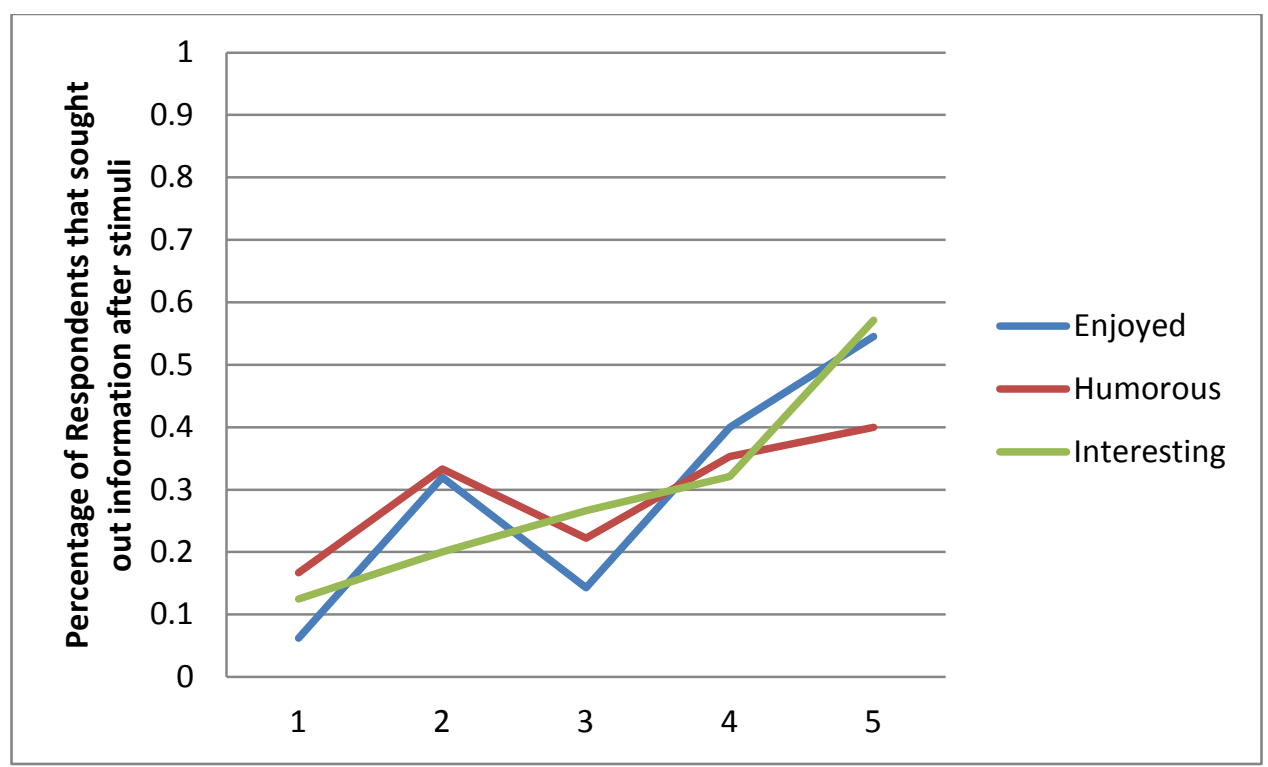

Issue attention is more than whether or not you decide to seek out information; another aspect of issues attention is how much time you spend on the topic. To that end, Figure 5.4 and Figure 5.5 show the time spent on the relevant article by how entertaining the respondents thought the stimuli were. Figure 5.4 shows the entertainment level by the amount of time spent on the fiscal Cliff article.

While there is not a clear direct relationship between level of entertainment and time spent on the fiscal Cliff article, there seems to be some differences in the behaviors of those who answered in the extremes. Those who reported that they found the stimuli very humorous, very interesting, or very enjoyable and chose to click on the fiscal cliff article were likely to stay there for an extended period of time. 


\section{Figure 5.4 Entertainment enjoyment and amount of time spent on fiscal cliff article}

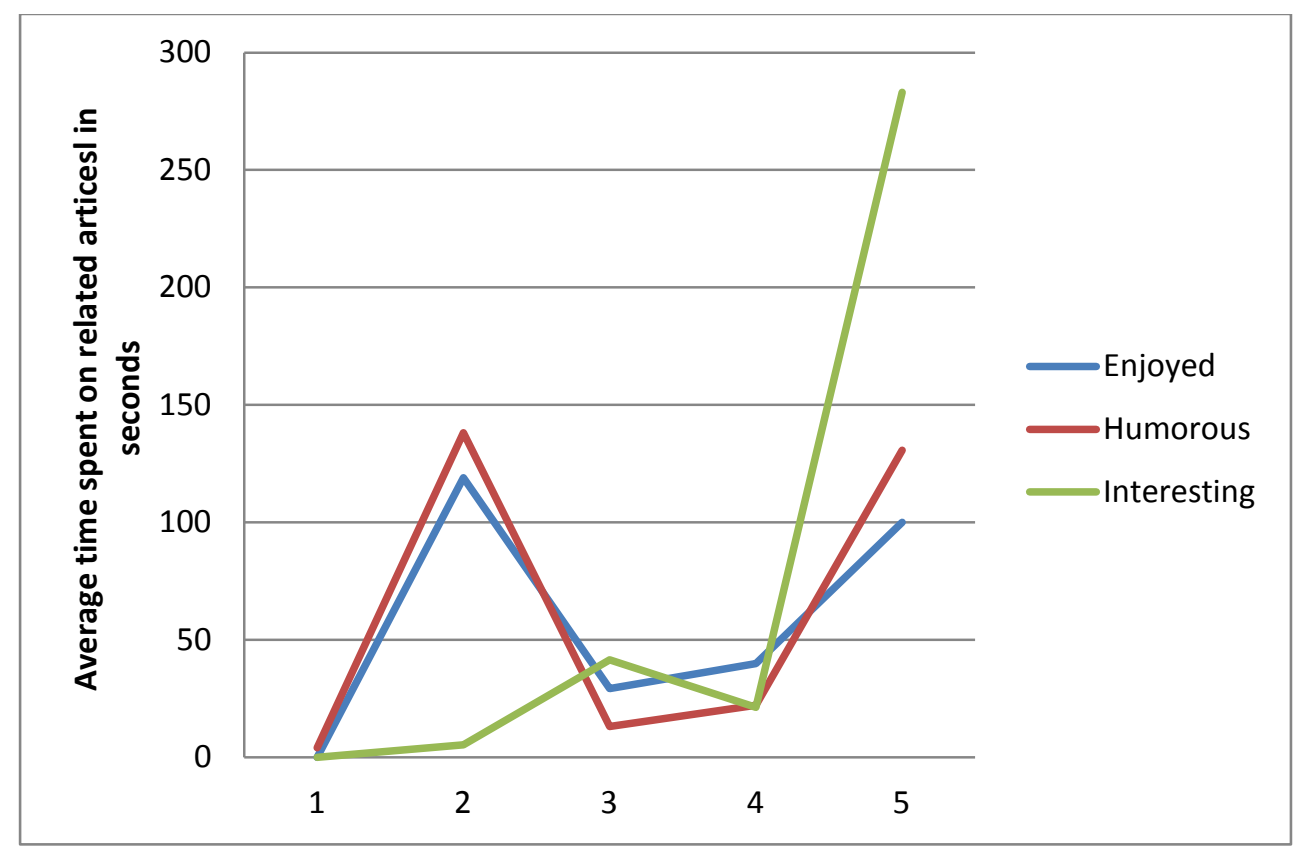

Although there is an apparent entertainment effect when it came to paying attention to the fiscal cliff article, there does not seem to be a humor effect when it comes to the average time viewing both the fiscal cliff article and the sequestration article (as shown in Figure 5.5). When both articles were present in the analysis, there appears to be an almost indirect relationship between how humorous a respondent thought the stimulus was and how long they spent on reading about the fiscal cliff and sequestration. 


\section{Figure 5.5 Entertainment enjoyment and amount of time}

spent on information seeking articles

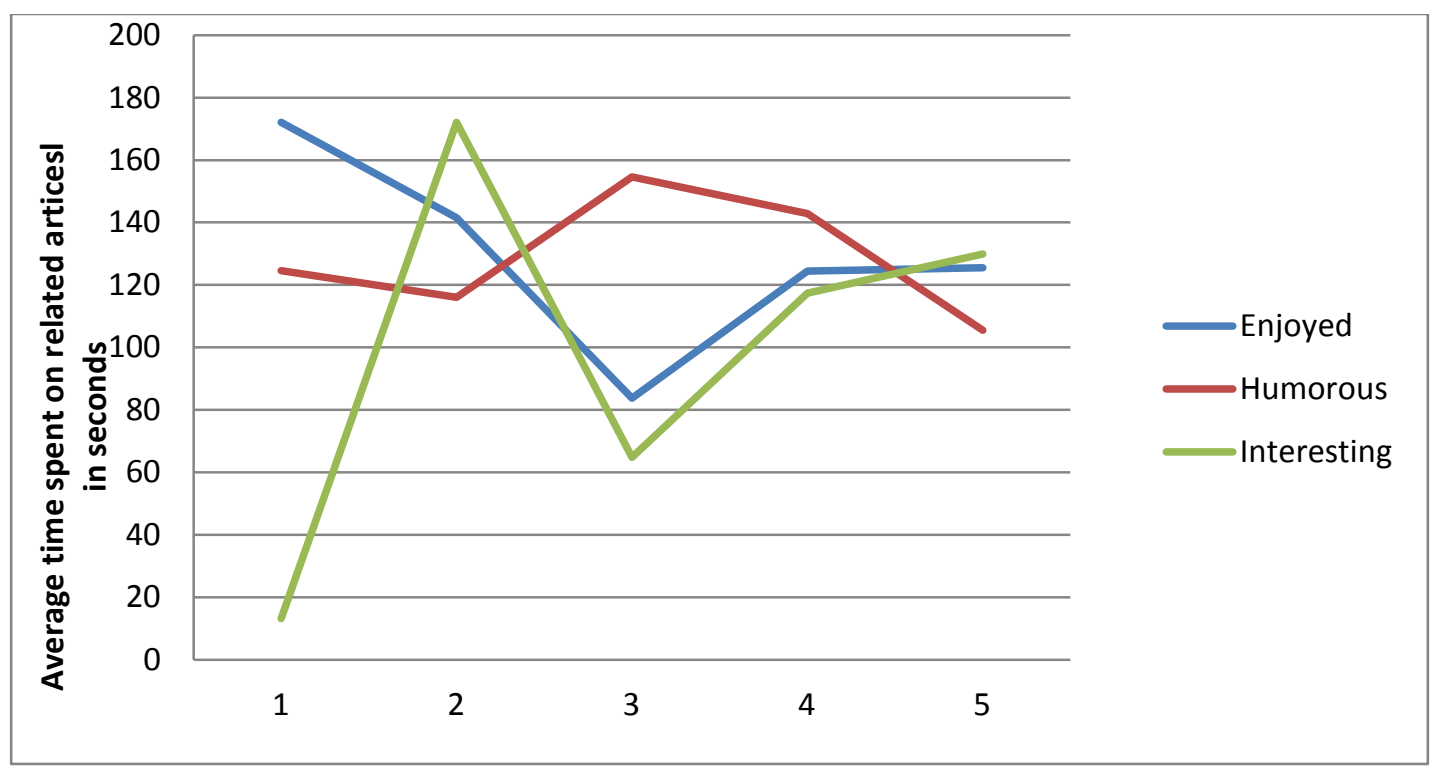

\section{Humor's Interest Spillover Effect}

Does encountering a political humor frame make one more interested in politics in general? Hypotheses 3 and 4 address the possibility that a humorous frame would increase interest beyond the bounds of the specific topic of the frame. Hypothesis 3 argues that exposure to a humorous frame increases likelihood of increased interest in politics in general. A test of this hypothesis is found in Table 5.4. Those who received the Colbert Report video condition did have a higher self reported interest in politics and government, but this difference was not statistically significant. 
Table 5.4 Analysis of Variance (ANOVA)- Interested in Following Matter of Politics and Government

\begin{tabular}{|l|l|l|l|l|l|}
\hline DV- I am very knowledgeable about fiscal cliff & \multirow{2}{*}{$\mathrm{N}$} & \multicolumn{4}{|l|}{} \\
\cline { 3 - 6 } (Three Experimental Groups) & & Mean & SD & F & Prob > F \\
\hline Colbert Video & 45 & 3.022 & 0.78 & 0.25 & 0.77 \\
\hline Control & 74 & 2.92 & 0.77 & & \\
\hline News Video & 42 & 2.95 & 0.76 & & \\
\hline
\end{tabular}

Hypothesis 4 suggests that there is a direct relationship between how entertaining the viewer finds a frame and how willing they are to say that they are interested in politics in general. Figure 5.6 is presented to support $\mathrm{H} 4$, that there is a positive correlation between the entertainment value of a frame and interest in matters of politics and government. There is not a steep increase in interest in government and politics, but there is a general positive correlation.

Figure 5.6 Interested in following matters of politics and government by level of entertainment

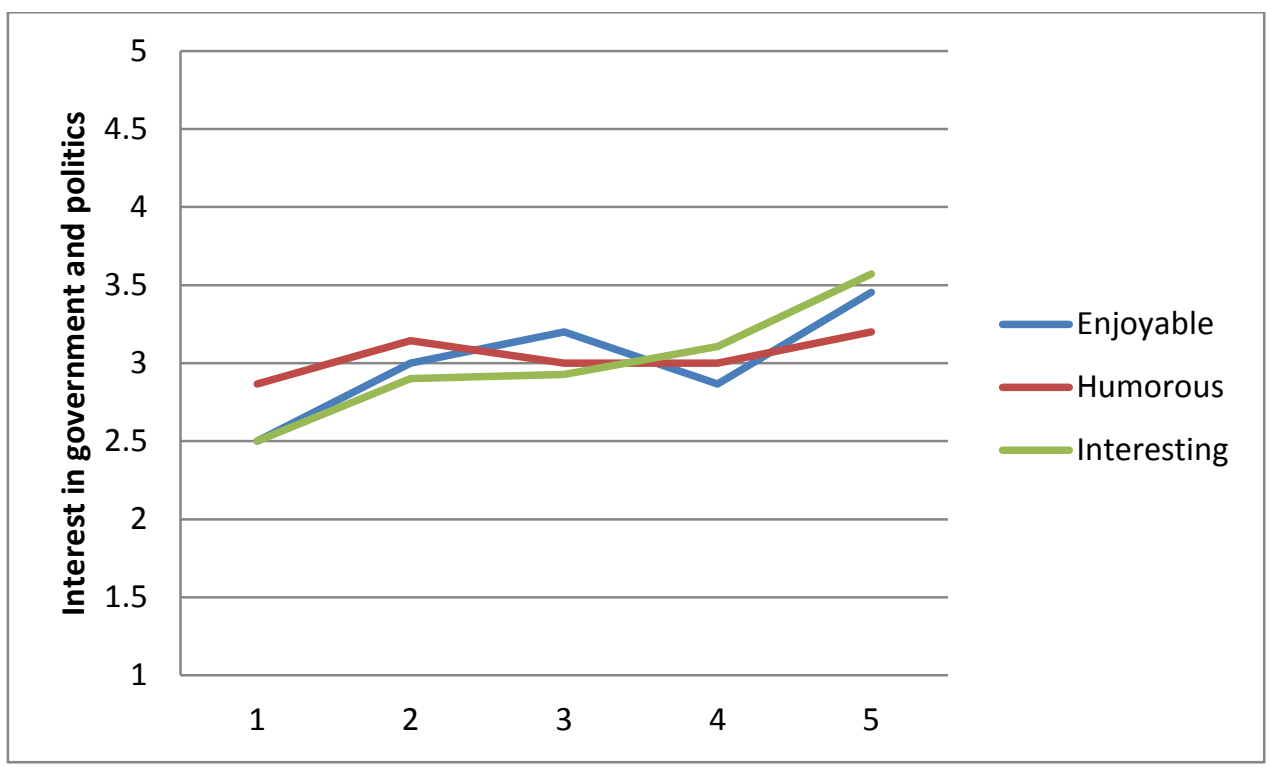




\section{Choosing more information: Logistic Regression Analysis}

This section of the analysis focuses on the choice of the respondents, after the experimental condition has been received, to search for information. In this survey, the choice was measured as a dichotomous variable. Either respondents chose to search for the information or they did not. The design of the survey allowed respondents to chose from multiple different news articles. Respondents were able to select and read as many as they wished. There were two articles of relevance: one on the fiscal cliff and one on sequestration. These articles are relevant because both experimental video conditions talked about these topics.

As a result of having multiple choices that are considered relevant information seeking, there are multiple groups of models that focus on the selection of the specific material. One group focuses on the selection of the sequestration article (as seen in Table 5.5). The other group is the choice to select the fiscal cliff article (seen in Table 5.6). Finally, the choice to have either one of the articles, measured as a dichotomous selection of 1 for searched for information or 0 for no search for information, can be seen in Table 5.7. Although Xenos and Becker (2009) only used the combination of their two information seeking articles, it is important to break down both articles in the analysis to be more encompassing.

In all of the models examined for this experiment, two of the dichotomous variables are two of the experimental condition groups. Both the group that got the Colbert clip and the control group are included in the model, while the news clip condition is represented as the constant. Since the use of dichotomous dummy variables requires the omission of one of the groups, which is captured by the constant, I have elected to have the news clip condition omitted, since it produces coefficient estimates have signs that are more readily interpreted. In addition a 
set of interaction terms are also included since the effect of some variables may be specified for some subgroups but not others.

Political interest is an important variable to have in any model of political information seeking. Therefore, political interest was included in all of the models. In accordance with previous research (Xenos and Becker 2009), political interest was the most important variable in the first and third logistic regression model groups (on Table 5.5 and Table 5.7). There were also two models in the second group (selecting the fiscal cliff article) where political interest was important. The importance of political interest to these models is intuitive, but it is surprising that the coefficients are not bigger than they are.

Exposure to the humorous frame was not significant in searching out information on sequestration (as seen in Table 5.5), but it was significant when it came searching for information on the fiscal cliff (Models 1 and 2 in Table 5.6). Being exposed to the humor frame video was also significant when it came to looking for either article, and when the political interest interaction was used (Model 2 in Table 5.7). There is some support for Hypothesis \#1 that being exposed to a humorous frame increases attentiveness to that issue.

The humor variable (how humorous respondents thought the video was) was only significant when it was interacting with the Colbert Report experimental condition group, and when the dependent variable was choosing the fiscal cliff article. This means that the logistical regression analysis does not support Hypothesis \#2. The null hypothesis cannot be rejected with this evidence. 
The best logit model for goodness of fit is model 2 in Table 5.5. That model, using selecting the sequestration article as the dependent variable, is very close to the model used by Xenos and Becker (2009) because it used the political interest interactions. The problem with that model is that it only found political interest to be significant independent variable. 
Table 5.5 Logit analysis of post video

stimulus sequestration information seeking

\begin{tabular}{|c|c|c|c|c|}
\hline & $\begin{array}{c}\text { Model } 1 \\
\text { (Stimulus Only) }\end{array}$ & $\begin{array}{c}\text { Model } 2 \\
\text { (with interest } \\
\text { interactions) }\end{array}$ & $\begin{array}{c}\text { Model } 3 \\
\text { (with humor } \\
\text { interactions) }\end{array}$ & $\begin{array}{c}\text { Model } 4 \\
\text { (with both } \\
\text { interactions) }\end{array}$ \\
\hline Colbert Clip & $-0.36(.57)$ & $3.68(3.22)$ & $0.10(1.41)$ & $3.15(3.34)$ \\
\hline Control Group & $-0.54(.52)$ & $3.46(2.98)$ & $-0.20(.94)$ & $3.46(2.90)$ \\
\hline Political Interest & $1.05(.33)^{* * *}$ & $1.97(.47)^{* * *}$ & $0.93(.31)^{* *}$ & $1.76(.72)^{* *}$ \\
\hline Colbert x Interest & & $-1.22(.95)$ & & $-0.96(.92)$ \\
\hline Control x Interest & & $-1.22(.88)$ & & $-1.15(.84)$ \\
\hline Humorous & & & $-0.20(.48)$ & $0.12(.53)$ \\
\hline Humorous x Colbert & & & $-0.23(.57)$ & $-0.15(.61)$ \\
\hline Constant & $-4.49(1.12) * * *$ & $-7.54(2.56)^{* *}$ & $-4.50(1.28) * * *$ & $-7.14(2.53) * *$ \\
\hline$x^{2}$ & $12.99 * *$ & $15.39 * *$ & $11.73 *$ & $13.84 *$ \\
\hline \multicolumn{5}{|l|}{$D f$} \\
\hline Pseudo $R^{2}$ & .09 & .10 & .08 & 0.09 \\
\hline $\mathrm{N}$ & 163 & 163 & 163 & 163 \\
\hline
\end{tabular}

$* \mathrm{p}<.05 ; * * \mathrm{p}<.01 ; * * * \mathrm{p}<.001$ (Numbers in parentheses are standard errors.) 
Table 5.6 Logit analysis of post video

stimulus fiscal cliff information seeking

\begin{tabular}{lcccc}
\hline & $\begin{array}{c}\text { Model 1 } \\
\text { (Stimulus Only) }\end{array}$ & $\begin{array}{c}\text { Model 2 } \\
\text { (with interest } \\
\text { interactions) }\end{array}$ & $\begin{array}{c}\text { Model 3 } \\
\text { (with humor } \\
\text { interactions) }\end{array}$ & $\begin{array}{c}\text { Model 4 } \\
\text { (with both } \\
\text { interactions) }\end{array}$ \\
\hline Colbert Clip & $1.45(.83)^{*}$ & $3.65(2.13)^{*}$ & $-1.21(2.37)$ & $0.87(3.00)$ \\
Control Group & $1.33(.79)$ & $1.34(.80)$ & $-0.75(2.08)$ & $-1.09(2.31)$ \\
Political Interest & $.41(.31)$ & $.66(.39)^{*}$ & $0.45(.31)$ & $.72(.39)^{*}$ \\
Colbert x Interest & & $-.70(.63)$ & & $-0.80(.66)$ \\
Humorous & & & $-1.72(1.89)$ & $-2.01(2.15)$ \\
Humorous x Colbert & $-4.25(1.21)^{* *}$ & $-5.04(1.46)^{* * *}$ & $-2.29(2.10)$ & $-2.82(2.36)$ \\
Constant & 6.35 & 7.57 & 8.02 & 9.54 \\
\multicolumn{1}{c}{$x^{2}$} & & & & $.88(1.91)$ \\
Df & .05 & .06 & 163 & .07 \\
Pseudo $\mathrm{R}^{2}$ & 163 & 163 & 163 \\
$\mathrm{~N}$ & & & & .06 \\
\hline
\end{tabular}

$* \mathrm{p}<.05 ; * * \mathrm{p}<.01 ; * * * \mathrm{p}<.001$ (Numbers in parentheses are standard errors.) 
Table 5.7 Logit analysis of post video

stimulus fiscal cliff and sequestration information seeking

\begin{tabular}{|c|c|c|c|c|}
\hline & $\begin{array}{c}\text { Model } 1 \\
\text { (Stimulus Only) }\end{array}$ & $\begin{array}{c}\text { Model } 2 \\
\text { (with interest } \\
\text { interactions) }\end{array}$ & $\begin{array}{c}\text { Model } 3 \\
\text { (with humor } \\
\text { interactions) }\end{array}$ & $\begin{array}{c}\text { Model } 4 \\
\text { (with both } \\
\text { interactions) }\end{array}$ \\
\hline Colbert Clip & $.58(.50)$ & $4.90(2.81)^{*}$ & $.15(1.22)$ & $4.44(3.02)$ \\
\hline Control Group & $.28(.47)$ & $4.65(2.67)$ & $.47(.82)$ & $4.77(2.75)$ \\
\hline Political Interest & $.67(.25)^{* * *}$ & $1.79(.71)^{* *}$ & $.66(.25)^{* *}$ & $1.77(.71)^{* *}$ \\
\hline Colbert x Interest & & $-1.34(.83)$ & & $-1.32(.84)$ \\
\hline $\begin{array}{l}\text { Control x } \\
\text { Interest }\end{array}$ & & $-1.34(.78)$ & & $-1.33(.79)$ \\
\hline Humorous & & & $.12(.41)$ & $.11(.52)$ \\
\hline $\begin{array}{l}\text { Humorous x } \\
\text { Colbert }\end{array}$ & & & $.06(.48)$ & $.07(.58)$ \\
\hline Constant & $\begin{array}{l}-3.33 \\
(.87)^{* * *}\end{array}$ & $\begin{array}{l}-7.01 * \\
(2.45)^{* *}\end{array}$ & $-3.52(1.11)^{* *}$ & $\begin{array}{l}-7.14 \\
(2.54)^{* *}\end{array}$ \\
\hline$x^{2}$ & $9.47 *$ & 13.10 & 10.06 & 13.68 \\
\hline \multicolumn{5}{|l|}{$D f$} \\
\hline Pseudo $\mathrm{R}^{2}$ & .05 & .07 & .05 & .07 \\
\hline $\mathrm{N}$ & 163 & 163 & 163 & 163 \\
\hline
\end{tabular}

$* \mathrm{p}<.05 ; * * \mathrm{p}<.01 ; * * * \mathrm{p}<.001$ (Numbers in parentheses are standard errors.)

Time Spent on Information: Tobit Regression Analysis

Information seeking can be measured in more ways than the choice of an article. It is also the amount of time spent on that article. To model the amount of time spent on the articles, a Tobit regression analysis must be done. This analysis, as discussed in the methodology chapter, aids in the understanding of what variables affect the attention spent on the articles. In other words, Tobit analysis helps researchers model a more nuanced operationalization of attention to an issue. These Tobit models were grouped and modeled the same way that the logistical regression models were done in the previous section. 
With the Tobit analysis, like the logistic regression analysis, the most important variable was self reported interest in politics. The significance of political interest can be seen in the modeling of time spent on the sequestration article (Table 5.9) and on time spent on both articles combined (Table 5.10).

Overall, the Tobit analysis offers little support of H1 and no support of H2. Support for H1 can be found on Model 1 on Table 5.8. The positive, and statistically significant, coefficient for the Colbert Clip condition in this model means that, relative to the constant (the news condition, those who were in the Colbert Clip were likely to spend more time on the fiscal cliff article. 
Table 5.8 Tobit analysis of post video

stimulus fiscal cliff information seeking

\begin{tabular}{|c|c|c|c|c|}
\hline & $\begin{array}{c}\text { Model 1 } \\
\text { (Stimulus Only) }\end{array}$ & $\begin{array}{c}\text { Model } 2 \\
\text { (with interest } \\
\text { interaction) }\end{array}$ & $\begin{array}{c}\text { Model } 3 \\
\text { (with humor } \\
\text { variable) }\end{array}$ & $\begin{array}{c}\text { Model } 4 \\
\text { (full model) }\end{array}$ \\
\hline Colbert Clip & 323.14(175.43)* & 656.73(497.05) & $328.73(214.29)$ & $655.81(504.28)$ \\
\hline Control Group & $324.59(165.93)^{*}$ & $334.41(169.78)$ & $320.40(189.41)$ & $335.43(194.04)$ \\
\hline Political Interest & $100.25(68.47)$ & $135.47(86.15)$ & $100.31(68.48)$ & $135.49(86.16)$ \\
\hline Colbert $x$ Interest & & $-105.19(144.68)$ & & $\begin{array}{l}-105.33 \\
(145.23)\end{array}$ \\
\hline Humorous & & & $-2.84(62.26)$ & $0.68(63.00)$ \\
\hline Constant & $\begin{array}{c}-1037.08 \\
(313.99) * * *\end{array}$ & $\begin{array}{c}-1158.11 \\
(372.63)^{* *}\end{array}$ & $\begin{array}{c}-1033.03 \\
(325.90)^{* *}\end{array}$ & $\begin{array}{l}-1159.20 \\
(386.05)^{* *}\end{array}$ \\
\hline$x^{2}$ & 7.28 & 7.82 & & 7.82 \\
\hline \multicolumn{5}{|l|}{$D f$} \\
\hline Pseudo $\mathrm{R}^{2}$ & 0.02 & 0.02 & & 0.02 \\
\hline $\mathrm{N}$ & 163 & 163 & & 163 \\
\hline
\end{tabular}

$* \mathrm{p}<.05 ; * * \mathrm{p}<.01 ; * * * \mathrm{p}<.001$ (Numbers in parentheses are standard errors.) 


\section{Table 5.9 Tobit analysis of post video}

stimulus of Sequestration information seeking

\begin{tabular}{|c|c|c|c|c|}
\hline & $\begin{array}{c}\text { Model } 1 \\
\text { (Stimulus Only) }\end{array}$ & $\begin{array}{c}\text { Model } 2 \\
\text { (with interest } \\
\text { interaction) }\end{array}$ & $\begin{array}{c}\text { Model } 3 \\
\text { (with humor } \\
\text { interaction) }\end{array}$ & $\begin{array}{c}\text { Model } 4 \\
\text { (full model) }\end{array}$ \\
\hline Colbert Clip & $-41.22(77.03)$ & $-17.76(300.41)$ & $3.54(191.25)$ & $31.41(353.49)$ \\
\hline Control Group & $\begin{array}{l}-54.19 \\
(70.11)\end{array}$ & $\begin{array}{l}-54.16 \\
(70.19)\end{array}$ & $\begin{array}{c}-23.74 \\
(119.95)\end{array}$ & $\begin{array}{c}-23.29 \\
(120.35)\end{array}$ \\
\hline Political Interest & $\begin{array}{c}116.05 \\
(43.68)^{* *}\end{array}$ & $\begin{array}{c}118.12 \\
(50.82)^{*}\end{array}$ & $\begin{array}{c}116.69 \\
(43.69)^{* *}\end{array}$ & $\begin{array}{c}119.09 \\
(50.85)^{* *}\end{array}$ \\
\hline Colbert x Interest & & $-7.26(89.92)$ & & $-8.40(89.76)$ \\
\hline Humorous & & & $18.63(59.14)$ & $18.88(59.38)$ \\
\hline $\begin{array}{l}\text { Humorous x } \\
\text { Colbert }\end{array}$ & & & $-22.85(73.01)$ & $-23.19(73.23)$ \\
\hline Constant & $\begin{array}{c}-565.44 \\
(168.86)^{* * *}\end{array}$ & $\begin{array}{c}-572.18 \\
(189.28)^{* *}\end{array}$ & $\begin{array}{l}-597.97 \\
(202.43)\end{array}$ & $\begin{array}{c}-606.20 \\
(221.76)^{* *}\end{array}$ \\
\hline$x^{2}$ & 9.63 & 9.64 & 9.74 & 9.75 \\
\hline \multicolumn{5}{|l|}{$D f$} \\
\hline Pseudo $\mathrm{R}^{2}$ & 0.02 & 0.02 & 0.02 & 0.02 \\
\hline $\mathrm{N}$ & 163 & 163 & 163 & 163 \\
\hline
\end{tabular}

$* \mathrm{p}<.05 ; * * \mathrm{p}<.01 ; * * * \mathrm{p}<.001$ (Numbers in parentheses are standard errors.) 


\section{Table 5.10 Tobit analysis of post video}

stimulus of fiscal cliff and sequestration information seeking

\begin{tabular}{|c|c|c|c|c|}
\hline & $\begin{array}{c}\text { Model 1 } \\
\text { (Stimulus Only) }\end{array}$ & $\begin{array}{c}\text { Model } 2 \\
\text { (with interactions) }\end{array}$ & $\begin{array}{c}\text { Model } 3 \\
\text { (with humor } \\
\text { interaction) }\end{array}$ & $\begin{array}{c}\text { Model } 4 \\
\text { (full model) }\end{array}$ \\
\hline Colbert Clip & 99.15 (93.74) & $167.53(321.52)$ & $84.15(227.71)$ & $159.05(385.58)$ \\
\hline Control Group & $85.93(86.12)$ & 86.77 (96.43) & $121.92(152.89)$ & $124.26(154.13)$ \\
\hline Political Interest & $\begin{array}{c}121.13 \\
(177.90)^{* *}\end{array}$ & $\begin{array}{c}127.95 \\
(56.06)^{*}\end{array}$ & $\begin{array}{c}121.78 \\
(46.64)^{* *}\end{array}$ & $\begin{array}{l}129.14 \\
(56.15)^{*}\end{array}$ \\
\hline Colbert $\mathrm{x}$ Interest & & $-21.68(97.44)$ & & $-23.57(97.92)$ \\
\hline Humorous & & & $21.95(76.07)$ & $22.82(76.70)$ \\
\hline Humorous x Colbert & & & $-7.23(89.66)$ & $-7.84(90.15)$ \\
\hline Constant & $\begin{array}{c}-657.61 \\
(177.90)^{* * * *}\end{array}$ & $\begin{array}{c}-679.75 \\
(205.72)^{* * *}\end{array}$ & $\begin{array}{c}-695.88 \\
(225.55)^{* *}\end{array}$ & $\begin{array}{c}-721.21 \\
(251.09)^{* *}\end{array}$ \\
\hline$x^{2}$ & 8.62 & & & 8.86 \\
\hline \multicolumn{5}{|l|}{$D f$} \\
\hline Pseudo $\mathrm{R}^{2}$ & 0.01 & & & 0.01 \\
\hline
\end{tabular}

\section{Conclusion}

In this chapter, the analysis of the video experiment was discussed. The chapter began with descriptive statistics about the respondents from both surveys. These statistics showed that the sample was generalizable to the demographic of the targeted population of college students. It was shown that the humorous condition was more humorous, enjoyable, and interesting than the news condition. The respondents did not experience a significant difference in perception of learning in the two experimental condition groups, and there was not a difference between 
experimental condition groups when it came to confidence in understanding American politics. But the Colbert Clip did result in a higher perceived knowledge about the fiscal cliff. Logit and Tobit models were presented. Descriptive data found support for all four hypotheses. The regression models found support for $\mathrm{H} 1$, but did not find support for $\mathrm{H} 2$. The next chapter uses the data from the single image experiment to test the same hypotheses. 


\section{Chapter 6}

\section{Image Experiment Results}

The empirical data presented in this chapter is from the single image experiment. The format of this chapter follows closely with the format of Chapter 5 . The descriptive statistics of the respondents is not discussed in this chapter because the statistics in Chapter 5 addressed the composition of the respondents from both surveys. This chapter begins with a short discussion about stimulus equivalence. Then the chapter discusses the empirical data in order from most descriptive to most inferential statistics.

In the first section, introducing the chapter, there is a discussion of stimulus equivalence. This includes a discussion of the general problem of stimulus equivalence, the need to avoid the problem, and this dissertation's attempt to overcome the problem. Overcoming the stimulus equivalence problem is the catalyst for the development of the single image meme experiment.

The analysis begins with descriptive statistics. First, manipulation checks were analyzed to test that the stimuli, mostly the humorous stimulus, generated the appropriate response relative to the other conditions. These manipulation checks include entertainment, learning, and confidence in understanding politics and government.

Next, policy issue attentiveness is analyzed. Policy issue attentiveness was measured by both selection of relevant news article and time spent on that article. Due to the simplicity of the single image meme, only the fiscal cliff article was considered as a relevant news article. These dependent variables, selection of article and time spent on the article, were analyzed using two ways. The first way is to compare the experimental condition groups. This is a way of testing Hypothesis 1 (that exposure to a humorous frame increases attentiveness). The second way that 
the dependent variables were tested is by comparing them to the level of enjoyment that respondents received from the stimuli. This tests Hypothesis 2 (that level of enjoyment positively correlates with attentiveness to an issue).

Finally, as with the video, logit models are presented. Because the dependent variable was simplified to only attentiveness to the fiscal cliff article, there are only two groups of models in this chapter. The first group contains the logit models on the selection of the fiscal cliff article. The second set of models are the Tobit models on the amount of time spent on the fiscal cliff article.

\section{Using memes to overcome the stimulus equivalence problem}

The problem of stimulus equivalence has been a problem for social science experimental researchers. A good definition of stimulus equivalence has been provided by psychologists (Plaud, Gaither, Franklin, Weller, and Barth 1998):

Stimulus equivalence can be defined as a relationship between two things such that one of those things may be substituted for (or come to take the place of) the other in a particular setting and not significantly alter the situation; that is, they come to evoke the same or nearly the same response.

For experimental research, stimulus equivalence is when you evoke the same response in every area except for the hypothesized variables. Stimuli should contain the same amount of information and differences between stimuli should be as controlled as possible.

As mentioned in Chapter 2, resent research on political humor has found it difficult to make the stimuli equivalent. The difficult feat of making stimuli equivalent is the stimulus equivalence problem. This is mostly due to video stimuli being the chosen medium for 
experiments. Fake news shows, like The Daily Show and The Colbert Report, are difficult to edit to fit the same information and time constraints of a news program (not to mention taking out the audiences' laughing). The difficulty of creating video stimuli that are equivalent has been mentioned in some studies on political humor (Baumgartner and Morris 2008, Kim and Vishak 2008, Xenos and Becker 2009, Young and Hoffman 2013), but acknowledgement of the problem and a good faith effort seem to be the only requirements for publication of video experiments.

Therefore, this dissertation uses single image memes to test the same hypotheses of the video experiment. These single image memes are images with a caption that is meant to convey information. There were two single images created for this experiment (these can be found in Chapter 2). Creating single image memes with the same image and a slightly different frame creates more equivalent stimuli than two videos. The amount of information contained in the images is equivalent. There is a slight word count difference, but the overall message is the same. The only difference is the humorously framed image has a joke and the neutrally framed image does not have the joke. The rest of this chapter examines the results of the experiment dealing with these two framed images.

\section{Single Image Experiment Manipulation Check}

In this section, the manipulation check questions are analyzed. To measure the amount of entertainment they felt they got from the image, respondents were asked how enjoyable, humorous, and interesting they found the image. These were 5-point Likert scale questions ${ }^{19}$.

\footnotetext{
${ }^{19}$ Likert scale answers were as followed: Enjoyablity answers: 1= Not Enjoyable at all, 2= Somewhat Enjoyable, $3=$ Neutral, 4=Enjoyable, 5=Very Enjoyable, 6=Don't know. Humorous Answers: 1= Not Humorous at all, 2= Somewhat Humorous, $3=$ Neutral, $4=$ Humorous, $5=$ Very Humorous, $6=$ Don't know. Interesting Answers: $1=$ Not Interesting at all, 2= Somewhat Interesting, 3= Neutral, 4=Interesting, 5=Very Interesting, 6=Don't know.
} 
Both experimental condition groups, the humorous frame and the neutral frame, received the same questions in the same order.

The manipulation check questions for the single image experiment were of particular interest because, with much of the stimulus being equivalent, it could show that the humor was much of the difference between the stimuli. The results shown in Figure 6.1 are similar to those given in Chapter 5; the humorous variable shows the most difference between the stimuli. All three manipulation check questions showed statistically different responses from the two experimental condition groups.

\section{Figure 6.1}

\section{Image Manipulation Check Questions}

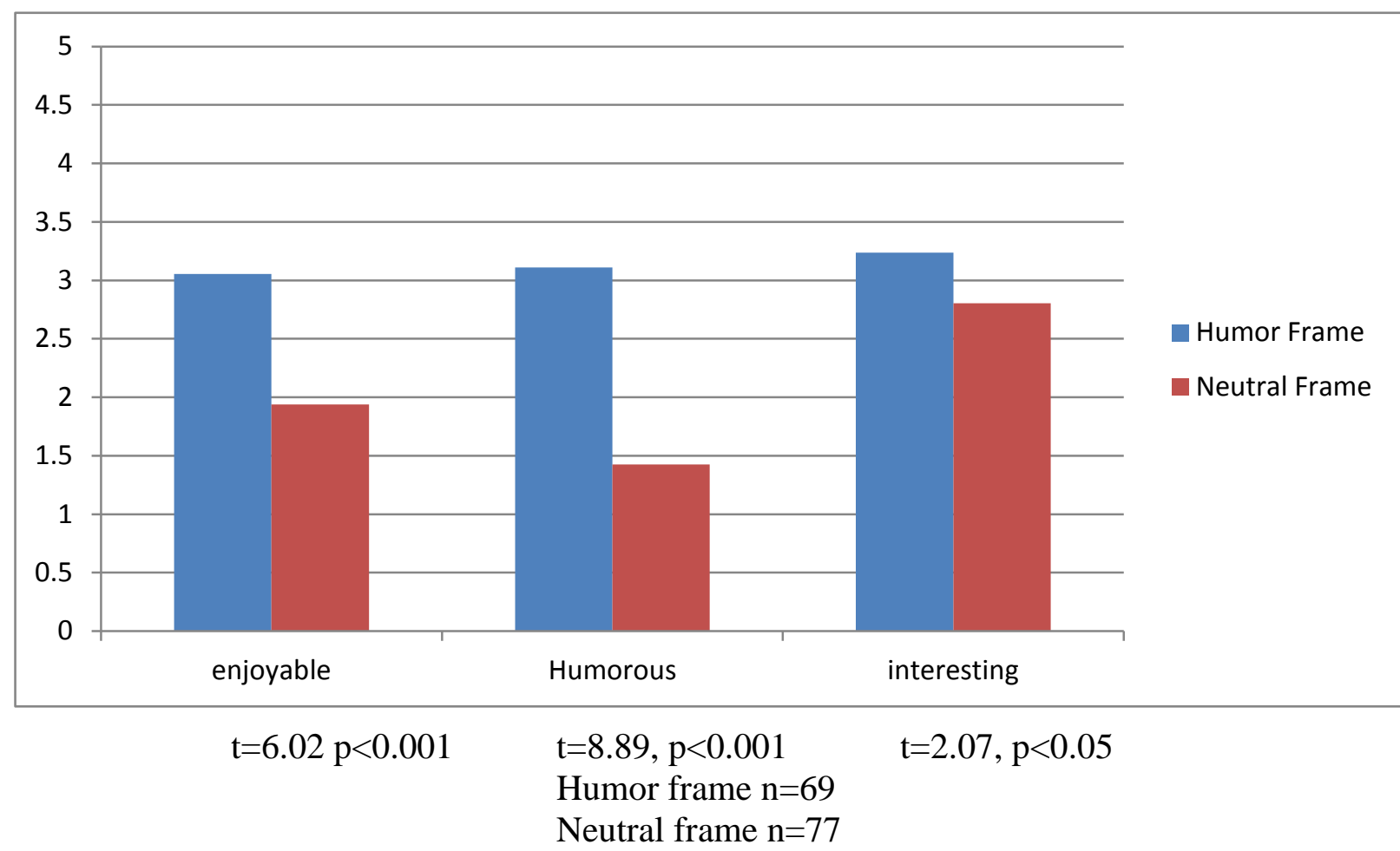




\section{Learning and Knowing: Differences between experimental condition groups}

Now that it has been established that the humorously framed single image was significantly more entertaining than the neutral frame, similarities need to be established. It is important, from a stimulus equivalence perspective, that both stimuli give an equal feeling of learning. Those who received the neutrally framed image and those who received the humorous framed image had a similar average score of feeling as if they learned, as shown in Figure 6.2. This is a similar to the difference seen in the video image in Chapter 5. Again, without a difference in perception of learning, there is less noise or assumptions in the model that could be confounding the research. In other words, the stimuli are equivalent on being seen as being informative by the respondents.

To accompany this lack of a learning effect, there was also not an effect when it came to feeling more informed about politics and government. When it comes thinking that they are better informed about politics and government than most people (shown in Table 6.1), there was not a significant difference between any of the experimental condition groups. The two-group difference of means t-tests with equal variance showed that there was no statistical difference between any combination of the groups when it came to thinking that they were more informed about politics and government. 
Figure 6.2

Image post stimulus perceived learning

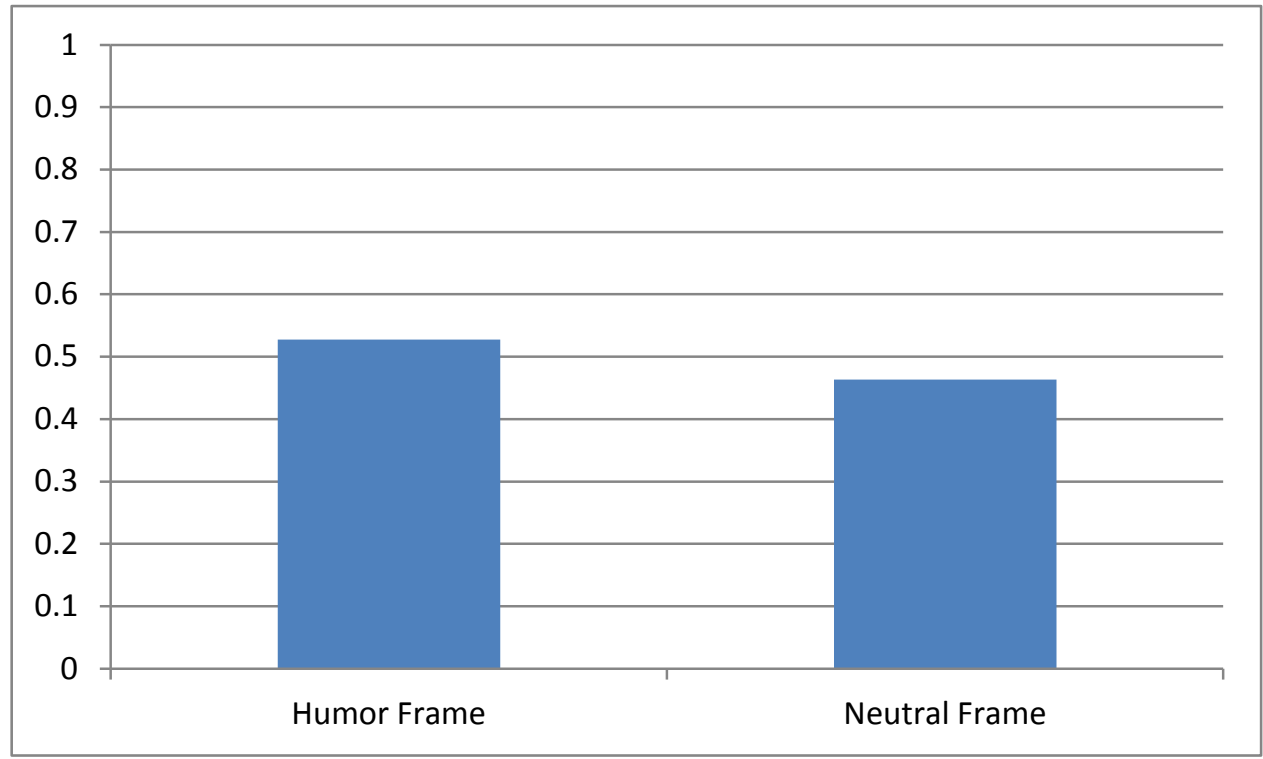

$\mathrm{t}=0.79 \mathrm{p}>0.05$

$\mathrm{N}=154$

Table 6.1 Analysis of Variance (ANOVA) - I think that I am better informed about politics and government than most people

\begin{tabular}{|l|l|l|l|l|l|}
\hline \multirow{2}{*}{$\begin{array}{l}\text { DV- I think that I better information } \\
\text { (Three Experimental Groups) }\end{array}$} & \multirow{2}{*}{ N } & \multicolumn{5}{|l|}{} \\
\cline { 4 - 7 } & & Mean & SD & F & Prob > F \\
\hline Humor Frame & 72 & 3.333 & 1.233 & 0.97 & 0.3793 \\
\hline Control & 74 & 3.122 & 1.170 & & \\
\hline Neutral Frame & 80 & 3.375 & 1.184 & & \\
\hline
\end{tabular}

Table 6.1 shows the average of the experimental condition groups responses to how knowledgeable they feel like they are when it comes to the fiscal cliff. There was a significant difference between the two experimental condition groups and the control when it comes to being knowledgeable about the "fiscal cliff." (Table 6.2) It is interesting that both conditions are significantly higher in reporting that they are knowledgeable about the "fiscal cliff" than the 
control, but were not significantly different from each other. This means that seeing the single image meme about the "fiscal cliff," the Internet equivalent of a bumper sticker, was enough to create a feeling of knowledge about the topic. This feeling of being knowledgeable about the topic could keep people from seeking out more information on the topic.

Table 6.2 Analysis of Variance (ANOVA) - I am very knowledgeable about the "fiscal cliff" as an issue in American politics

\begin{tabular}{|c|c|c|c|c|c|}
\hline \multirow{2}{*}{$\begin{array}{l}\text { DV-I think that I better information } \\
\text { (Three Experimental Groups) }\end{array}$} & \multirow[t]{2}{*}{$\mathrm{N}$} & & & & \\
\hline & & Mean & $\mathrm{SD}$ & $\mathrm{F}$ & Prob $>F$ \\
\hline Control & 74 & 2.500 & 1.213 & 8.23 & 0.0004 \\
\hline Humor Frame & 72 & 3.222 & 1.274 & & \\
\hline Neutral Frame & 80 & 3.088 & 0.957 & & \\
\hline
\end{tabular}

\section{Exposure to humor and information seeking}

Hypothesis 1 suggests that receiving a humorous frame increases attention to a policy issue. Table 6.3 depicts the information seeking behavior of the respondents grouped by their experimental condition group. Because sequestration was not mentioned in the single image stimuli, the numbers on the sequestration searching differences is just presented in the interest of comparison. Those who were in the humor image experimental condition group and selected the article stayed on for a longer period of time than either the neutral frame or the control group. 


\section{Table 6.3}

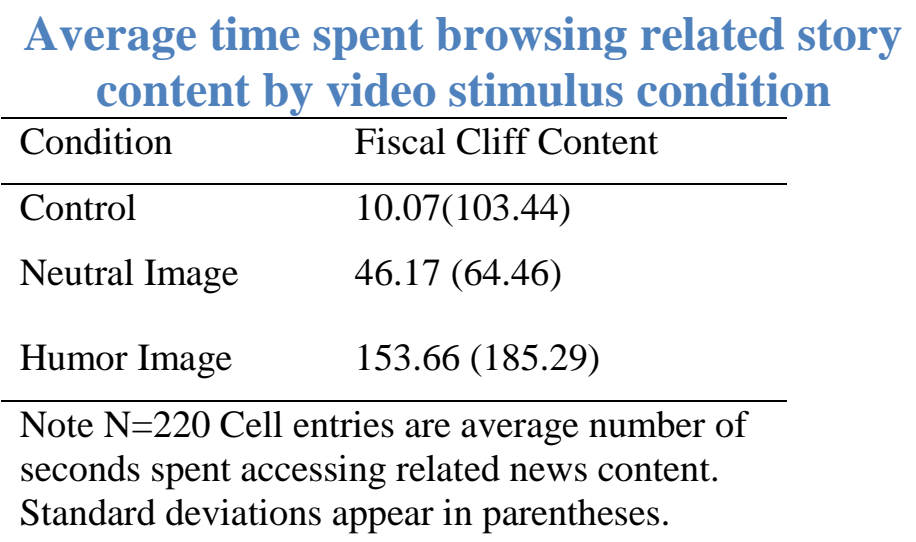

To test Hypothesis 1, that exposure to the humorous frame results in relevant information seeking, Table 6.4 shows the average selection of the fiscal cliff article for each experimental condition group. Also in Table 6.4, the average selection of the fiscal cliff article of each group is compared to the other groups. The resulting difference of means t-tests are presented on the bottom of Table 6.4. These numbers show support for Hypotheses 1 because those who received the humor frame picked the fiscal cliff article at a higher rate than the control group or those who received the neutrally framed image.

\section{Table 6.4 Analysis of Variance (ANOVA) - Selection of the Fiscal Cliff Article}

\begin{tabular}{|l|l|l|l|l|l|}
\hline DV- I think that I better information & \multirow{2}{l|}{} \\
(Three Experimental Groups) & & \multicolumn{4}{|l|}{} \\
\cline { 4 - 7 } & & Mean & SD & F & Prob > F \\
\hline Control & 74 & 0.149 & 0.358 & 2.43 & 0.0903 \\
\hline Humor Frame & 72 & 0.250 & 0.436 & & \\
\hline Neutral Frame & 80 & 0.122 & 0.329 & & \\
& & & & & \\
\hline
\end{tabular}


The numbers on Figure 6.3 could be deceiving because of a low number of observations. Therefore, a line graph is presented in Figure 6.3 so show the number of people that spent time in different time groups. While there is not a completely clear and direct relationship when it comes to the different groups, the experimental condition group that received the humorous frame had nine respondents that spent 150 seconds or more on the fiscal cliff article, while the other two experimental condition groups group had four respondents that spent 150 seconds or more on the same article.

While this difference seems meaningful, Figure 6.4 shows that when we compare the average time spent on information seeking by experimental condition group, there is not a significant difference. Although those who were in the humorous frame experimental condition group seemed to spend more time on the article, the difference was not significant. The reason for this is simple. This analysis was done by using the time spent on the fiscal cliff article by those who chose to read the article. This means that this analysis was done with a small $\mathrm{N}$ and may produce significant results if it were tested on a larger $\mathrm{N}$. 
Figure 6.3 Time spent on Fiscal Cliff

Article by experimental condition group

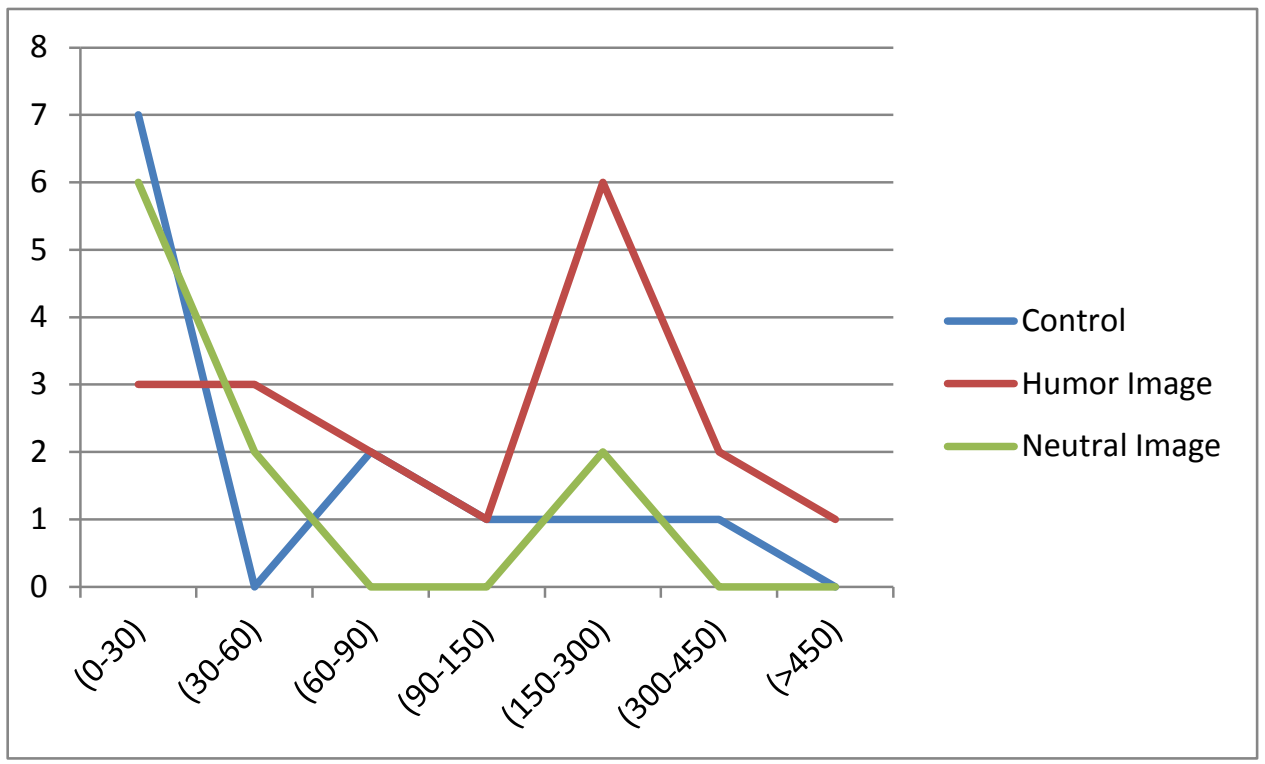

Figure 6.4 Average time spent on information seeking by experimental condition group

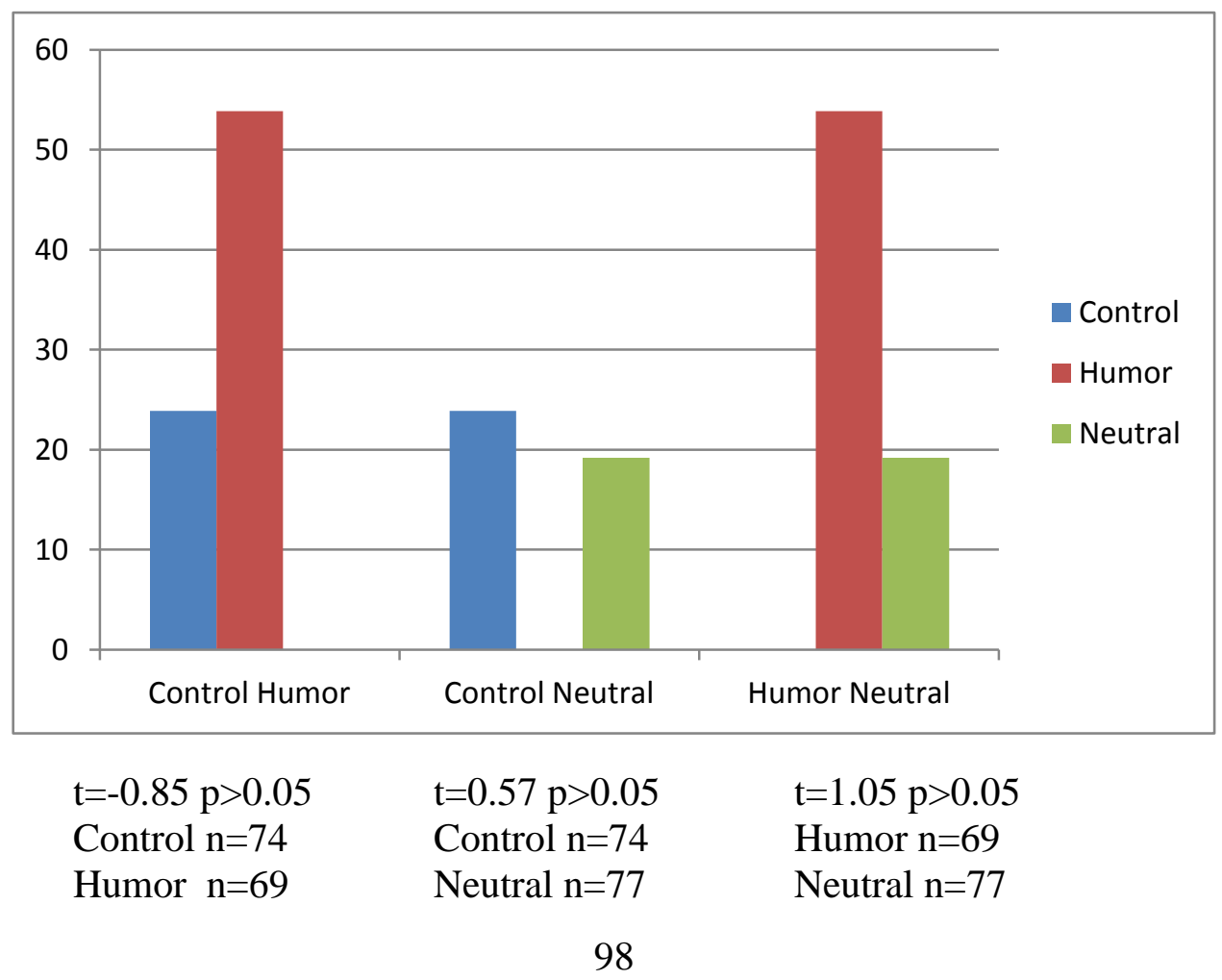




\section{Level of Entertainment and information seeking}

The second hypothesis suggests that level of enjoyment from a humorous frame increases information seeking Figure 6.5 and Figure 6.6 test this hypothesis. Figure 6.6 shows that there is, generally speaking, a direct relationship between finding the frame humorous and selecting the fiscal cliff article. Finding the image interesting had a similar relationship to finding it humorous. There is a counterintuitive dip in the probability of selecting the fiscal cliff article when respondents enjoyed the image very much.

Figure 6.5 Average selection of fiscal cliff article by enjoyment of image

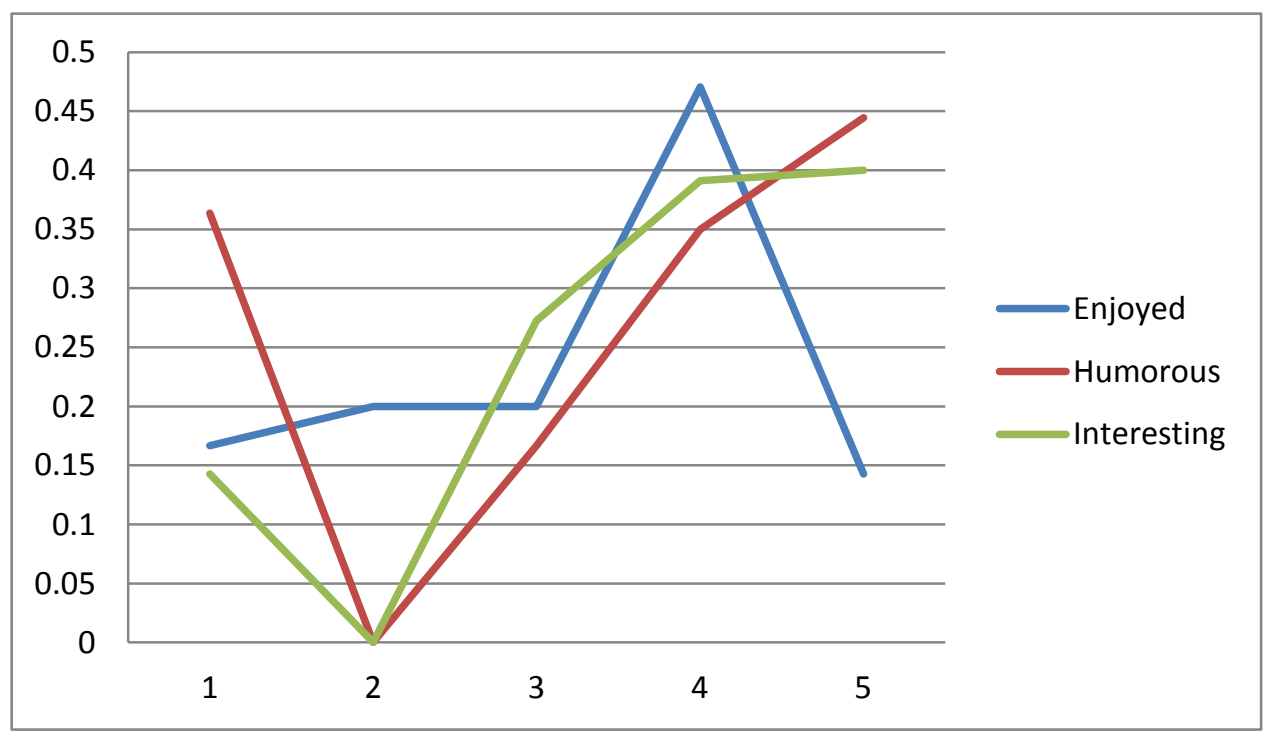

The other measure of attention, average time spent on the article, shows a possibility of a humor effect. Figure 6.6 shows that there is a positive correlation between how much respondents enjoyed the image and the average time they spend on the fiscal cliff article. This is most prominent in the level of humor that the respondents attributed to the image. The average 
amount of time spent on the fiscal cliff article goes up from 3 (being neutral on the Likert scale) to 4 (which is enjoyed, found humorous, or found interesting). While there was a large upswing in average time spent on the article when respondents found the single image very humorous (5 on the Likert scale). Those who thought the image was very humorous averaged over two minutes on the article.

Figure 6.6 Average time spent on fiscal cliff article by how much they enjoyed image

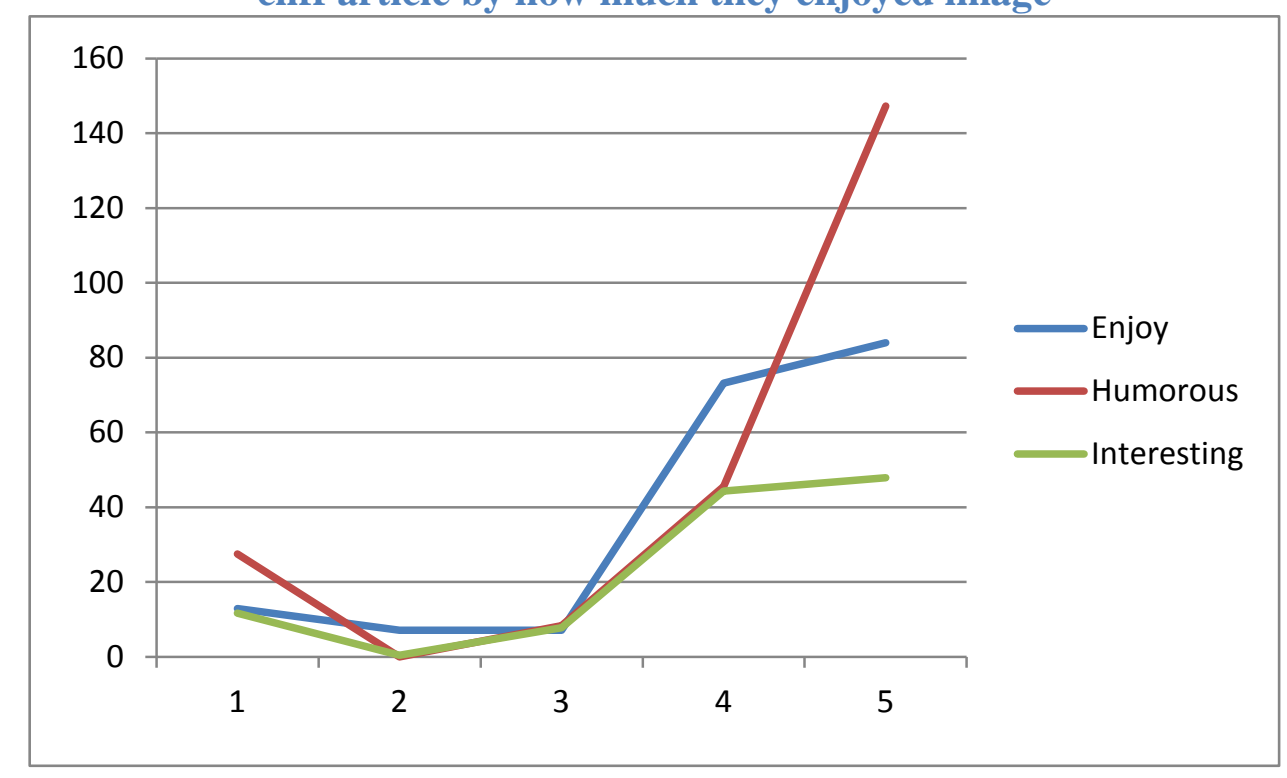

It is interesting to note the differences in the measures of attentiveness in those who found the frame to be very humorous. As shown in Figure 6.5, those who found the image to be very humorous were unlikely to choose the fiscal cliff article. Juxtapose that with the finding on Figure 6.6 that those who did select the article and found the image to be very humorous averaged more than two minutes on the article. This would be a more interesting finding if there was a larger $\mathrm{N}$, but these preliminary findings could help guide future research. 


\section{The Spillover Effect of Humor}

This section of this chapter is focused on Hypotheses 3 and 4 of this dissertation.

Hypotheses 3 and 4 argue that political humor has the ability to generally increase interest in politics. The main idea for these hypotheses comes from the negative "spillover effect" that researchers found political humor can have when it comes to evaluating politics and government (Baumgartner 2013). The main idea in that research was that negative attitudes towards a politician that was being made fun of could "spillover" to a person's perception of politics being negative. If a humorous frame can make a political issue interesting and more palatable, then could that interest also "spillover" to the person's perception of politics being interesting?

Table 6.5 is presented to test Hypothesis 3, that exposure to political humor increases interest in politics. Although receiving the humorous frame resulted in statistically higher interest than the control group, it did not have the same statistical difference relative to the neutral frame. The difference between the control group and the neutral frame also did not have a statistically significant difference. These mixed results point to a possible increase in interest in politics from single image frames in general, but more research needs to be done.

\section{Table 6.5 Analysis of Variance (ANOVA) - Interested in Following Matters of Politics and Government by Experimental Stimulus Group}

\begin{tabular}{|l|l|l|l|l|l|}
\hline DV- I think that I better information & N & \multicolumn{3}{|l|}{} \\
\cline { 5 - 7 } (Three Experimental Groups) & & Mean & SD & F & Prob > F \\
\hline Control & 74 & 2.919 & 0.772 & 1.56 & 0.2133 \\
\hline Humor Frame & 72 & 3.152 & 0.781 & & \\
\hline Neutral Frame & 80 & 3.037 & 0.843 & & \\
\hline
\end{tabular}


In the interest of testing hypothesis 4 , that enjoyment of the humorous frame increases interest in politics and government, Figure 6.7 shows a slight positive correlation between level of entertainment and stated interest in politics and government. While there is some noise in the relationship, it points to the possibility of a relationship. A similar relationship was found in Chapter 5. This finding is not dramatic, but it does help illuminate the effect of humor on perception of politics and could help guide future research in this area.
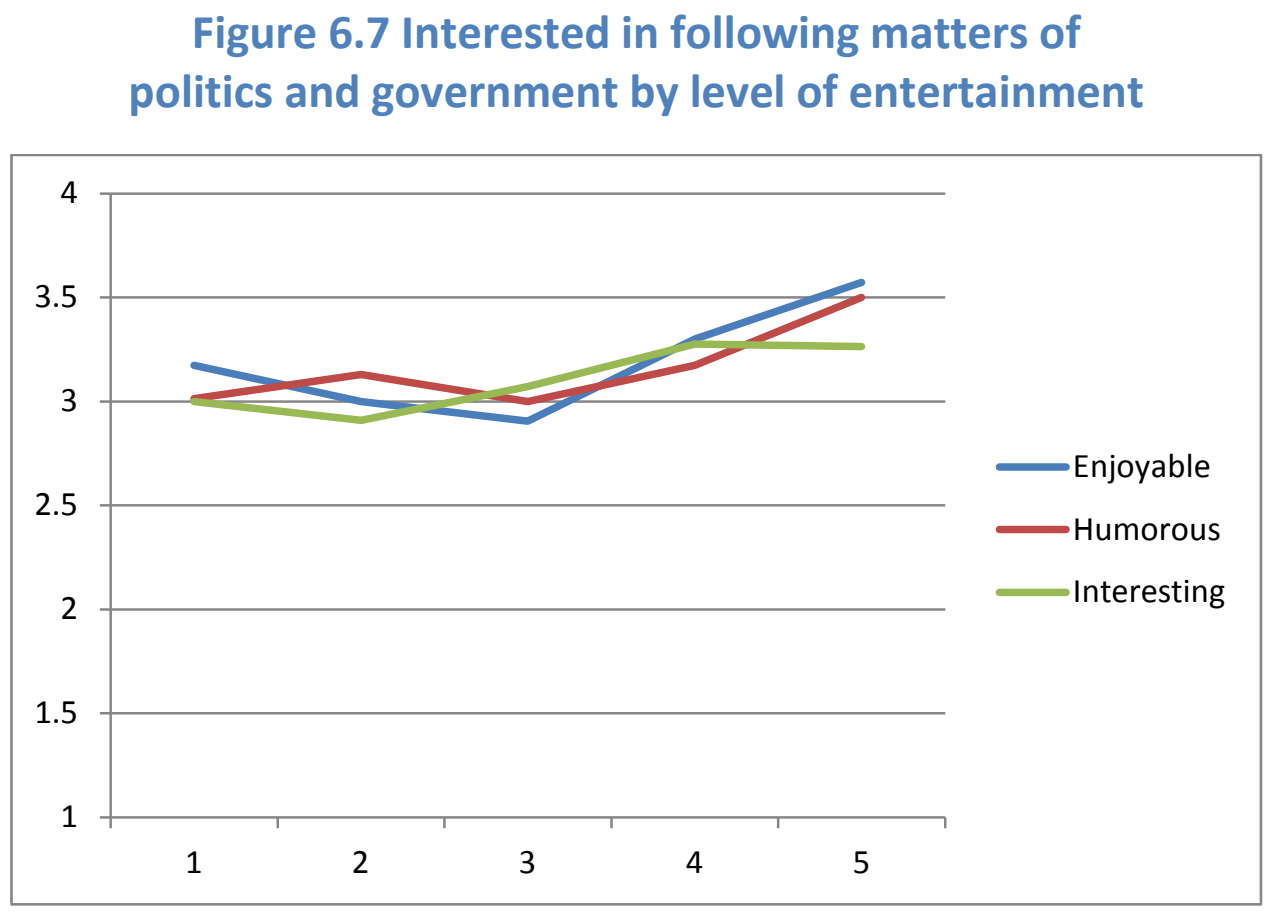

\section{Logit Analysis}

The choice of the respondents to search for information, after the experimental condition has been received, is the focus of this section. In this survey, the choice was measured as a dichotomous variable. Either respondents chose to search out for the information or they did not. The design of the survey allowed respondents to chose from multiple different news articles. 
Respondents were able to select and read as many as they like. The only article of interest for this experiment was the one about the fiscal cliff ("After "fiscal cliff" dive, more battles, new cliffs"). The article about sequestration ("Sequestration not favored method to cut budget deficit and how it might be a disservice to those who serve") was not considered information seeking that was initiated by the stimuli because the connection between the fiscal cliff and the sequestration is not made by the simple single image stimuli.

The logistical regression analysis from the single image experiment (Table 6.6 shows much of the same results as the video experiment from Chapter 5. In the first model in that table, both political interest and receiving the humor frame positively correlated with choosing the fiscal cliff article. The other models, that included the interaction terms, did not find significant variables. It is important to note that the baseline, or constant, is the group that received the neutral frame. 
Table 6.6 Logit analysis of post image stimulus fiscal cliff information seeking

\begin{tabular}{|c|c|c|c|c|}
\hline & $\begin{array}{c}\text { Model } 1 \\
\text { (Stimulus Only) }\end{array}$ & $\begin{array}{c}\text { Model } 2 \\
\text { (with interest } \\
\text { interactions) }\end{array}$ & $\begin{array}{c}\text { Model } 3 \\
\text { (with humor } \\
\text { interactions) }\end{array}$ & $\begin{array}{c}\text { Model } 4 \\
\text { (with both } \\
\text { interactions) }\end{array}$ \\
\hline Humor Frame & $0.83(.44)^{*}$ & $-0.65(1.85)$ & $0.56(.54)$ & $-0.93(1.92)$ \\
\hline Control Group & $0.27(.47)$ & $-1.11(1.95)$ & $0.79(.59)$ & $-0.54(2.02)$ \\
\hline Political Interest & $0.41(.24)^{*}$ & $0.10(.40)$ & $0.38(.24)$ & $0.08(.41)$ \\
\hline Colbert x Interest & & $0.46(.56)$ & & $0.46(.57)$ \\
\hline Control x Interest & & $0.41(.61)$ & & $0.42(.61)$ \\
\hline Humorous & & & $0.24(.17)$ & $0.24(.17)$ \\
\hline Humorous x Colbert & & & $-0.10(.14)$ & $-0.09(.14)$ \\
\hline Constant & $-3.26(.84)^{* * *}$ & $-2.27(1.31)$ & $-3.47(.88)^{* * *}$ & $-2.54(1.32)$ \\
\hline$x^{2}$ & $7.67 *$ & 8.47 & 9.60 & 10.71 \\
\hline \multicolumn{5}{|l|}{$D f$} \\
\hline Pseudo $\mathrm{R}^{2}$ & 0.04 & 0.04 & 0.05 & 0.05 \\
\hline $\mathrm{N}$ & 227 & 227 & 227 & 227 \\
\hline
\end{tabular}

$* \mathrm{p}<.05 ; * * \mathrm{p}<.01 ; * * * \mathrm{p}<.001$ 


\section{Tobit Analysis}

This section of the chapter uses Tobit analysis to analyze the attentiveness to the policy issue of the fiscal cliff. Tobit analysis allows researchers to model durations as a dependent variable even if many of the values equal zero. The Tobit analysis for this experiment, shown in Table 6.7, shows no significant variables for any of the models. As mentioned before, the problem with these models could be that the $\mathrm{N}$ is too small and a study done with more participants could have a chance at producing some results. 


\section{Table 6.7 Tobit analysis of post image stimulus fiscal cliff information seeking}

\begin{tabular}{|c|c|c|c|c|}
\hline & $\begin{array}{l}\text { Model } 1 \\
\text { (Stimulus } \\
\text { Only) }\end{array}$ & $\begin{array}{c}\text { Model } 2 \\
\text { (with interest } \\
\text { interactions) }\end{array}$ & $\begin{array}{c}\text { Model } 3 \\
\text { (with humor } \\
\text { interactions) }\end{array}$ & $\begin{array}{c}\text { Model } 4 \\
\text { (with both } \\
\text { interactions) }\end{array}$ \\
\hline Humor Frame & $16.25(22.82)$ & $-13.71(83.07)$ & $15.91(27.70)$ & $-16.04(83.55)$ \\
\hline Control & $14.38(22.31)$ & $-52.16(81.05)$ & $8.43(28.50)$ & $-59.01(82.96)$ \\
\hline Political Interest & $-6.75(11.43)$ & $-18.87(20.95)$ & $-6.54(11.38)$ & $-18.88(20.79)$ \\
\hline Colbert $\mathrm{x}$ Interest & & $10.99(28.41)$ & & $11.40(28.17)$ \\
\hline Control x Interest & & $23.49(28.12)$ & & 23.76 \\
\hline Humorous & & & $-1.50(8.67)$ & \\
\hline Humorous x Colbert & & & $2.10(6.31)$ & \\
\hline Constant & $\begin{array}{l}-91.12 \\
(45.94)^{*}\end{array}$ & $-56.76(59.12)$ & $-89.93(64.45)$ & \\
\hline$x^{2}$ & 0.97 & 1.72 & 1.09 & \\
\hline$D f$ & 3 & 5 & 5 & \\
\hline Pseudo $\mathrm{R}^{2}$ & 0.007 & 0.012 & 0.007 & \\
\hline $\mathrm{N}$ & 227 & 227 & 227 & \\
\hline
\end{tabular}




\section{Conclusion}

This chapter examined the empirical evidence collected from the single image experiment. The equivalence problem was discussed and the single captioned image was used to overcome that problem. It was shown that the humorously captioned image, although simple and minimal, was still significantly more entertaining and humorous than the neutrally captioned image. Many of the expected similarities between the humorous frame and the neutral frame, like feeling informed about the fiscal cliff, lacked a significant statistical difference.

The descriptive statistics and difference of means t-tests showed some support for this dissertation's hypotheses. There is some strong evidence, through difference of means t-tests and logit analysis, to support Hypothesis 1. The support for Hypothesis 2 is not as robust as desired and the level of enjoyment from a frame could use more research. There was some support for Hypotheses 3 and 4, but more research is needed to see if there is a spillover in interest in politics from a humorous frame.

The most important finding of this chapter was that the single image meme seemed to have an effect if it was humorous or not. Those that received a single image meme about the fiscal cliff said that they were more knowledgeable about the fiscal cliff and were more likely to say they were more interested in politics and government than the control group. More research needs to be done to test the effect of single image memes on opinions and attitudes towards politics. They are becoming more prevalent means of communicating ideas online and they are likely affecting people's attitudes towards politics.

Now that the data from both the video and single image experiments have been 
discussed, the next chapter concludes this dissertation with a discussion of the takeaways from this analysis and possible directions for future research. 


\section{Chapter 7}

\section{Conclusion}

[T] he mass media may not be successful much of the time in telling people what to think, but the media are stunningly successful in telling their audience what to think about.

Cohen (1963, p. 16)

\section{Introduction}

This dissertation explores the role of a humorous political frame in information seeking behavior and in garnering interest in the areas of politics. The first chapter described the current situation that exists when it comes to the problem. Innovation and technology, namely the internet, has made political information abundant and constantly accessible. Yet, there are still reports of young people being uninformed. Many attribute the lack of information obtained by the young to a lack of interest (Popkin and Dimock 1999). The goal of this dissertation was to examine the possibility that political humor increases young people's interest in domestic policies and politics in general.

Chapter 2 also discussed the soft news literature. Research on soft news on opinions and behavior in the political realm is a burgeoning area of research and more research can be done. This research has found that political humor contains political content (Baum 2002; Beavers 2011; Brewer and Marquardt 2007) and that it affects its audience's political judgments and behaviors (Baumgarnter 2013; Baumgarnter and Morris 2006; Baumgarnter and Morris 2008; Xenos and Becker 2009). Chapter 3 focused on arguing how political humor is an catalyzing agent for information seeking. The main argument of this dissertation project, as presented in the first three chapters, is that this deficiency in interest could be alleviated with political humor 
(Baum 2002; Xenos and Becker 2009). The overall theory is fairly straight forward: people are generally not interested in politics (Popkin and Dimock 1999), but a humorous frame on something could increase their interest. This increased interest, and desire to tell the joke at the water-cooler the next day (Baum 2002), would prompt them to seek out more information. Furthermore, it was theorized that the level of enjoyment of the humorous frame, or how funny it is perceived to be, positively correlates with attention seeking behavior.

In addition, it was hypothesized that there would be a "spillover" of interest in politics in general from the humorous frame of a single topic. This was a hypothesis that came from research that found that humor that made fun of a candidate had a negative impact on the viewer's opinion of that candidate, and there was a "spillover effect" to how those viewers felt about politics in general (Baumgartner 2013).

There were other key points made in Chapter 3. Also discussed in Chapter 3 was the importance of the fiscal cliff as an issue in American politics. The issue of the fiscal cliff was an important singular event, but it has also become a trend in how Congress deals with budget decisions. The methodology that was used in this dissertation was the topic of Chapter 4 .

The results of the video experiment were analyzed in the fifth chapter. Manipulation check questions were analyzed and found that the stimuli had the desired effect of being more enjoyable and humorous while not affecting the respondent's perception of learning. Correlational analyses found support for the hypotheses, while the regression analyses did not find support for the hypotheses. The respondents that received the humorous video were more likely to think that they were relatively informed about the fiscal cliff than the control group. This difference was not significant between other groups. 
Information seeking behavior for the video experiment was measured by the selection of either a fiscal cliff article or an article on sequestration, or selection of either one. There were signs that both exposure to and enjoyment of political humor were positively correlated with information seeking behavior. The exposure to political humor and choosing to seek out more information were significant in a difference of means t-test. The level of enjoyment of the video and choosing to seek out information were positively correlated. Some of the models for the logit analysis showed support for exposure to political humor and choosing to seek out more information.

When it came to the spillover effect, Chapter 5 found little support for a positive spillover of interest from exposure to a humorous video. Although there was no relationship between exposure and interest in politics, there seemed to be a positive relationship between enjoyment of the video stimuli and self identified interest in politics in government. This means that enjoyment of a frame does have some relationship to the effect of the frame.

Chapter 6 discussed the results of the framed single image experiment. This chapter began with a discussion of the research problem of stimulus equivalence, that the experimental stimuli need to be the same on every level except the desired difference so that false cause does not confound the study, because it was thinking about that problem that inspired using framed single images to test the effect of humor on its audience. It is interesting to see that a framed single image is enough of a prime to give people a sense of knowledge about a topic. This suggests that framed single image memes could be studied for effects. 
When it came to information seeking, those who received the humorously framed image spent much more time on the fiscal cliff article than those in the control group or in the neutrally framed image group.

The interest in politics for the humorous frame did spillover relative to the control group, but not relative to neutral group.

\section{Contributions to the Literature}

The evidence in this dissertation shows that a humorous frame of a policy issue has similar effects as a neutral frame of that same issue. In some ways, political humor makes people more engaged and interested in the issue and politics in general. Just as suggested by Baum (2002, 2003), political humor can help people that are generally disinterested in politics become more interested in politics. This is to counter the arguments of Postman (1984) and Prior (2003) that entertainment-based media do not play a positive role in America's democracy. This research demonstrates that political humor does have an effect on how people perceive a topic and politics in general.

This dissertation adds to the field of research on the effects of "soft news," and more specifically political humor, on the American public. This dissertation contributes to the "soft news" or "infotainment" literature, and to the boarder media effects literature, in a few ways. First of all, this dissertation examines the amount of enjoyment and humor that the audience perceives the frame. Secondly, this dissertation develops a way to deal with the stimulus equivalence problem and a methodology to study framing effects by using the popular single image meme technique. Thirdly, this dissertation attempted to use Tobit analysis to study 
information-seeking behavior. While using Tobit analysis was not as fruitful as was hoped, it could still be used in a survey with a bigger number of participants and, hypothetically, yield significant results.

\section{Limitations and Future Research}

Survey research has some inherent advantages and disadvantages. Although experiments are the only way of approaching testing what happens in real life, there are shortcomings of experimental surveys. Experimental surveys are done in an "artificial" environment that is controlled to the researcher's specifications to meet a research objective (Campbell and Stanley, 1963). The result generated in the artificial environment may not be reflected in a real world environment (Kinder and Palfrey, 1993). Although this dissertation was mindful of external validity by creating a static information board that looked much like Google News and creating framed single images that are popular in digital communications, the experiment is still subject to these criticisms. These critiques are valid of many experimental surveys, but it is difficult to operationalize the impact of political humor on information seeking with doing an experiment.

Other than the typical problems with survey research in general, and experimental research more specifically, there were some limitations of this research that future research could find a way to overcome. First of all, there was an issue getting the survey out in a timely manner. The fiscal cliff crisis was a problem in December 2012, but the survey was not implemented until early 2013. This shortcoming was partially a function of getting dissertation committee approval, and partially a function of editing the video to an acceptable condition. The fiscal cliff was subsequently delayed and was still significant when the survey took place, but a more timely survey would have been better. Future research can overcome this problem with a better 
understanding, and availability, of video editing tools. Also, simply utilizing the framed single image meme could also streamline the process.

Another limitation is that this study did not test whether or not the stimuli actually produced knowledge. As a proxy, perception of knowledge was used. This choice was made because of a concern for respondent fatigue that might confound the results. Future research could look at the possibility of testing the learning that takes place in one study while testing information seeking in another (much like the work done by Xenos and Becker 2009). Another way to address learning, without confounding the study with testing knowledge, could be a Likert scale question instead of the dichotomous questions of learned or not learned. The choice to measure learning as a self-reported, dichotomous variable is still valid because it is still measuring whether or not the respondent felt like they learned from the stimuli, but more dynamic measures could be used in the future.

The level of enjoyment could be looked at more dynamically than analyzed in this study. Future research could look at the potential mediating relationship between exposure and enjoyment. It could be theorized that the level of enjoyment could intensify the exposure effects of humor on interest. Enjoyment could be measured differently as well. A study could be done where the researcher could observe respondents for audible laughter or chuckles as a measure of enjoyment.

Although the policy issue of the fiscal cliff was chosen because of the complexity of the issue and the potential for learning, that policy issue could be something that complicated the study. Perhaps this issue is one that is not easily accessible to a college population, therefore 
receiving any information on it would result in learning. This might be the reason that those receiving the humorous frame reported to learn at the same rate as those who received the neutral frame. Future research could look at different policy issues, or campaign news, that are less complex and see if there is a significant difference. Studying opinions and learning of the fiscal cliff issue is valid in-and-of-itself, but it may not be generalizable to other policy areas and, therefore, more research on other policy areas needs to be done.

There is also a problem with the conceptualization of finding political humor funny leading to information seeking. The problem with this conceptualization, a common problem in social science research, is the identification of causation. Finding the humor in the political frame could raise interest in the individual, or it could be a sign that the individual was previously interested and engaged in politics before the frame. While this could be problematic, the measure is still valid because changing the order of the questions would confound this study. Future research could investigate whether finding a political humor frame funny increases interest or if political interest will lead to finding the political humor frame to be funny. The answer to this question is most likely dependent on the complexity of the issue and the information provided in the frame.

Also, the use of a static information board instead of the dynamic processing tracing methodology developed by Lau and Redlawsk (2001) could be seen as a shortcoming of this research. The static information board was chosen because it fit the need to test the need for this research. The dynamic processing tracing methodology does a good job of simulating a process, like a campaign, as it is happening to test the attention of the subjects to that topic. This technique would be a great way to look at political humor consumption and its effect on behavior 
during something predictable, like a political campaign. Using the dynamic processing tracing method could add to the external validity of research that looks a political information seeking and attention.

The most significant limitation of this research was the low number of participants in the survey. The number of participants in this survey was lower than desirable. This limitation could be avoided in future research. It would also be preferable if the survey took place in multiple universities, or a nationwide survey. A difficultly that this dissertation ran into was the lack of resources to make the nationwide survey a possibility. The videos for this survey were put on a server on the university's campus, and respondents that attempted to take the survey too far off campus ran into problems running the video. More resources could put the video on a faster server and in a smaller format.

An important avenue for future research would be to compare different types of humor to understand the impact of the different varieties of humor. This research could examine the different impacts of parody and satire. Future research could find a way to use experimental design to compare the effect of The Colbert Report to The Daily Show. Also, types of humor could be tested for differing effects on information seeking. Different types of humor (gallows humor, satire, parody, sarcasm) could, theoretically have different effects on the people that view it.

\section{Conclusion}

A knowledgeable citizenry is a key facet of a fully functioning democracy, but citizens are not able to obtain this knowledge without the motivation to seek out political information 
(Patterson 2000). Political humor still might serve as an educational component (Baum 2002), and, as this dissertation argues political humor could help create interest in politics (Xenos and Becker 2009). With interest in politics, and the internet at their fingertips, Americans could become increasingly more knowledgeable about politics and could affect politics in ways that uninformed citizens cannot. This dissertation suggests that political humor could nudge people towards seeking out more information and interest in politics. More research will need to be done to explore what makes political humor more or less effective and if different groups of people are more likely to be positively affected by humor. 


\section{References}

Baum, Mathew A. (2002). Sex, lies, and war: How soft news brings foreign policy to the inattentive public. American Political Science Review, 96, 91-109.

2003. Soft News and Political Knowledge: Evidence of Absence or Absence of Evidence? Political Communications, 20, 173-190.

Baumgartner, Jody. (2013). No laughing matter? Young adults and the 'spillover effect' of candidate-centered political humor. Humor: International Journal of Humor Research, 26(1), 23-43.

Baumgartner, Jody and Jonathan Morris. (2006). The Daily Show Effect: Candidate

Evaluations, Efficacy, and American Youth. American Politics Research; 34; 341.

Baumgartner, Jody and Jonathan Morris. (2008). One 'Nation,' Under Stephen? The Effects of the Colbert Report on American Youth. Journal of Broadcasting and Electronic Media; Dec2008; Vol. 52 Issue 4, p622-643.

Baumgartner, J. C., Morris, J. S., \& Walth, N. L. (2012). The Fey Effect Young Adults, Political Humor, and Perceptions of Sarah Palin in the 2008 Presidential Election Campaign. Public Opinion Quarterly, 76(1), 95-104.

Beavers, Staci L. (2011). Getting Political Science in on the Joke: Using The Daily Show and Other Comedy to Teach Politics. PS: Political Science \& Politics, 44, pp 415-419.

Bedient, Douglas and David Moore. "Student Interpretations of Political Cartoons." Journal of Visual/Verbal Languaging. 5, No. 2 (1985): 29-35. 
Berr, Jonathan. 2009, June 15th. "Crisis at Comedy Central: Audience for Stewart, Colbert is getting older." Daily Finance. http://www.dailyfinance.com/2009/06/15/jon-stewartsaudience-is-getting-older/

Bibel, Sara. 2013, April 4th. "'The Daily Show' and 'The Cobert Report' Finish First Quarter 2013 as Number 1 and Number 2 Among Adults 18-47." TV By the Numbers. http://tvbythenumbers.zap2it.com/2013/04/04/the-daily-show-and-the-colbert-report-

$\underline{\text { finish-first-quarter- } \quad \text { 2013-as-number-1-and-number-2-among-adults-18-49/176487/ }}$

Bloom, Edward A. and Lillian D. Bloom. 1979. Satire's Persuasive Voice. Ithaca: Cornell University Press.

Boskin, Joseph. American Political Humor: Touchables and Taboos. International Political Science Review (1990), Vol. 11, No. 4, 472-482.

Brewer, P. R., \& Marquardt, E. (2007). Mock news and democracy: Analyzing The Daily Show. Atlantic Journal of Communication, 15, 249-267.

Cao, X. 2006. "Political Comedy shows and knowledge about primary campaigns: The moderating effects of age and education." Mass Communication and Society, 11, 43-58.

Campbell, D. T., \& Stanley, J. C. (1963). Experimental and quasi-experimental designs for research. Chicago: Rand McNally.

Carter, Bill. 2012. Stewart and Colbert Extent Comedy Central Contracts. Media Decoder: Behind the Scenes, Between the Lines. The New York Times. http://mediadecoder.blogs.nytimes.com/2012/07/25/stewart-and-colbert-extend-comedycentral-contracts/?_php=true\&_type=blogs\&_php=true\&_type=blogs\&_r=2 
Chaffee, Steven H., and Stacey F. Kanihan. 1997. "Learning About Politics from the Mass Media." Political Communication 14 (October-December): 421-30.

Chambers, S. 2003. "Deliberative democratic theory." Annual Review of Political Science, 6, $307-326$.

Chong, D., \& Druckman, J. N. 2007. "A theory of framing and opinion formation in competitive elite environments." Journal of Communication, 57(1), 99-118.

Cohen, B. 1963. The press and foreign policy. Princeton: Princeton University Press.

Converse, Philip E. 1964. "The Nature of Belief Systems in Mass Publics." Pp. 206-61 in Ideology and Discontent, edited by David E. Apter. New York: Free Pres

Converse, P.E. 2000. "Assessing the capacity of mass electorates." Annual Review of Political Science, 3, 331-53.

Cooper, Matthew. (2012, December 3) "Poll Shows Ambivalence on Fiscal Cliff, Support for Rice. National Journal. Link: http://www.nationaljournal.com/daily/poll-shows$\underline{\text { ambivalence-on-fiscal-cliff-support-for-rice-20121203 }}$

Cornick, Jorge, Thomas L. Cox, and Brian W. Gould. "Fluid milk purchases: A multivariate tobit analysis." American Journal of Agricultural Economics 76.1 (1994): 74-82.

Daft, Richard L., and Robert H. Lengel. "Organizational information requirements, media richness and structural design." Management science32.5 (1986): 554-571.

Dagenais, Marcel G. "Application of a threshold regression model to household purchases of automobiles." The Review of Economics and Statistics 57.3 (1975): 275-285. 
Delli Carpini, M., \& Keeter, S. (1996). What Americans know about politics and why it matters New Haven, CT: Yale University Press.

DeSousa, Michael and Martin Medhurst. "The Editorial Cartoon as Visual Rhetoric: Rethinking Boss Tweed." Journal of Visual/Verbal Languaging. 2, No. 2 (1982): 43-52.

Dudden, Author Power. “The Record of Political Humor.” American Quarterly. Vol. 37, No 1, Special Issue: American Humor (Spring 1985), 50-70.

Druckman, James N. 2004. "Political Preference Formation: Competition, Deliberation, and the (Ir)relevance of Framing Effects.” American Political Science Review (2004), $98: 4: 671-686$

Fairleigh Dickinson University Public Mind Poll, May 3, 2012, http://publicmind.fdu.edu/2012/confirmed/final.pdf

Fowler, J. H. (2008). The Colbert Bump in Campaign Donations: More Truthful than Truthy. PS: Political Science and Politics, 41(3), 533-539.

Gamson, W.A., \& Modigliani, A. 1989. Media discourse and public opinion on nuclear power: A constructionist approach. American Journal of Sociology, 95, 1-37.

Goldstein, Jeffrey H., and Paul E. McGhee. Ed.1972. The Psychology of Humor: Theoretical Perspectives and Empirical Issues.” New York: Academic Press.

Gruner, Charles. 1992. "Satire as Persuasion." Paper presented at the Annual Meeting of the Speech Communication Association, Chicago, IL, October 28-November 1, 1992. Habermas, J. (1984). A theory of communicative action (T. McCarthy, Trans.). Boston: Beacon 
Harrison, J.D. 2013, August 5. "Obama reopens the fiscal cliff tax debate for small businesses." The Washington Post http://articles.washingtonpost.com/2013-

\section{5/business/41069576_1 tax-rate-individual-rates-john-arensmeyer}

Holbert, R. L. "A Typology for the Study of Entertainment Television and Politics." The American Behavioral Scientist 49.3 (2005): 436-53.

Iyengar, Shanto, Mark D. Peters, and Donald R. Kinder. 1982. "Experimental Demonstrations of the "Not-So-Minimal" Consequences of Television News Programs." The American Political Science Review, Volume 76, Issue 4 (December), 848-858.

Iyengar, Shanto and Adam Simon. 2000. "New Perspectives and Evidence on Political Communication and Campaign Effects.” Annual Review of Psychology. Vol. 51: 149169 (Volume publication date February 2000)

Jones, Jeffrey P. 2010. Satiric Television and Political Engagement. New York: Rowman \& Littlefield.

Keeley, Michael, Philip Robins, Robert Spiegelman, and Richard West, "The Labor Supply Effects and Costs of Alternative Negative Income Tax Programs," Journal of Human Resources 13 (Winter 1978), 3-36.

Kellstedt, Paul M. 2000. "Media Framing and the Dynamics of Racial Policy Preferences." American Journal of Political Science, Vol. 44, No. 2, April 2000, Pp. 239-255.

Kinder, Donald R., and Thomas R. Palfrey. "On behalf of an experimental political science." Experimental foundations of political science (1993): 1-39.

Kinder, D., \& Sears, D. (1985). Public opinion and political action. In G. Lindzey, \& E. Aronson (Eds.), Handbook of social psychology (pp. 659-741). New York: Random House. 
Langeveld, Willem. "Political Cartoons as a Medium of Political Communication." International Journal of Political Education. 4, No. 4 (1981): 343-71.

Lanoue, D. (1992). One that made a difference: Cognitive consistency, political knowledge, and the 1980 Presidential debate. Public Opinion Quarterly, 56, 168-184.

Lau, Richard. In Lodge, Milton and Kathleen M. McGraw. Ed. 1995. Ann Arbor The University of Michigan Press

Levine, J. Humor. In D.L. Sills (Ed.), International encyclopedia of the social sciences, Vol. 7 New York: Macmillan, 1968.

Lippmann, W. 1922. Public Opinion. New York: Harcourt, Brace.

Martineau, William H. "A Model of the social functions of Humor" In Goldstein, Jeffrey H., and Paul E. McGhee. Ed.1972. The Psychology of Humor: Theoretical Perspectives and Empirical Issues.” New York: Academic Press.

McDevitt, M., \& Chaffee, S. (2000). Closing gaps in political communication and knowledge: Effects of a school intervention. Communication Research, 27, 259-292.

McQuail, D. (1987). Mass communication theory: An introduction (2nd ed.). London, England: Sage.

Moy, P., Xenos, M. A., \& Hess, V. K. (2005). Communication and citizenship: Mapping the political effects of infotainment. Mass Communication \& Society, 8, 111-131.

Nelson Thomas E., Zoe M. Oxley, and Rosalee A. Clawson 1997. Toward a Psychology of Framing Effects." Public Behavior 19 (3): pp. 221-246. 
Nelson, T. E., \& Oxley, Z. M. (1999). Issue framing effects on belief importance and opinion. The Journal of Politics, 61(04), 1040-1067.

Neuman, R. (1986). The paradox of mass politics: Knowledge and opinion in the American electorate Cambridge: Harvard University Press.

Neuman, W. Russell, Just, Marion R., Ev Crigler, Ann N. (1992). Common knowledge: News and the construction of political meaning. Chicago: University of Chicago Press.

No Fact Zone. 2010. http://www.nofactzone.net/2010/09/14/daily-showcolbert-report-showstrong-ratings-growth/

Paine, A. B. (1912). Mark Twain: A Biography (Vol. 2, p. 1010). Harper and brothers. http://www.smartelibrary.com/45546787466473922384754657483201232476456383293 23948575745/files/mark_twain_biography.pdf

Paletz, David L. "Political Humor and Authority: From Support to Subversion." International Political Science Review (1990), Vol. 11, No. 4, 483-493.

Patterson, Thomas E. 2000. "Doing Well and Doing Good." Faculty Research Working Paper Series, RWP01-001 (December). Cambridge, MA: John E Kennedy School of Government, Harvard University. http://papers.ssrn.com/sol3/papers.cfm?abstract_id=257395

Pew Research Center. 2011. http://www.pewresearch.org/daily-number/colbert-fans-prefernews-without-views/.

Pew Research Center, 2012 http://www.people-press.org/2012/09/27/section-4-demographicsand-political-views-of-news-audiences/ 
Pew Research Center's Project for Excellence in Journalism, "Journalism, Satire or Just Laughs? 'The Daily Show with Jon Stewart,' Examined," May 8, 2008. http://www.journalism.org /2008/05/08/journalism-satire-or-just-laughs-the-daily-show-with-jon-stewart-examined/

Plaud, J. J., Gaither, G. A., Franklin, M., Weller, L. A., \& Barth, J. (1998). The effects of sexually explicit words on the formation of stimulus equivalence classes. The Psychological Record, 48(1), 63-79

Popkin, S. L. \& Dimock, M. A. (1999). Political knowledge and citizen competence. In Elkin, S. L. and Soltan, K. E. (Eds.) Citizen competence and Democratic Institutions (pp. 117 146). Penn State Press.

Postman, Neil. 1984. Amusing Ourselves to Death: Public Discourse in the Age of Show Business. New York: Penguin.

Purcell, Kristen, Lee Raine, Amy Mitchell, Tom Rosenstiel, and Kenny Olmstead. "Understanding the participatory news consumer: How internet and cell phone users have turned news into a social experience." The Pew Research Center's Internet \& American Life Project, Washington, D.C. (March 1, 2010). http://www.pewinternet.org/Reports/2010/Online News/Part-1/1-Introduction.aspx

Putnam, Robert. 2000. Bowling Alone: The Collapse and Revival of American Community. New York: Simon and Shuster.

Qin, Susu, "The uses, gratifications and political knowledge young adults obtain from watching network newscasts and late night comedy shows" (2008). Graduate Theses and Dissertations.Paper 11635. 
Rosen, Harvey, "Taxes in a Labor Supply Model with Joint Wage-Hours Determination," Econometrica 44 (May 1976), 485-507.

Sander, Libby. 2012. Mixed Portrait of Freshman Political Views. The Chronicle of Higher Education. http://chronicle.com/article/In-an-Election-Year-a-Complex/130463/

Schultz, Charles. 1977. Political Humor: From Aristophanes to Sam Ervin. Cranbury: Associated University Presses.

Shishko, Robert, and Bernard Rostker, "The Economics of Multiple Job Holding," American Economic Review 66 (June 1976), 298-308.

Shah, D. V., Watts, M. D., Domke, D., \& Fan, D. P. (2002). News framing and cueing of issue regimes: Explaining Clinton's public approval in spite of scandal. Public Opinion Quarterly, 66(3), 339-370.

Simon, Herbert. 1957. Models of Man. New York: Wiley.

Steinfirst, Susan. 1995. "Using Editorial Cartoons in the Curriculum to Enhance Visual (and Political) Literacy." Literacy: Traditional, Cultural, Technological. Selected Papers from The Annual Conference of the International Association of School Librarianship, 63-69. Tansel, Aysit, and Fatma Bircan. "Demand for education in Turkey: A tobit analysis of private tutoring expenditures." Economics of Education Review 25.3 (2006): 303-313.

Tobin, James, "Estimation of Relationships for Limited Dependent Variables," Econometrica 26 (Jan. 1958), 24-36.

Tuchman, G. (1978). Making news: A study in the construction of reality. New York: Free Press. 
Verba, Sidney, Kay Lehman Schlozman, and Henry E. Brady. 1995. Voice and Equality: Civic Volunteerism in American Politics. Cambridge: Harvard University Press.

Verba, Sidney and Norman H. Nie. 1972. Participation in America: Political Democracy and Social Equality. Chicago: University of Chicago Press.

Winograd, M., \& Hais, M. D. (2008). Millennial makeover: MySpace, YouTube, and the future of American politics. Rutgers University Press.

Young, Dannagal Goldthwaite. (2004). “The Counterargument-Disputation Model of Political Humor (CADIMO): An Experiment exploration of the effects of late-night political jokes on cognitive elaboration and the conditional effects of partisanship." Paper presentation at the annual meeting of the American Political Science Association in Chicago, IL.

Zaller, John. 1992. The Nature and Origins of Mass Opinion. New York: Cambridge University Press. 


\section{Appendixes}

Appendix A

Survey Advertisement

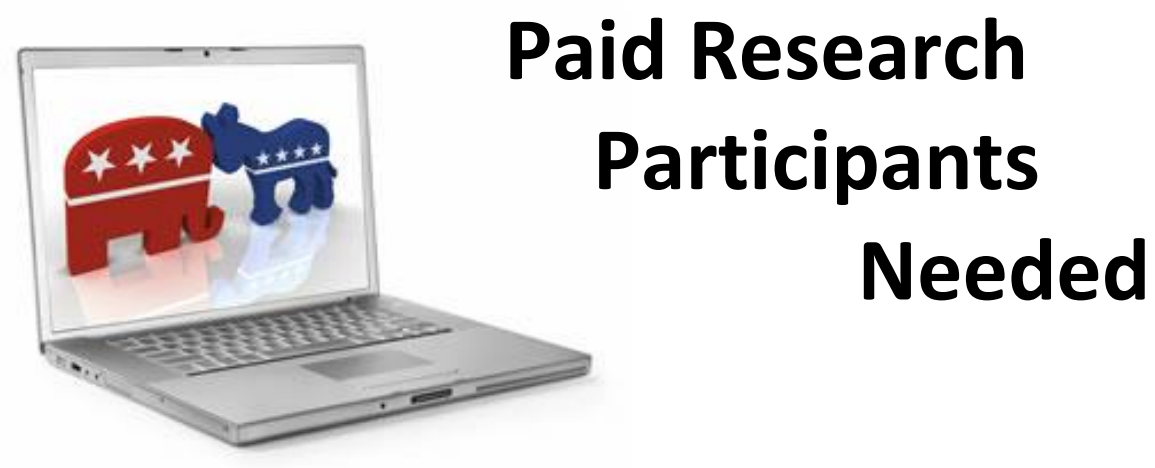

Volunteers are needed to participate in a survey that is designed to understand political information on the internet and the accessibility of that information.

You will need to be 18 years of age or older in order to participate. This research study is being conducted for a Doctoral dissertation in the Department of Political Science here at WVU.

If you choose to participate, you can do so by going to http://www.polsci.wvu.edu/PolinfoSurvey. The survey will take approximately 20 minutes.

Each participant will be entered into a drawing for a chance to win $\$ 50.00$. Chances of winning are about 1 in 100 . For further details email Bret Wilson at bwilso16 @ mix.wvu.edu or call 304-293-9808.

\begin{tabular}{|c|c|c|c|c|c|c|c|c|c|c|c|c|c|c|c|}
\hline \begin{tabular}{l|l} 
\\
0 \\
0 \\
0
\end{tabular} & 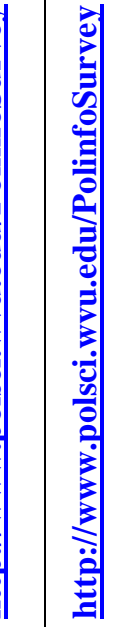 & 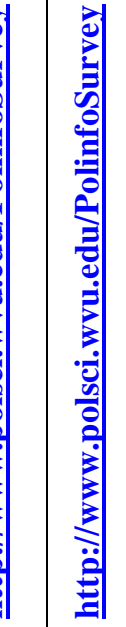 & 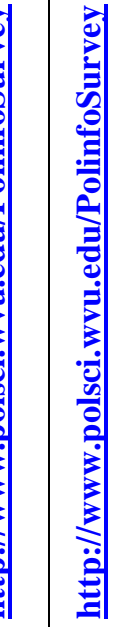 & 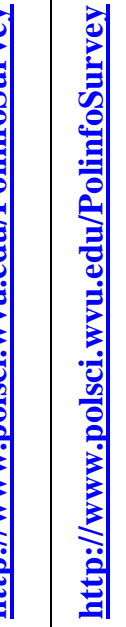 & 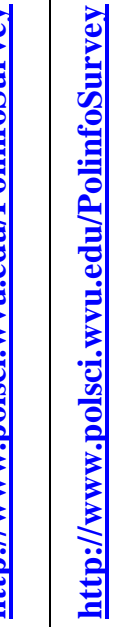 & 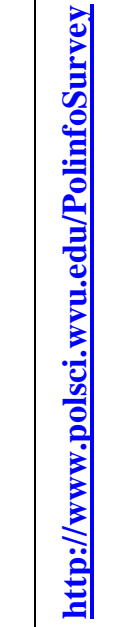 & $\begin{array}{l}0 \\
0 \\
0 \\
0 \\
0 \\
0 \\
0 \\
0 \\
0 \\
0 \\
0 \\
0\end{array}$ & 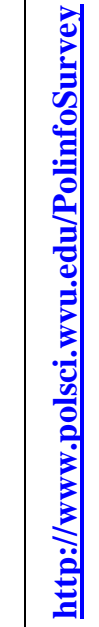 & $\begin{array}{l}0 \\
0 \\
0 \\
0 \\
0 \\
0 \\
0 \\
0 \\
0 \\
0 \\
0\end{array}$ & 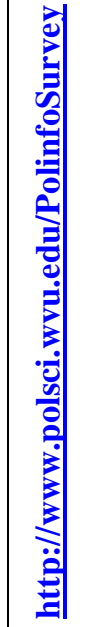 & 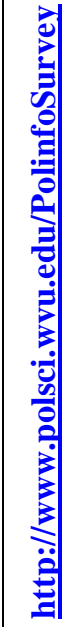 & 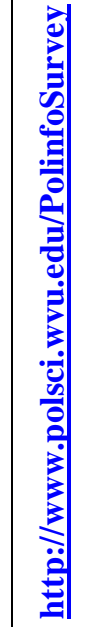 & 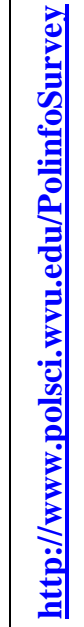 & 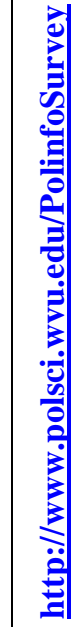 & 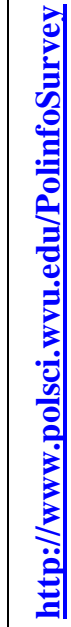 \\
\hline
\end{tabular}




\section{Appendix B \\ Fiscal Cliff News from ABC, Newsy, and CNN}

David Muir (ABC News): To another giant number on the horizon, the one facing lawmakers in Washington, the cuts that will kick in and the taxes that will go up if they don't come up with a deal to avoid the fiscal cliff at the end of the year.

Zach Toombs? (Newsy): A Fiscal Cliff, automatic cuts and tax hikes set to take effect next January will rain in military and domestic spending by 1.2 trillion dollars over the next decade. It is a deal neither party wanted, but was put into place anyway after the failure of the debt reduction super committee last year.

In a story first reported by the Washington Post, Obama plans to make the best of that cut in tax, or duel trigger sequestration plan, by vetoing any Republican effort to abandon it. That is, unless GOP agrees to let the Bush tax cuts on top earners expire.

White House press secretary, Jay Carney, confirmed the report Thursday. Telling reporters "The President has long made clear he will veto an extension of tax cuts for the top 2 percent of Americans. That has been his position, as you know, for a very long time."

The automatic duel trigger cuts and taxes are generally unpopular with lawmakers across the board, but Ezra Kline of the Washington Post say the plan, which cuts heavily on defense spending and brings in significant new revenue through tax, is certainly more acceptable for Democrats than it is for Republicans.

Kline notes that the tax to cuts ratio is much higher than GOP debt reduction plans, namely Congressman Paul Ryan's budget. And the spending cuts that are proposed fall heavily on Defense, but spare many social services, again a positive for Democrats. So that would give Republicans in Congress a choice, though it's likely not one they would be very happy about, make a deal with Obama to let the Bush tax cuts expire or run into a veto from the president that would raise taxes for about $90 \%$ of US households. 
David Muir (ABC News): And tonight, what could be a turning point. Some Republicans saying that are now willing to break that longtime pledge of no new taxes.

Wolf Blitzer (CNN News): Republican lawmakers standing up, in a limited way, to a beltway power broker named Grover Norquist over the 1980s pledge he pressures them to sign. Promising to not raise taxes, any taxes, ever.

Lindsey Graham: I want to buy down debt and cut rates to create jobs, but I will violate the pledge, long story short, for the good of the country.

Bob Corker: I am not obligated on the pledge. I made Tennesseans aware, the only thing I am only thing I am honoring is the oath that I take when I am sworn in this January.

Peter King: A pledge to sign 20 years ago, 18 years ago, is for that congress. For instance, if I were in Congress in 1941, I would have signed a, eh, a support for a declaration of war against japan. I am not going to attack Japan today; the world has changed.

David Kerley? (ABC News): They are talking about this man's pledge. Americans for tax reform's president, Grover Norquist. Who has gotten hundreds of Republican to sign.

David Kerley Interviewing Gover Norquist: Do you feel like you and your pledge are under assault?

Grover Norquist: No. What the pledge does, of course, is allows elected officials to make it clear, openly to their voters, where they stand. Are they going to be with reforming government or raising taxes to continue more of the same.

David Kerley (ABC News): Norquist's threat? That he will help fund Republican campaign challenges against any member of Congress that violates the pledge.

Clip of Gover Norquist: Peter Kings knows... Congressman Peter King of New York knows full well that the pledge that he signed and others have is for while you're in congress. It's not far two-year period. 
David Kerley (ABC News): What I think I hear you saying is: We will not go over the cliff.

Grover Norquist: I think we will continue the tax cuts, eh, not raise taxes five hundred billion dollars.

David Kerley (ABC News): While Norquist tries to keep

Republican in line, major unions have already spent three hundred thousand dollars. Targeting Democrats. Hoping to stop any cuts to entitlement programs.

David Kerley (ABC News): Congressional staffers met over the holiday week and Congressional leader hope to meet with the President in the coming week. There are predictions that this could all be wrapped up before Christmas. We'll see. David.

David Muir (ABC News): ABC News correspondent, David Kerley, at the White House tonight. David.

731 Words; Three Minutes and forty three seconds 


\section{Appendix C \\ The Colbert Report: The Fiscal Cliff Compromise- November $27^{\text {th }}, 2012$}

Colbert: Now folks, it is the Christmas season, and the fact that Canada doesn't get one brings us all joy. But let's not forget that there is always something out there to scare us. For instance, when the clock strikes twelve one New Year's eve you can kiss your date and you can kiss our economy goodbye. Because we will all be going over...

Montage of news personalities:

Carol Costello: that fiscal cliff

Suzanne Malveaux: fiscal cliff

Bret Baier: fiscal cliff

Randi Kaye: fiscal cliff

Michael Eric Dyson: that dreaded fiscal cliff.

Colbert: Yes, the 'dreaded fiscal cliff:' an unavoidable plunge to the razor sharp financial rocks below. It all started back in 2011, during a showdown over raising our debt ceiling. When Republicans wanted spending cuts and Obama wanted to raise taxes. Which lead to a budget crisis that Congress solved by not solving it. Instead, they handed it over to something called the 'super Congress,' which couldn't fail because it was super.

Unfortunately, it was still Congress, so it failed.

And, as a result, we are facing another thing called 'sequestration.' Which, at first, sounds like rationing the amount to watch Sea Quest, but it is even worse than that. Sequestration is automatic spending cuts that both sides agree would trigger a new recession. Its like Congress put a gun to the economy's head and swore it would pull the trigger if Congress doesn't put its own gun down. It's kind of like a Mexican standoff without any Mexicans.

Of course, Obama's answer to this budget crisis is to raise taxes on the wealthy just because he ran on that "promise" (air 
quotes) and "won the election" (air quotes). It's like he is totally disregarding my "dismissive finger quotes" (air quotes). What part of "this" (air quotes) don't you understand, President "Obama" (air quotes)?

Here is what is really scaring me, folks, Republicans might let him do it. Even though every Republican in Congress has signed the no taxes pledge created by the president for taxes reform, Grover Norquist. The two most terrifying words a republican can hear, other than buenas dias. But now, but now, some Republicans are abandoning the anti tax pledge as fast as they abandoned... oh, what's his name? Ehhhhh. I got it. I got it. Don't tell me. Shhh. Don't help me. Don't help me. Rip Flambay. No, no, that's my personal trainer. No. The point is conservatives are jumping ship.

\section{Montage of Politicians:}

Lindsey Graham: I want to buy down debt and cut rates to create jobs. I will violate the pledge for the good of the country.

Bob Corker: I am not obligated by the pledge. The only thing I am only thing I am honoring is the oath that I take when I am sworn in this January.

Peter King: A pledge to sign 20 years ago, 18 years ago, is for that congress. For instance, if I were in Congress in 1941, I would have signed a, eh, a support for a declaration of war against japan. I am not going to attack Japan today; the world has changed.

Colbert: You heard it, folks. Congressman Peter King is not only raising your taxes, he is surrendering to Tōjō and his boys. But not me, I will never give up the fight against Emperor Hirohito and his kamikaze beast men. Besides, that's a lot of tough talk from a known lesbian. Grover and I, Grover and I know that the pledge lasts a lot longer than two years.

Clip of Gover Norquist: Congressman Peter King of New York knows full well that the pledge that he signed and others have is for while you're in congress. It's not far two-year period. 
Colbert: Yes, an anti-tax pledge is eternal and unbreakable. It's like a pact with the devil or a gym membership. You'll get your money, Rip Flambe! And...

627 words; Four minutes and twenty three seconds 


\section{Appendix D}

\section{Static Information Board}

Choose as many stories to read about as you want. The stories you pick will be displayed when you proceed to the next page. There will be questions to answer after you are done reading your story.

\section{$\underline{\text { US News }}$}

\section{GOP Budget Is 'Romney Plan On Steroids}

Wall Street gains as investors buy on dips

$\ulcorner$ Stephen Colbert's sister attempts to grab House seat in South Carolina

$\ulcorner$ Sequestration not favored method to cut budget deficit and how it might be a disservice to those who serve

$\ulcorner\quad$ After "fiscal cliff" dive, more battles, new cliffs

$\ulcorner$ GOP to spend $\$ 10$ million on outreach to ethnic groups International News

$\ulcorner$ Who won Israel's coalition talks?

$\ulcorner$ U.N. nuclear chief presses Iran on access to military base

$\ulcorner$ White House lowers expectations for Obama's Middle East trip

$\ulcorner$ Syrian rebels report capture of provincial capital

$\ulcorner$ David Hasselhoff returns to Berlin to save the wall he helped to topple

$\ulcorner$ China's new president promises 'great renaissance' $\underline{\text { Sports }}$

Bright Beginnings, Sad Endings In Sports News

$\ulcorner$ Obsessed fan who shot player, inspired movie, dies

$\ulcorner 2014$ Brazil World Cup to offer seats for obese fans

$\ulcorner$ The Reasons We Go Crazy for March Madness

$\ulcorner$ Liverpool FC accounts: Ian Ayre on LFC's debt, FSG's loan, turnover and revenues

Entertainment and Life

$\ulcorner$ Decades after death, Chile's Neruda to be exhumed after accusation of murder 
$\square$ Jimi Hendrix estate rolls out "People, Hell and Angels" studio set

$\ulcorner$ Supermodel Heidi Klum new judge on NBC's "America's Got Talent"

Legend of Zelda hack makes Link the damsel in distress

Justin Bieber Disses Lindsay Lohan 